NBER WORKING PAPER SERIES

\title{
THE EFFECTS OF COGNITIVE AND NONCOGNITIVE ABILITIES ON LABOR MARKET OUTCOMES AND SOCIAL BEHAVIOR
}

\author{
James J. Heckman \\ Jora Stixrud \\ Sergio Urzua \\ Working Paper 12006 \\ http://www.nber.org/papers/w12006 \\ NATIONAL BUREAU OF ECONOMIC RESEARCH \\ 1050 Massachusetts Avenue \\ Cambridge, MA 02138 \\ January 2006
}

This research was supported by NIH Grant R01-HD043411 and a Pew Foundation grant to Heckman. This paper was presented at a Mark Berger memorial conference, University of Kentucky, October 2004; as on of the Ely lectures, Johns Hopkins University, April 2005; at University College, Dublin, Ireland, April 2005; at the Institute for Research on Poverty Workshop, Madison, June 2005 at the Second IZA Prize Conference, Berlin, Germany, October 2005 and at the Workshop in Public Policy and Economics at the Harris School of the University of Chicago in September 2005. We also presented it at the AEA annual meeting, Boston, January 2006. We thank participants for their comments. We thank the editors William Johnson and James P. Ziliak and two anonymous referees for helpful comments. We also thank Jeff Grogger, Bruce Meyer and Derek Neal for very helpful comments that led to revisions and clarifications. Supplementary materials are on our website at jenni.uchicago.edu/noncog. We thank Federico Temerlin and Tae Ho Whang for very competent research assistance. The views expressed herein are those of the author(s) and do not necessarily reflect the views of the National Bureau of Economic Research.

(C2006 by James J. Heckman, Jora Stixrud, and Sergio Urzua. All rights reserved. Short sections of text, not to exceed two paragraphs, may be quoted without explicit permission provided that full credit, including ( notice, is given to the source.

The Effects of Cognitive and Noncognitive Abilities on Labor Market Outcomes and Social 
Behavior

James J. Heckman, Jora Stixrud, and Sergio Urzua

NBER Working Paper No. 12006

January 2006

JEL No. C31

\begin{abstract}
This paper established that a low dimensional vector of cognitive and noncognitive skills explains a variety of labor market and behavioral outcomes. For many dimensions of social performance cognitive and noncognitive skills are equally important. Our analysis addresses the problems of measurement error, imperfect proxies, and reverse causality that plague conventional studies of cognitive and noncognitive skills that regress earnings (and other outcomes) on proxies for skills. Noncognitive skills strongly influence schooling decisions, and also affect wages given schooling decisions. Schooling, employment, work experience and choice of occupation are affected by latent noncognitive and cognitive skills. We study a variety of correlated risky behaviors such as teenage pregnancy and marriage, smoking, marijuana use, and participation in illegal activities. The same low dimensional vector of abilities that explains schooling choices, wages, employment, work experience and choice of occupation explains these behavioral outcomes.
\end{abstract}

James J. Heckman

Department of Economics

The University of Chicago

1126 E. 59th Street

Chicago, IL 60637

and NBER

j-heckman@uchicago.edu

Jora Stixrud

Department of Economics

The University of Chicago

1126 E. 59th Street

Chicago, IL 60637

stixrud@uchicago.edu

Sergio Urzua

Department of Economics

The University of Chicago

1126 E. 59th Street

Chicago, IL 60637

surzua@uchicago.edu 


\section{Introduction}

Numerous studies establish that measured cognitive ability is a strong predictor of schooling attainment and wages. ${ }^{1}$ It also predicts a range of social behaviors. ${ }^{2}$ Less well investigated is the role of personal preference and personality traits on economic and social behavior.

Common sense suggests that personality traits, persistence, motivation and charm matter for success in life. Marxist economists (Bowles and Gintis, 1976; Edwards, 1976) have produced a large body of evidence that employers in low skill labor markets value docility, dependability, and persistence more than cognitive ability or independent thought (see the survey by Bowles, Gintis, and Osborne, 2001). Sociologists have written extensively about the role of noncognitive skills in predicting occupational attainment and wages (see the essay by Peter Mueser in Jencks, 1979) and several studies in the psychology literature have shown the important role of noncognitive skills on the schooling performance of children and adolescents (Wolfe and Johnson, 1995; Duckworth and Seligman, 2005).

This paper presents an analysis of the effects of both cognitive and noncognitive skills on wages, schooling, work experience, occupational choice and participation in a range of adolescent risky behaviors. We show that a model with one latent cognitive skill and one latent noncognitive skill explains a large array of diverse behaviors.

Our approach differs from previous methods used to address these issues by accounting for the effects of schooling and family influence on the measurements of the latent skills used in our empirical analysis. We allow the latent skills to determine measured skills and schooling choices, and for schooling to determine measured skills.

We find that both types of latent skills are important in explaining a diverse array of outcomes. The skills are priced differently in different schooling markets. There are important gender differences in the effects of these skills but, for most behaviors, both factors play an important role for both men and women.

For a variety of dimensions of behavior and for many labor market outcomes, a change in noncognitive skills from the lowest to the highest level has an effect on behavior comparable or

\footnotetext{
${ }^{1}$ See, e.g., the evidence summarized in Cawley, Heckman, and Vytlacil (2001).

${ }^{2}$ See Herrnstein and Murray (1994).
} 
greater than a corresponding change in cognitive skills. This evidence contradicts the " $g$ " theory of human behavior espoused by Herrnstein and Murray (1994), Jensen (1998) and others that focuses on the primacy of cognitive skills in explaining socioeconomic outcomes.

Our evidence has important implications for the literature on labor market signalling as developed by Arrow (1973) and Spence (1973). That literature is based on the notion that schooling only conveys information about a student's cognitive ability and that smarter persons find it less costly to complete schooling. Our findings show that schooling signals multiple abilities. This observation fundamentally alters the predictions of signalling theory. ${ }^{3}$

Our approach recognizes that test scores measuring both cognitive and noncognitive abilities may be fallible. It also recognizes that a person's schooling and family background at the time tests are taken affect test scores. Observed ability-wage and ability-schooling relationships may be consequences of schooling causing measured ability rather than the other way around. Building on the analysis of Hansen, Heckman, and Mullen (2004), we correct measured test scores for these problems.

Our analysis supports the common sense view that noncognitive skills matter. As conjectured by Marxists economists (Bowles and Gintis, 1976), we find that schooling determines the measures of noncognitive skills that we study. We find that latent noncognitive skills, corrected for schooling and family background effects, raise wages through their direct effects on productivity as well as through their indirect effects on schooling and work experience. Our evidence is consistent with an emerging body of literature that finds that "psychic costs" (which may be determined by noncognitive traits) explain why many adolescents who would appear to financially benefit from schooling do not pursue it (Carneiro and Heckman, 2003; Carneiro, Hansen, and Heckman, 2003; Cunha, Heckman, and Navarro, 2005b; Heckman, Lochner, and Todd, 2006).

Our evidence bolsters and interprets the findings of Heckman and Rubinstein (2001) who show that GEDs (high school dropouts who exam certify as high school equivalents) have the same achievement test scores as high school graduates who do not go on to college yet they earn, on average, the wages of dropouts. The poor market performance of GEDs is due to their low levels of noncognitive skills, which are lower than those of high school dropouts who do not get the GED.

\footnotetext{
${ }^{3}$ See Araujo, Gottlieb, and Moreira (2004).
} 
Both cognitive and noncognitive skills are valued in the market. The GED surplus of cognitive skills is not outweighed by the GED deficit in noncognitive skills

Carneiro and Heckman (2003), Cunha, Heckman, Lochner, and Masterov (2006) and Heckman and Masterov (2004), and the numerous papers they cite, establish that parents play an important role in producing both the cognitive and noncognitive skills of their children. More able and engaged parents have greater success in producing both types of skills. Because cognitive and noncognitive abilities are shaped early in the lifecycle, differences in these abilities are persistent, and both are crucial to social and economic success, gaps among income and racial groups begin early and persist.

Evidence from early interventions also motivate our work. Early interventions, such as enriched childcare centers coupled with home visitations, have been successful in alleviating some of the initial disadvantages of children born into adverse family environments. The success of these interventions is not attributable to IQ improvements of children, but rather to their success in boosting noncognitive skills (Heckman, 2005).

As an example, the Perry Preschool Program intervened early in the lifecycle of disadvantaged children. Children were randomly assigned to treatment and control groups and both were followed to age 40. The program did not boost IQ (see Figure 1) but raised achievement test scores, schooling and social skills. For example, $66 \%$ of the individuals in the treatment group graduated from high school by age 18 versus only $45 \%$ of the control group, $49 \%$ of the individuals in the treatment group performed at or above the lowest 10th percentile in the California Achievement Test (age 14) versus $15 \%$ of the control group, and individuals in the treatment groups are significantly less likely to get involved in illegal activities before age $40 .{ }^{4}$ This evidence is consistent with the interpretation that noncognitive traits matter for successful social performance and that noncognitive traits were boosted by the program, but not cognitive traits, at least as measured by IQ.

Our analysis explains the phenomenon of correlated risky behaviors using the same low dimensional model of latent skills that explains wages, employment and schooling attainment. Biglan (2004) documents that risky behaviors such as antisocial behavior (aggressiveness, violence and criminality), cigarette smoking, alcohol use and the like are pursued by the same cluster of adolescents. We find that latent cognitive and noncognitive skills explain all of these behaviors and the

\footnotetext{
${ }^{4}$ See figures S1A and S1B in our Web Appendix for more evidence on the Perry Program.
} 
observed clustering pattern.

The plan of this paper is as follows. Section 2 introduces the data used in our analysis and presents empirical analyses using conventional methods. We reproduce key findings reported in the previous literature. We then discuss interpretive problems that plague the conventional approach. Section 3 presents a model of schooling, employment, occupational choice, work experience and wages generated by latent skills as well as observables. Section 4 extends the model to account for correlated risky behaviors. Section 5 shows how our econometric model can be interpreted as an approximation to a lifecycle model. Section 6 discusses how we empirically implement our model. Section 7 presents our evidence. Section 8 relates our analysis to previous work in the literature. Section 9 concludes.

\section{Some Evidence Using Conventional Approaches}

We use data from the National Longitudinal Survey of Youth 1979 (NLSY79). The NLSY data are standard and widely used. It is the data source for the " $g$ " analysis of Herrnstein and Murray (1994). It contains panel data on wages, schooling and employment for a cohort of young persons, age 14 to 21 at their first interview in 1979. This cohort has been followed ever since. Important for our purposes, the NLSY contains information on cognitive test scores as well as noncognitive measures. Web Appendix A describes the sampling frame of the data in detail.

Our analysis of test scores uses five measures of cognitive skills (arithmetic reasoning, word knowledge, paragraph comprehension, mathematical knowledge, and coding speed) derived from the Armed Services Vocational Aptitude Battery (ASVAB), which was administered to all sample participants in 1980 and 1981. A composite score derived from these sections of the test battery can be used to construct an approximate Armed Forces Qualifications Test (AFQT) score for each individual. The AFQT is a general measure of trainability and a primary criterion of eligibility for service in the Armed Forces. It has been used extensively as a measure of cognitive skills in the literature (see, e.g. Cameron and Heckman, 1998, 2001; Ellwood and Kane, 2000; Heckman, 1995; Neal and Johnson, 1996; Osborne-Groves, 2004). The noncognitive measures available in the data set are the Rotter Locus of Control Scale which was administered in 1979 and the Rosenberg 
Self-Esteem Scale which was administered in 1980. The Rotter Scale measures the degree of control individuals feel they possess over their life and has been commonly used in previous studies analyzing the role of noncognitive skills on labor outcomes (Osborne-Groves, 2004). The Rosenberg Scale measures perceptions of self worth. All of these tests are discussed in detail in Web Appendix A.

This section of the paper presents a standard least squares analysis of the effects of cognitive and noncognitive skills on wages. We obtain the same qualitative results that have been reported by previous analysts (see e.g. Jencks, 1979; Osborne-Groves, 2004; Bowles, Gintis, and Osborne, 2001). We use the standardized average of an individual's five ASVAB components as a measure of cognitive skills and the standardized average of the person's scores on the Rotter and Rosenberg scales as a measure of noncognitive skills. Figure 2 presents the distributions of the cognitive and noncognitive measures by gender and final schooling level. The distributions of both measures of skill are ordered by schooling level, with college graduates having the most favorable distribution of skills and high school dropouts the worst.

Conditioning on schooling, both cognitive and noncognitive tests predict wages (see Table 1, the A columns). However, schooling is a choice variable and any convincing analysis must account for the endogeneity of schooling. Deleting schooling from the wage equation (see Table 1, the B columns) produces larger estimated effects of both abilities on wages. Removing the conditioning on schooling solves the problem of endogeneity of schooling in wage equations and produces an estimate of the net effect of the abilities on wages (their direct effects plus their effects through schooling).

Not controlling for schooling, the cognitive ability measure explains $9 \%$ of the variance of $\log$ wages. For men, the noncognitive measure explains only $0.9 \%$ of the variance. For women, the corresponding figures are $12.4 \%$ and $0.4 \%$. We will show that even though cognitive ability explains a larger share of wage variance than noncognitive ability, both are important in the sense that moving persons from the top to the bottom of the ability distribution has similar effects for both types of abilities.

This evidence suggests that both noncognitive and cognitive abilities significantly affect wages, as an entire literature has found (see Jencks, 1979). However, this evidence is not without its problems. First, we note that there is an important distinction between intelligence tests (i.e., IQ 
tests) and achievement tests. Although IQ is fairly well set by age 8, achievement tests have been demonstrated to be quite malleable. Neal and Johnson (1996) and Hansen, Heckman, and Mullen (2004) demonstrate that each additional year of schooling increases an individual's measured AFQT score by 2 to 4 percentage points, on average. This creates a reverse causality problem. The least squares estimates reported in Table 1 cannot distinguish whether higher "ability" (as proxied by our cognitive measure) causes higher wages or whether additional years of schooling cause both higher measured cognitive scores and higher wages. They likely overstate the contribution of ability to wages and understate the contribution of schooling to wages. ${ }^{5}$

The analysis of Bowles and Gintis (1976) suggests that a similar phenomenon may be at work for noncognitive skills. They claim that schooling builds traits that are useful in the workplace. In their language, schooling produces a docile proletariat. In addition, scores on the attitude scales used to proxy noncognitive ability, as well as the cognitive scores, are likely to be affected by family background characteristics, and are at best imperfect measures of an individual's true noncognitive and cognitive abilities. The least squares estimates reported in Table 1 will be biased and inconsistent unless the measures used are perfect proxies for cognitive and noncognitive skills.

Standard $I V$ methods for addressing measurement error and simultaneity in test scores also require important qualifications. First, the instruments selected for instrumental variables analyses are often controversial. Second, in a model with heterogeneous responses, it is far from clear how instrumental variables can solve these problems (Heckman, Urzua, and Vytlacil, 2004; Heckman and Vytlacil, 2005). The empirical strategy presented in this paper, unlike the $I V$ strategy, is able to account for the problems of reverse causality and measurement error. ${ }^{6}$

We develop an alternative to $I V$ that postulates a low dimensional vector of latent cognitive and noncognitive abilities that generates measured cognitive and noncognitive test scores and that

\footnotetext{
${ }^{5}$ See Carneiro, Heckman, and Masterov (2005).

${ }^{6}$ Table S1 in our Web Appendix extends the analysis presented in Table 1 to consider other labor market and behavioral outcomes. It presents estimates of the effects of the measured abilities on schooling, occupational choice, smoking, drug use, incarceration, participation in illegality (whether an individual participated in any of the following illegal activities in 1979 or 1980: attempting to "con" someone, taking a vehicle without the owner's permission, shoplifting, intentionally damaging another's property, or using force to obtain things), work experience and premarital pregnancy. These models are estimated using probit analysis and multinomial choice models. At a purely descriptive level both measured cognitive and noncognitive traits are associated with a variety of behavioral outcomes for males and females. At issue is whether the relationships in Table S1 have any causal status. The same issue applies to the results presented in Table 1. Simple $I V$ strategies that might be useful for linear outcome models do not apply in analyzing the nonlinear (discrete choice/discrete outcome) models analyzed in Table S1.
} 
is the source of dependence not only among test scores, schooling choices, and wages, but also employment, occupational choice and behavioral outcomes. Controlling for the latent skills solves the problems of endogeneity and measurement error. Our method extends the LISREL model of Jöreskog (1977) and the MIMIC model of Jöreskog and Goldberger (1975) to account for the effects of choice variables (schooling) and background variables on the measurements of cognitive and noncognitive skills where the schooling, in turn, depends on the latent factors. Our model is a factor model with endogenous factor loadings. Our methodology is a form of matching where the match variables that create the conditional independence are unobserved and their distributions are estimated nonparametrically. Carneiro, Hansen, and Heckman (2003) and Hansen, Heckman, and Mullen (2004) develop this method. We now present our model.

\section{A Model of Schooling, Employment, Work Experience, Occupational Choice and Wages Based on Latent Skills}

Cognitive and noncognitive skills can affect the endowments of persons, their preferences, their technology of skill formation (see Cunha, Heckman, Lochner, and Masterov, 2006), or all three. Thus they might affect risk preference, time preference, and the efficiency of human capital production without necessarily being direct determinants of market wages. Cognitive and noncognitive skills might also raise the productivity of workers, and directly affect wages. Our empirical analysis suggests that both cognitive and noncognitive skills play multiple roles.

We postulate the existence of two underlying factors representing latent cognitive and noncognitive ability. Conditioning on the observables, these factors account for all of the dependence across choices and outcomes. The levels of an individual's factors may result from some combination of inherited ability, the quality of the environment provided by her parents, her early efforts and the effects of any early interventions. We assume that levels of both factors are known by each individual but not by the researcher, and that they are fixed by the time the individual makes her schooling and behavior choices.

Let $f^{C}$ and $f^{N}$ denote the levels of latent cognitive and noncognitive abilities, respectively. 
We assume that latent abilities are mutually independent $\left(f^{C} \Perp f^{N}\right)$, and both determine the individual's wage, schooling, employment, work experience and occupational decisions.

The assumption that one latent factor captures cognitive ability is traditional in the literature (see e.g. Jensen, 1998). The " $g$ " theory used by Herrnstein and Murray (1994) and many others is based on it. Heckman (1995) shows that it applies to the NLSY data we use. The assumption that one latent factor captures noncognitive ability is less traditional. Since there are many aspects of noncognitive skills - self control, time preference, sociability, and so forth - it is less likely that one trait captures all aspects of these behaviors. ${ }^{7}$ Nonetheless, a model with one factor each for cognitive and noncognitive skills is a useful starting point, and we use it throughout this paper. ${ }^{8}$

The assumption of independence between $f^{C}$ and $f^{N}$ is motivated by the evidence presented in our Web Appendix A. ${ }^{9}$ Table S3 shows that correlations of test scores within the batteries of cognitive tests and noncognitive tests are much stronger than they are across cognitive and noncognitive tests. The cross-correlations weaken further when we condition on family background variables. We can account for the dependence across cognitive and noncognitive test scores, even invoking independence between $f^{C}$ and $f^{N}$, by allowing observables to affect means and factor loadings. In addition, both factors affect schooling. In our model, the factor loadings in the test score equations depend on schooling at the time of the test. Therefore, for those who complete their schooling by the time of the test both latent factors affect both cognitive and noncognitive tests (albeit in an indirect way). We now present our model for wages.

\subsection{An Hedonic Model for Wages and Work Experience}

We allow for the possibility that different schooling groups operate in different labor markets. Both latent abilities and observable variables determine wages in the different schooling markets, and may be priced differently in different markets. Denote by $s$ the schooling level attained by the

\footnotetext{
${ }^{7}$ The evidence in our Web Appendix A, Table S2, argues against the existence of only one latent factor that summarizes all aspects of noncognitive ability. For cognitive scores, one factor explains $77 \%$ of the trace of the cognitive test score correlation matrix for males. The second factor explains only $9 \%$ of the trace. For noncognitive skills, one factor explains only $31 \%$ of the trace of the correlation matrix. The second factor explains $9 \%$ of the trace.

${ }^{8}$ We relax this assumption in work underway.

${ }^{9}$ See Cunha and Heckman (2003) who relax this assumption in their theoretical model.
} 
individual. Wages are given by a linear-in-the-parameters specification:

$$
Y_{s}=\beta_{Y, s} X_{Y}+\alpha_{Y, s}^{C} f^{C}+\alpha_{Y, s}^{N} f^{N}+e_{Y, s} \quad \text { for } \quad s=1, \ldots, \bar{S}
$$

where $X_{Y}$ is a vector of observed controls, $\beta_{Y, s}$ is the vector of returns associated with $X_{Y}, \alpha_{Y, s}^{C}$ and $\alpha_{Y, s}^{N}$ are the cognitive and noncognitive loadings, respectively, and $e_{Y, s}$ represents an idiosyncratic error term such that $e_{Y, s} \Perp\left(f^{N}, f^{C}, X_{Y}\right)$ for $s=1, \ldots, \bar{S}$. This equation allows for separate prices for workers of different schooling categories, who operate in different labor markets.

We estimate a parallel equation for work experience:

$$
R_{s}=\beta_{R, s} X_{R}+\alpha_{R, s}^{C} f^{C}+\alpha_{R, s}^{N} f^{N}+e_{R, s} \quad \text { for } \quad s=1, \ldots, \bar{S}
$$

where $X_{R}$ is a vector of observed controls, $\beta_{R, s}$ is the vector of returns associated with $X_{R}, \alpha_{R, s}^{C}$ and $\alpha_{R, s}^{N}$ are the cognitive and noncognitive loadings, respectively, and $e_{R, s}$ represents an idiosyncratic error term such that $e_{R, s} \Perp\left(f^{N}, f^{C}, X_{R}\right)$ for $s=1, \ldots, \bar{S}$.

\subsection{The Model for Schooling}

Each agent chooses the level of schooling, among $\bar{S}$ possibilities, that maximizes his benefit. Let $I_{s}$ represent the net benefit associated with each schooling level $s(s=\{1, \ldots, \bar{S}\})$ and assume the following linear-in-the-parameters model for the benefit of schooling level $s$ :

$$
I_{s}=\beta_{s} X_{s}+\alpha_{s}^{C} f^{C}+\alpha_{s}^{N} f^{N}+e_{s} \text { for } \quad s=1, \ldots, \bar{S}
$$

where $X_{s}$ is a vector of observed variables affecting schooling, $\beta_{s}$ is its associated vector of parameters, $\alpha_{s}^{C}$ and $\alpha_{s}^{N}$ are the parameters (also known as factor loadings) associated with the cognitive and noncognitive latent abilities, respectively, and $e_{s}$ represents an idiosyncratic component assumed to be independent of $f^{N}, f^{C}$, and $X_{s}$. The individual components $\left\{e_{s}\right\}_{s=1}^{\bar{S}}$ are mutually independent. All of the dependence across these choices comes through the observable, $X_{s}$, and the common factors $f^{N}$ and $f^{C}$. The $I_{s}$ solve out the effects of wages and other benefits on the utility associated 
with schooling.

The agent chooses the level of schooling with the highest benefit. Formally,

$$
D_{S}=\underset{s \in\{1, \ldots, \bar{S}\}}{\operatorname{argmax}}\left\{I_{s}\right\}
$$

where $D_{S}$ denotes the individual's chosen schooling level. Notice that conditional on $X_{s}$ (with $s=$ $1, \ldots, \bar{S})$, equations $(1)$ and $(2)$ produce a standard discrete choice model with a factor structure. ${ }^{10}$

The assumption of linearity in the parameters and separability of the factors simplifies the analysis. In more tightly specified economic models the factors would be nonlinear and nonseparable as e.g. time preference parameters, risk aversion parameters, human capital production function parameters and endowment parameters in dynamic models of skill accumulation (see e.g. Cunha, Heckman, Lochner, and Masterov, 2006; Cunha and Heckman, 2003). We interpret $f^{N}$ and $f^{C}$ as approximations to the basic parameters of preferences, technology and endowments that generate the outcomes we study. We discuss a more tightly specified model in Section 5. We next develop the equation for employment.

\subsection{The Model for Employment}

Let $I_{E}$ denote the net benefit associated with working and assume a linear-in-the-parameters specification

$$
I_{E}=\beta_{E} X_{E}+\alpha_{E}^{C} f^{C}+\alpha_{E}^{N} f^{N}+e_{E}
$$

where $\beta_{E}, X_{E}, \alpha_{E}^{C}, \alpha_{E}^{N}$, and $e_{E}$ are defined as in the schooling model. Then $D_{E}=1\left(I_{E}>0\right)$ is a binary variable that equals 1 if the individual is employed and 0 otherwise (where 1 is an indicator function, $1(A)=1$ if $A$ is true and $1(A)=0$ otherwise). The error term $e_{E}$ is such that $e_{E} \Perp\left(f^{N}, f^{C}, X_{E}\right)$.

\footnotetext{
${ }^{10}$ See Heckman (1981) where this model was first introduced.
} 


\subsection{The Model for Occupational Choice}

Let $I_{O}$ denote the latent utility associated with choosing a white collar occupation (where the alternative is a blue collar occupation). We postulate the following linear model for $I_{O}$ :

$$
I_{O}=\beta_{O} X_{O}+\alpha_{O}^{C} f^{C}+\alpha_{O}^{N} f^{N}+e_{O}
$$

where $\beta_{O}, X_{O}, \alpha_{O}^{C}, \alpha_{O}^{N}$ and $e_{O}$ are defined analogously to the model of equation $(3) . D_{O}=1\left(I_{O}>0\right)$ is an indicator of choice of white collar occupational status. The error term in equation (4) is such that $e_{O} \Perp\left(f^{N}, f^{C}, X_{O}\right)$.

Further, assume that $e_{Y, s} \Perp e_{R, s^{\prime}} \Perp e_{s^{\prime \prime}} \Perp e_{E} \Perp e_{O}$ for any schooling levels $s, s^{\prime}$ and $s^{\prime \prime}$, and that all of the error terms are independent of both factors $\left(f^{C}\right.$ and $\left.f^{N}\right)$ and all the observables $(X$ variables with subscripts) in our model.

\subsection{A Measurement System that Accounts for Simultaneity in Cogni- tive and Noncognitive Test Scores}

Identification of the model of Sections 3.1-3.4 is established using the strategy developed in Carneiro, Hansen, and Heckman (2003) and elaborated in Hansen, Heckman, and Mullen (2004) and Heckman and Navarro (2006). For the sake of brevity, in this paper we summarize their results without repeating their proofs. ${ }^{11}$

Our identification strategy assumes the existence of two sets of measurements (each with at least two elements), with one set measuring cognitive skills and the other set measuring noncognitive skills. ${ }^{12}$ In our case, latent cognitive ability is only allowed to affect scores on cognitive measures, and latent noncognitive ability is only allowed to affect scores on noncognitive measures. ${ }^{13}$

Building on the analysis of Hansen, Heckman, and Mullen (2004), we address the possibility of

\footnotetext{
${ }^{11} \mathrm{~A}$ more technical discussion of aspects of identification is presented in our Web Appendix B.

${ }^{12} \mathrm{We}$ can weaken the number of required measurements if we assume nonnormality of the factors following the analysis in Bonhomme and Robin (2004) and the discussion in Heckman and Navarro (2006).

${ }^{13}$ These conditions are sufficient but not necessary. See Carneiro, Hansen, and Heckman (2003, Footnote 18) for a factor system where all but one test can depend on both factors. Thus if there is one test (e.g. a component of AFQT like coding speed) that depends on only one factor ("cognitive ability") all other cognitive and noncognitive tests can depend on both components.
} 
reverse causality between schooling and cognitive and noncognitive test scores. In the context of this paper, the problem is likely to arise since our measures of cognitive and noncognitive abilities were administered to all sample members in 1979 and 1980, when they were between 14 and 22 years of age. Many had finished their schooling. Consequently, the observed measures may not be fully informative about the latent cognitive and noncognitive skills of the individuals, since they may be influenced by the schooling level at the date of the test.

Our procedure allows each individual's schooling level at the time of the test to affect the coefficients of the measurement system. Thus, if we denote by $s_{T}$ the schooling level at the time of the test $\left(s_{T}=1, \ldots, \bar{S}_{T}\right)$, the model for the cognitive measure $C_{i}\left(i=1, \ldots, n_{C}\right)$ is

$$
C_{i}\left(s_{T}\right)=\beta_{C_{i}}\left(s_{T}\right) X_{C}+\alpha_{C_{i}}\left(s_{T}\right) f^{C}+e_{C_{i}}\left(s_{T}\right) \quad \text { for } \quad i=1, \ldots, n_{C} \text { and } s_{T}=1, \ldots, \bar{S}_{T}
$$

where $e_{C_{i}}\left(s_{T}\right) \Perp\left(f^{C}, X_{C}\right)$ and $e_{C_{i}}\left(s_{T}\right) \Perp e_{C_{j}}\left(s_{T}^{\prime}\right)$ for any $i, j \in\left\{1, \ldots, n_{C}\right\}$ and schooling levels $s_{T}$ and $s_{T}^{\prime}$ such that $i \neq j$ for any $\left(s_{T}, s_{T}^{\prime}\right)$ or $s_{T} \neq s_{T}^{\prime}$ for any $(i, j) .{ }^{14}$

Likewise, the model for the noncognitive measure $N_{i}\left(i=1, \ldots, n_{N}\right)$ is

$$
N_{i}\left(s_{T}\right)=\beta_{N_{i}}\left(s_{T}\right) X_{N}+\alpha_{N_{i}}\left(s_{T}\right) f^{N}+e_{N_{i}}\left(s_{T}\right) \quad \text { for } \quad i=1, \ldots, n_{N} \text { and } s_{T}=1, \ldots, \bar{S}_{T}
$$

where $e_{N_{i}}\left(s_{T}\right) \Perp\left(f^{N}, X_{N}\right)$ and $e_{N_{i}}\left(s_{T}\right) \Perp e_{N_{j}}\left(s_{T}^{\prime}\right)$ for any $i, j \in\left\{1, \ldots, n_{N}\right\}$ and schooling levels $s_{T}$ and $s_{T}^{\prime}$ such that $i \neq j$ for any $\left(s_{T}, s_{T}^{\prime}\right)$ or $s_{T} \neq s_{T}^{\prime}$ for any $(i, j)$. Again, all error terms $(e$ variables with subscripts) are mutually independent, independent of $\left(f^{N}, f^{C}\right)$ and all the observable $X^{\prime}$ 's.

Since there are no intrinsic units for the latent ability measures, one $\alpha$ coefficient devoted to each ability must be normalized to unity to set the scale of each ability. Therefore, for some $C_{i}\left(i=1, \ldots, n_{C}\right)$ in $C$ and $N_{j}\left(j=1, \ldots, n_{N}\right)$ in $N$, we set $\alpha_{C_{i}}\left(s_{T}\right)=1$ and $\alpha_{N_{j}}\left(s_{T}^{\prime}\right)=1$. Carneiro, Hansen, and Heckman (2003) establish that these assumptions provide enough structure to semiparametrically identify the model, including the distributions of the factors and the equationspecific shocks, provided that the regressors have sufficient support.

Our assumptions imply that conditional on $X$ variables, the dependence across all measurements,

\footnotetext{
${ }^{14}$ Our procedure includes the case where $s_{T}$ is final schooling. See Hansen, Heckman, and Mullen (2004).
} 
choices and outcomes comes through $f^{N}$ and $f^{C}$. If we control for this dependence, we control for the endogeneity in the model. ${ }^{15}$ If the $\left(f^{N}, f^{C}\right)$ were observed, we could use matching to control for this dependence. Instead, we assume that the match variables are unobserved, and estimate their distributions, along with the other parameters of the model.

\section{Incorporating Behavioral Outcomes into the Model}

Much of the literature estimating the impact of cognitive and noncognitive abilities has focused on the effects of these abilities on educational and labor market outcomes (e.g. Cameron and Heckman, 2001; Bowles, Gintis, and Osborne, 2001; Osborne-Groves, 2004; Segal, 2005). Herrnstein and Murray (1994) present evidence on the correlation between levels of cognitive ability and different dimensions of social behavior (e.g. marriage, out-of-wedlock birth, and crime). They only consider the predictive power of cognitive ability measures. We use our model to consider the predictive power of both cognitive and noncognitive measures. We establish that noncognitive factors are important in explaining numerous labor market outcomes and social behaviors.

We investigate the effects of both types of latent abilities on individuals' decisions regarding teenage pregnancy and marital status and whether or not to smoke daily by age 18, use marijuana in 1979 or 1980, participate in activities that lead to incarceration by age 30, and participate in other illegal activities in 1979 or 1980. Our model assumes that each of these decisions is jointly determined by latent cognitive and noncognitive abilities, as well as by observable variables and outcome-specific shocks.

The models that we fit are all in the form of linear-in-parameters index models that generate discrete outcomes of the sort presented in Section 3. Let $I_{j}$ be the linear-in-parameters index for behavior $j$, with associated vector $X_{j}$ and coefficient vector $\beta_{j}$. Let $\alpha_{j}^{C}$ be the loading on the cognitive factor and $\alpha_{j}^{N}$ the loading on the noncognitive factor where $e_{j}$ is independent of $f^{C}, f^{N}$

\footnotetext{
${ }^{15}$ Recall that the factor loadings in the measurement equations can depend on schooling at the time of the test and hence that the dependence is more complicated than in the standard factor analytic model.
} 
and $X_{j} ; f^{C}$ and $f^{N}$ are independent of $X_{j}$. The latent index generating choices is

$$
\begin{aligned}
I_{j} & =\beta_{j} X_{j}+\alpha_{j}^{C} f^{C}+\alpha_{j}^{N} f^{N}+e_{j} \\
D_{j} & =\mathbf{1}\left(I_{j} \geq 0\right) .
\end{aligned}
$$

We analyze daily smoking, marijuana use, imprisonment, and illegal activities using this framework. We study teenage pregnancy and marriage for women using a multinomial choice model. Let $I_{p}$ denote the latent utility associated with the decision $p$ ( $p=1$ (Single with No Child), 2 (Married with a Child), 3 (Married with No Child), and 4 (Single with a Child)). We postulate the following linear-in-parameters model for $I_{p}$ :

$$
I_{p}=\beta_{p} X_{p}+\alpha_{p}^{C} f^{C}+\alpha_{p}^{N} f^{N}+e_{p} \quad \text { for } \quad p=1, \ldots, 4
$$

where $\beta_{p}, X_{p}, \alpha_{p}^{C}, \alpha_{p}^{N}$ and $e_{p}$ are defined analogously to the previous cases. From (7) we define the outcome selected by

$$
D_{P}=\underset{p \in\{1, \ldots, 4\}}{\operatorname{argmax}}\left\{I_{p}\right\}
$$

so that $D_{P}$ denotes the individual's chosen marital and pregnancy status We assume that the $X$ 's are independent of $f^{N}, f^{C}$ and the $e_{p}$ 's. The $f^{N}, f^{C}$ are independent of the $e_{p}$ 's and the components of the $e_{p}$ 's are mutually independent. Again, all of the dependence across equations comes from the $X$ 's and the factors $f^{N}, f^{C}$. All distinctly subscripted $e$ variables (across all labor market and behavioral outcomes) are mutually independent and independent of $f^{C}, f^{N}$, and all subscripted $X$ variables. Again, this is a form of matching where the match variables are independent and we estimate their distribution. 


\section{Interpreting our Model as an Approximation to an Ex- plicit Economic Model}

Our statistical model is an approximation to a simple lifecycle model of youth and adult decision making over horizon $T$. We now sketch that model. Let consumption and labor supply at period $t$ be $c(t)$ and $l(t)$, respectively. Consumption is a vector and includes a variety of behaviors, such as smoking, drug use, etc. Let the vector $P(t)$ denote the market prices of the consumption goods. Utility is $U(c(t), l(t) ; \eta)$ where the $\eta$ are preference parameters. The agent discounts utility at time preference rate $\rho$. Human capital in period $t$ is $h(t)$. It is produced by the human capital production function

$$
\dot{h}(t)=\varphi(h(t), I(t) ; \tau)
$$

where the $\tau$ are productivity parameters, $I(t)$ is investment at $t$, and $\dot{h}(t)$ denotes the rate of change of the human capital stock. The initial condition is given by $h(0)$. There can be a vector of human capitals.

Wages in period $t(Y(t))$ are given by human capital and productivity traits $\theta$ :

$$
Y(t)=R(h(t) ; \theta)
$$

Assuming perfect credit markets at interest rate $r$, the law of motion for assets at period $t(A(t))$, given initial condition $A(0)$ and ignoring taxes, is

$$
\dot{A}(t)=Y(t) h(t) l(t)-P(t)^{\prime} c(t)+r A(t)
$$

The agent maximizes

$$
\int_{0}^{T} \exp (-\rho t) U(c(t), l(t) ; \eta) d t
$$

subject to the laws of motion of assets and human capital.

In this specification, cognitive and noncognitive skills can affect preferences $\left(\eta=\eta\left(f^{C}, f^{N}\right)\right.$, $\left.\rho=\rho\left(f^{C}, f^{N}\right)\right)$, human capital productivity $\left(\tau=\tau\left(f^{C}, f^{N}\right)\right)$ and direct market productivity 
$\left(\theta=\theta\left(f^{C}, f^{N}\right)\right)$. They might also affect initial conditions $h(0)=h_{0}\left(f^{C}, f^{N}\right)$ and $A(0)=A_{0}\left(f^{C}, f^{N}\right)$.

Our econometric model is a linear-in-the-parameters approximation to this general model. In this paper, we do not estimate relationships for each of the channels through which cognitive and noncognitive abilities might operate. Noncognitive abilities affect some combination of $\eta, \rho, \tau$ and $\theta$ (market productivity). Cognitive abilities operate through $\theta$ as well as some combination of $\eta, \rho$, and $\tau .^{16}$

An open question, which we plan to address in other work, is the relationship between the psychologist's measure of noncognitive skills as elicited from test scores and the fundamental parameters of risk aversion, time preference and human capital productivity, which can be estimated from behaviors (see, e.g., Browning, Hansen, and Heckman, 1999). In principle, one can determine which factors are common across tests and preference parameters. Test scores and behaviors can be used interchangeably to proxy factors. This task is left for future work.

\section{Implementing the Model}

We use Bayesian MCMC methods to compute the sample likelihood. Our use of Bayesian methods is only a computational convenience. Our identification analysis is strictly classical. ${ }^{17}$ Under our assumptions, the priors we use are asymptotically irrelevant. Explanatory variables and exclusion restrictions are reported in Tables $2 \mathrm{~A}$ and $2 \mathrm{~B}$.

Our empirical model has six schooling levels $(\bar{S}=6)$ : high school dropout, GED, high school graduate, some college-no degree, 2-year college degree and 4-year college degree. To facilitate identification of the educational choice model, we assume that tuition at 2 and 4 year colleges only

\footnotetext{
${ }^{16}$ Cunha and Heckman (2003) estimate a more general model in which the $\left(f^{C}, f^{N}\right)$ evolve over time and are consequences of investment behavior.

${ }^{17}$ The analysis in Carneiro, Hansen, and Heckman (2003), Hansen, Heckman, and Mullen (2004), and Heckman and Navarro (2006), establishes conditions on the support of the regressors that allow for semiparametric identification of the model. Figure S2 presents evidence on the support conditions for both males and females. It graphs the sample distributions of probabilities of different schooling attainment levels. For the support conditions for semiparametric identification to hold, the support of the distribution of each probability should be the unit interval $[0,1]$. It is evident from Figure S2 that this condition is not met, although for 4-year college graduation the condition is nearly satisfied. This evidence suggests that the empirical results that we generate are identified from the parametric structure of the model. However, we use robust mixture of normal approximations to the underlying distributions. Varying the components of the mixtures (adding more components beyond the ones we report) does not change our empirical estimates. Our estimates are not artifacts of normality assumptions, and relaxing normality is essential in getting a good fit to the data.
} 
affects the benefits of obtaining those degrees, and that the cost of obtaining the GED only affects the benefit of obtaining that degree. ${ }^{18}$ We also assume that local wages and unemployment rates at age 17 for individuals with each final schooling level (i.e., high school dropouts, high school graduates, some college and college graduates) partly determine the opportunity cost and expectations of returns associated with each of the final schooling levels. Family background characteristics, race and cohort dummies, as well as both factors, are also allowed to affect educational choices.

Wage equations at age 30 are estimated for individuals of each final schooling level. Race and ethnicity dummies, cohort dummies, local labor market conditions and region of residence dummies are included in these equations, as well as the cognitive and noncognitive factors. ${ }^{19}$ We assume that, fixing these variables, family background characteristics and childhood residence do not affect adult wages. The local labor market variables are based on the Bureau of Economic Affairs data base discussed in Cameron and Heckman (2001), updated for our sample year.

The employment and occupational choice latent indices are assumed to depend on the same list of variables that determine adult wages. Family background characteristics, race and cohort dummies, and both factors, enter in the index functions determining daily smoking, marijuana use, incarceration, participation in illegal activities and teenage pregnancy. Family background characteristics, race and cohort dummies, and both factors, also enter the equations determining work experience by age 30 .

Our theoretical model is static and does not consider the timing of decisions. We analyze smoking and marital/pregnancy (for women only) decisions as of age 18, marijuana use and participation in illegal activities in 1979 or $1980,{ }^{20}$ and incarceration by age 30 (for men only). Labor market outcomes and schooling decisions are studied as of age 30 .

Following the analysis in Section (3.5), our cognitive and noncognitive measures are allowed to depend on the cognitive $\left(f^{C}\right)$ and noncognitive $\left(f^{N}\right)$ factors, respectively. Each equation is

\footnotetext{
${ }^{18}$ Exclusions are required for semiparametric identification of the choice equations unless curvature restrictions are introduced (see Cameron and Heckman, 1998; Heckman and Navarro, 2006). Alternatively, we can invoke a parametric distributional assumption.

${ }^{19}$ Estimating the equations separately by race and ethnicity produces some important differences across groups. We are presenting this evidence in another paper, currently in preparation. We find that noncognitive skills play a stronger role in explaining gradients in black socioeconomic outcomes than they do for whites (Heckman, Stixrud, and Urzua, 2006). The current paper allows the means of the unobservables to differ across race and sex groups but not the other features of the distributions.

${ }^{20}$ The definition of illegal activities is given at the base of Table 2A.
} 
estimated allowing the highest grade attained at the time of the test to affect means and factor loadings and includes as controls family background characteristics and cohort dummies. ${ }^{21}$ Our cognitive measures are five ASVAB test scores. We use two attitudinal scales, the Rotter Locus of Control Scale and the Rosenberg Self-Esteem Scale, as our noncognitive measures. We choose these measures because of their availability in the NLSY. Ideally, it would be better to use a wider array of psychological measurements and, as previously noted, to connect them with more conventional measures of preference parameters in economics.

As explained in Section (3.5) two normalizations are required to assure identification of the model. These set the scale of the factors. We normalize the loadings $\left(\alpha_{C_{i}}\left(s_{T}\right), \alpha_{N_{j}}\left(s_{T}^{\prime}\right)\right)$ of the cognitive $\left(f^{C}\right)$ and noncognitive $\left(f^{N}\right)$ factors to be equal to 1 in the equations associated with coding speed (ASVAB 5) and the Rosenberg Self-Esteem Scale for individuals in grades 9 to 11 at the time of the test, respectively.

The distributions of the unobservables are identified nonparametrically. We do not impose distributional assumptions on the unobservables. The factors are estimated as three component mixtures of normals. The uniquenesses (the $e$ ) of the wage equations are distributed as three component mixtures of normals. ${ }^{22}$ The other uniquenesses are normally distributed. When we permit them to be non-normal, we do not improve the fit of the model.

\section{Evidence from the Model}

Estimates of the parameters of the equations of the model are presented in Web Appendix Tables S4S20. The model fits the data on wages and other outcomes. ${ }^{23}$ Overall goodness of fit tests are passed for all outcome and choice equations. ${ }^{24}$ The loadings on both cognitive and noncognitive factors are statistically significant in most equations. Both factors are required to produce a model that

\footnotetext{
${ }^{21}$ The schooling levels at test date considered in the estimation of the cognitive measurement system are: grades 9-11, grade 12, 13 to 15 years of schooling and 16 or more years of schooling. For the noncognitive measurement system the schooling levels are: grades 9-11, grade 12 and 13 or more years of schooling. This difference is due to the years in which the different tests were administered. See Web Appendix A for details.

${ }^{22}$ Models for wages with fewer mixture components do not fit the data as well.

${ }^{23}$ See Figures S3A and S3B at our Web Appendix at jenni.uchicago.edu/noncog.

${ }^{24}$ See Appendix Tables S21A and S21B for men and women.
} 
passes goodness of fit tests. ${ }^{25}$ The estimated distributions of the factors are highly non-normal. Standard normality assumptions would produce seriously biased estimates of the true factors and force symmetry onto highly asymmetric data. ${ }^{26}$ We find strong evidence that schooling affects both measured cognitive ability and measured noncognitive ability. ${ }^{27}$ The first finding corroborates the earlier analyses of Neal and Johnson (1996), Hansen, Heckman, and Mullen (2004) and Heckman, Larenas, and Urzua (2004). The second result is new and corroborates the claims of the Marxist economists (see e.g. Bowles and Gintis, 1976).

Because our model is nonlinear and multidimensional, the best way to understand it is to simulate it. Figure 3 plots the densities of the estimated cognitive and noncognitive factors by schooling level for men and women. These are to be compared with the densities of the raw test scores presented in Figure 2. The distributions of $f^{N}$ and $f^{C}$ are clearly non-normal. On the cognitive factor, the sorting patterns are about the same in Figures 2 and 3 although the shapes are different. More cognitively able people attain higher levels of education. GEDs are smarter than dropouts and their distribution of the cognitive trait is very close to that of high school graduates who do not go on to college.

Our estimated distribution of noncognitive ability reverses the pattern for dropouts and GEDs that is found in the raw data reported in Figure 2. Male GEDs have a worse noncognitive ability distribution than dropouts. For females, dropouts and GEDs have the same distribution of noncognitive skills. Thus male GEDs are the same or worse than high school dropouts in terms of noncognitive factors but are better in cognitive terms. This confirms an hypothesis of Heckman and Rubinstein (2001) that GEDs are smarter than ordinary dropouts but have lower noncognitive skills.

Figure $4 \mathrm{~A}$ summarizes the estimated effects of schooling at the date of the test $\left(s_{T}\right)$ on components of the ASVAB for males of average cognitive and noncognitive ability. Since the means

\footnotetext{
${ }^{25}$ Table S22 in the web appendix shows that we reject the null hypotheses that either cognitive or noncognitive factors do not belong in the outcome and choice equations.

${ }^{26}$ See Web Appendix Table S23 and Figures S4A and S4B.

${ }^{27}$ For males, the $\chi^{2}$ test for the null that schooling does not affect measured cognitive tests (means and factor loadings) is 431.65 with 150 degrees of freedom. Hence we reject the null (the critical values are 172.5 (95\%), 179.5 $(90 \%))$. The $\chi^{2}$ test for the null that schooling does not affect the means and factor loadings of the latent noncognitive test is 116.53 with 40 degrees of freedom. Hence we reject that hypothesis as well (the critical values are 55.75 (95\%), $51.80(90 \%))$. For females we obtain similar results. Table S24 in the Web Appendix presents these results.
} 
of $f^{N}$ and $f^{C}$ are zero, these figures isolate the effect of schooling on the intercepts of the test score equations. Schooling raises measured test scores. Figure 4B summarizes, for men, the effect of schooling at the test date on the noncognitive measures. Schooling raises scores on the Rotter Scale at lower levels of schooling. For the Rosenberg Scale, scores are raised across all grades of schooling. ${ }^{28}$

Figures 5-25 graphically summarize the main implications of our model for a variety of outcome measures. We report results for both men and women when there are differences by gender. Otherwise we only report the results for men, posting the results for women at our Web Appendix. The structure of these figures is the same across all outcomes. Each figure has three panels. Panel (i) displays the joint distribution of the outcome reported by deciles of the cognitive and noncognitive factors, while panels (ii) and (iii) display the marginal effects of one factor holding the effect of the other factor constant at its mean.

Mean log hourly wages by decile of cognitive and noncognitive ability for men and women are displayed in Figures 5A and 5B, respectively. In these figures we display log wage levels as a function of the factors rather than deciles of wage distributions as a function of the factors. Standard error bands are presented along with the main graphs. For both men and women, cognitive skills have about the same effect on wages as noncognitive skills. The effect of noncognitive skills for men is slightly less strong, as measured by the slope of the log wage-ability decile curve, than it is for women.

Figures 5A and 5B display the net effect of increases in the abilities on log wages inclusive of the direct effect of ability on log wages holding schooling fixed, the effect of ability on schooling and the generated effect of schooling on log wages. Tables $3 \mathrm{~A}$ and $3 \mathrm{~B}$ show that the factor loadings (hedonic prices) on latent skills vary substantially across schooling levels. Noncognitive traits are not valued in the labor market for male four year college graduates, although they are for female college graduates. In most of the educational labor markets, noncognitive factors are valued for both genders. For men, noncognitive traits are valued more highly in low skill markets. For women, noncognitive traits are more uniformly valued.

\footnotetext{
${ }^{28}$ The results for women are comparable and can be found at jenni.uchicago.edu/noncog. See Figures S5A and S5B.
} 
Figures 6-11 show the valuation of each type of skill in different schooling labor markets jointly (panel (i)) and holding the factor not being studied at its mean level (panels (ii) and (iii)). Panels (ii) and (iii) also display the proportion of individuals with the indicated level of schooling whose cognitive (panel (ii)) and noncognitive (panel (iii)) abilities lie in each decile of the distribution. When the proportions are small, the standard error bands are larger. Across schooling markets different factors are priced differently. Thus in the male dropout market, the log wage gradient for cognitive ability is greater than that for noncognitive ability. A similar pattern is found for females. In the GED market, this pattern is reversed, especially for females. For the high school markets, the gradients are similar across skills for men and women but the gradients are much steeper for women.

For those attending some college, the noncognitive gradients are much steeper than the cognitive gradients, but again the female noncognitive gradient is much steeper than the male gradient. In the market for two year college graduates, the gradients are about equally strong across skills and across sex groups. For males in the four-year college market, noncognitive skills have little marginal value while cognitive skills have a strong gradient. For females in the four-year college market, both skills command high marginal prices.

Figures 12A and 12B display the effects of cognitive and noncognitive skills on employment for men and women, respectively. For both genders, the gradient on noncognitive skills is greater than it is for cognitive skills. The pattern is especially pronounced for women.

The effects of both cognitive and noncognitive ability on employment cumulate over the lifecycle into effects on work experience. Figures 13A-13D show the effects of both cognitive and noncognitive ability on work experience for male workers in different educational labor markets. Except for the market for 4-year college graduates - the highest skill market we study - the gradient for noncognitive skills is much steeper than for cognitive skills. If anything, the results are more dramatic for women.

For both genders, cognitive ability has a slightly larger effect on the choice of white versus blue collar occupations than noncognitive ability, although both latent abilities are important determinants of this choice. See Figures 14A and 14B.

We next consider the effects of cognitive and noncognitive abilities on schooling decisions. For 
the sake of brevity, we report results for selected schooling levels. We report results for women when they are different from those of men.

Figure 15 shows the effects of the latent abilities on the high school dropout decision. Those at the top of the cognitive ability distribution are very unlikely to drop out. Both types of ability have strong effects on the dropout decision, but cognitive ability is more important in the sense of the gradient of the probability of dropout-ability decile curve. ${ }^{29}$ For the decision to drop out from high school and attain a GED and not continue on to college, the opposite is the case (see Figure 16). For a man with cognitive ability in the lowest decile, increasing his noncognitive ability from the lowest to the highest decile decreases the probability that he will obtain a GED. The cognitive ability GED curve is flat. Noncognitive factors play a strong role, with those who have high noncognitive skills unlikely to attain a GED.

The effects of both cognitive and noncognitive ability on attaining a high school degree and stopping there are not monotonic (see Figure 17 for men). At the lowest deciles of both abilities, increasing either ability raises the probability of graduating from high school and obtaining no further schooling. At higher levels, it decreases the probability as more able people (in both senses of ability) do not stop their education at high school but go on to attain higher levels of schooling. Similar phenomena appear for persons who attend (but do not graduate from) college. See Figures S9 and S10 posted in our Web Appendix.

The effects of cognitive and noncognitive ability on the probability of graduating from a community college are weak (see Figure 18). The effects of noncognitive abilities are nonmonotonic. Figure 19 shows that both cognitive and noncognitive abilities have strong effects on graduating from a four year college. The gradient of noncognitive ability on the probability of graduating from a four year college is smaller for women (see Figure S12 in our Web Appendix).

For daily smoking by age 18, an equivalent decile movement in the noncognitive factor induces a much larger change in behavior for males than does a change in the cognitive factor. For women, the opposite is true. See Figures 20A and 20B.

For men of average cognitive (noncognitive) ability, increasing noncognitive (cognitive) ability from the lowest to the highest decile decreases their probability of using marijuana. See Figure 21.

\footnotetext{
${ }^{29}$ The results for women show a steeper gradient for noncognitive skills (see Figure S6 at our Web Appendix).
} 
Cognitive skills are not strong predictors of marijuana use.

Figure 22 displays the probability of incarceration by age 30 for males. ${ }^{30}$ Although both factors are important, we find that the noncognitive factor induces a much larger change in behavior than a comparable decile change in the cognitive factor. For males in the lowest decile of the cognitive distribution, moving from the lowest to the highest decile of the noncognitive distribution substantially decreases the probability of incarceration. In comparison, taking the same males who are in the lowest deciles of both distributions and moving them to the highest decile of the cognitive distribution only slightly decreases their probability of incarceration. Contrary to claims made by Herrnstein and Murray (1994) and Herrnstein and Wilson (1985), it is noncognitive ability that is the dominant factor in explaining different rates of participation in crime, and not cognitive ability.

We also consider the effects of cognitive and noncognitive abilities on participation in illegal activities. These results are displayed in Figure 23. Again, noncognitive abilities have much stronger effects in the sense of having a steeper gradient. For women (see our Web Appendix Figure S14) both gradients are essentially zero.

Although both factors are important determinants of marital status and pregnancy by age 18, changing the noncognitive factor has greater effects on behavior. Figure 24 shows the effects of both types of latent abilities on being single with no child by age 18. Changes in the cognitive factor are important, but have weaker effects than changes in the noncognitive factor. This evidence illustrates the importance of noncognitive skills in explaining the chances of a woman being single with no child. The probability of being a teenage mother is equally responsive to changes in cognitive and noncognitive skills. See Figure 25. At the highest levels of cognitive and noncognitive skills, the probability of teenage pregnancy is essentially zero.

We use Children of NLSY data (CNLSY79) to corroborate some of the findings reported in this paper. One potential advantage of these data is that they contain very early (age 3-6) measurements of both cognitive and noncognitive abilities. Such measurements are not affected by later schooling. A disadvantage of these data is that many of the children are still young and we lack information on their wages, occupational status and employment at age 30. In addition, the samples are small. The evidence from the CNLSY data is broadly consistent with the evidence reported in this paper,

\footnotetext{
${ }^{30}$ For females, incarceration is not an empirically important phenomenon.
} 
but the parameters are much less precisely estimated. See Table S25 in our Web Appendix. ${ }^{31}$

Two latent factors associated with cognitive and noncognitive skills explain a wide array of teenage and young adult behaviors. Noncognitive abilities play a major role in explaining these behaviors and they are valued as direct determinants of wages in most educational labor markets.

\section{Relationship of Our Work to Previous Research}

Early work by Bowles and Gintis (1976) presents evidence suggesting that employers in low skill markets value docility, dependability, and persistence more than cognitive skills. In a similar vein, Edwards (1976) shows that dependability and consistency are more valued by blue collar supervisors than are cognitive ability or independent thought. Klein, Spady, and Weiss (1991) document that the premium accorded high school graduates compared to high school dropouts in semiskilled and skilled occupations is due primarily to the higher level of job stability (lower quit rates) and dependability (lower absenteeism) of high school graduates, and not their greater productivity in final output. However, they do not present estimates of the effects of noncognitive skills on wages. Peter Mueser, writing in chapter 5 of Jencks (1979), uses least squares to find that skills such as industriousness, perseverance, and leadership have statistically significant influences on wagescomparable to estimated effects of schooling, IQ, and parental socioeconomic status - even after controlling for standard human capital variables.

In more recent work, Osborne-Groves (2004) studies the effect of personality and behavioral traits on the wages of females. Using two data sets and alternative instruments for adult personality measures, she finds that personality traits such as fatalism, aggression, and withdrawal have significantly negative effects on wages. She does not control for the effect of schooling on the measurements she uses. ${ }^{32}$ Bowles, Gintis, and Osborne (2001) present a model in which incentiveenhancing preferences that allow employers to induce greater effort at a lower cost (such as a low

\footnotetext{
${ }^{31}$ There is an additional problem with these data. Both cognitive and noncognitive abilities change with age. Cunha and Heckman (2003) model the evolution of both cognitive and noncognitive skills over the lifecycle. Even IQ is not stable before age 8 (see Cunha, Heckman, Lochner, and Masterov, 2006). Let $a_{t}$ be ability at age $t$. If $a_{t}=\lambda a_{t-1}+b_{t}+\varepsilon_{t}$, where $b_{t}$ is a growth trend and $\varepsilon_{t}$ is an iid innovation, early measurement of $a_{t}$ may be a poor approximation for the later measurement used in this paper. Thus, while use of early measurements circumvents the problem of reverse causality, it creates a measurement error problem because $a_{t^{\prime}}\left(t^{\prime}<t\right)$ is not the same as $a_{t}$.

${ }^{32}$ Her instruments include lagged wages, and so are suspect.
} 
time discount rate, a high degree of self-directedness and personal efficacy, a low disutility of effort, and a tendency of being helpful toward other employees) are rewarded in a competitive labor market in the form of increased wages. Our evidence supports their analysis because noncognitive traits raise wages in most labor markets for schooling of different levels.

Heckman and Rubinstein (2001) use evidence from the General Educational Development (GED) testing program (an exam-certified alternative high school degree) to demonstrate the quantitative importance of noncognitive skills. GED recipients have the same cognitive ability as high school graduates who do not go to college, as measured by the AFQT score. However, once cognitive ability is controlled for, GED recipients have the same or lower hourly wages as those of high school dropouts. Their earnings are lower. This pattern would be predicted by our model because GEDs have lower noncognitive skills than dropouts (see Figure 3) and hence are less likely to be employed and to acquire work experience, and also have lower levels of a characteristic valued in the labor market.

Darity, Goldsmith, and Veum (1997) use the NLSY79 to estimate the effect of Rosenberg and Rotter scales on wages. They control for the endogeneity of the test scores in wage equations using an instrumental variables procedure but they do not correct for the endogeneity of schooling in the wage equation nor do they estimate the distributions of latent ability. However, their reported estimates qualitatively agree with ours. Elasticities of wage equations with respect to predicted noncognitive test scores are of comparable magnitudes as elasticities of wage equations with respect to conventional human capital variables.

It is quite instructive to compare our results on the effects of cognitive and noncognitive skills on wages to results from conventional approaches. As discussed in Section 2, the standard approach of regressing wages on measured test scores suffers from several problems. First, wages are typically regressed on cognitive and noncognitive test scores, schooling dummies and a set of other controls (as in Column A in Table 1). This is problematic because schooling is a choice variable and schooling choices depend on cognitive and noncognitive skills, as we have shown. Removing schooling dummies solves this source of endogeneity problems and changes the parameters estimated to be net effects of these skills on wages (as in Column B in Table 1). These net effects do not isolate the effect of ability on wages. Furthermore, since schooling at the time of the test affects test scores, test 
scores are still endogenous in the wage equation. Finally, there is the problem of measurement error. Test scores are imperfect proxies for latent cognitive and noncognitive abilities because they are affected by measured characteristics such as family background. Because these problems likely bias the estimates in different directions, we cannot predict whether OLS estimates will be higher or lower than those of our model.

We can simulate our model given the exogenous conditioning variables to predict the test score that each individual would have received had he been in grades 9-11 at the time he took the test. We predict test scores by drawing the factors from the population distribution. Using these corrected test scores in an OLS wage regression alleviates the problem that schooling affects the test score, but measurement error remains because the test score is not the same as the factor it proxies. Table 4 displays the (standardized) coefficients from OLS on measured test scores (columns i and iv), OLS using corrected test scores (ii and v) and the same simulated factor as used to generate the corrected test score without measurement error. ${ }^{33}$ We find that estimated returns to ability are typically much smaller using corrected rather than actual test scores. Endogeneity of test scores (and reverse causality in the regressions that are not run separately by schooling level) produces estimates that are generally upward biased. Estimates using the simulated factor are typically much larger than those using corrected (or even actual) test scores. Measurement error causes a significant downward bias, that is typically larger than the upward bias due to endogeneity and reverse causality. This effect is especially pronounced for noncognitive skills.

\section{Conclusion}

This paper presents new evidence that both cognitive and noncognitive abilities determine social and economic success. For many dimensions of behavior and for the sense of "importance" adopted in this paper, noncognitive ability is as important, if not more important, than cognitive ability. Our findings challenge a pervasive view in the literatures in economics and psychology that cognitive ability, as measured by test scores, plays a dominant role in explaining personal achievement. Although cognitive skills explain much more of the variance of (log) wages, their effects on (log)

\footnotetext{
${ }^{33}$ The standardized coefficient is obtained by multiplying the original coefficient by the standard deviation of the variable to which it is associated.
} 
wages (as measured by skill gradients) are similar to the effects of the noncognitive traits. In fact noncognitive skills are about equally strong in many outcomes and are stronger for some outcomes. Of course, equal strength in the sense we have used it does not translate into equal cost of changing these skills.

A low dimensional model of cognitive and noncognitive abilities explains a diverse array of outcomes. It explains correlated risky behaviors among youth. Noncognitive ability affects the acquisition of skills, productivity in the market and a variety of behaviors. Cognitive ability affects market productivity, skill acquisition and a variety of behaviors. Schooling raises measured cognitive ability and measured noncognitive ability.

Our evidence is consistent with an emerging body of literature that establishes the importance of psychic costs in explaining why many students do not continue their schooling, even though it is financially rewarding to do so. Cunha, Heckman, and Navarro (2005a,b, 2006) and Cunha and Heckman (2005)establish that these costs are related to cognitive ability. Our evidence suggests that noncognitive ability - motivation, persistence and self-esteem - also plays a substantial role, but we have not, in this paper, linked our measures of noncognitive ability to conventional measures of time preference, risk aversion and preferences for leisure.

Our evidence that multiple abilities determine schooling challenges the conventional single skill signalling model due to Arrow (1973) and Spence (1973). A special challenge is the GED program where the credential (the GED test) conveys multiple conflicting signals. GED recipients are smarter than other high school dropouts but they have lower noncognitive skills. This violates the standard single crossing property used in conventional signalling theory and requires a substantial reformulation of that theory. See Araujo, Gottlieb, and Moreira (2004).

Our demonstration that noncognitive skills are important in explaining a diverse array of behaviors helps to explain why early childhood programs, like Headstart and the Perry Preschool program, are effective. The evidence from these programs indicates that they do not boost IQ but they raise noncognitive skills and therefore promote success in social and economic life. Our evidence of gender differentials in the effects of noncognitive skills on certain behaviors goes part way in explaining the gender differentials found in the Perry Preschool program (Heckman, 2005, discusses these differentials). The differential effect of Perry on raising female employment at age 27 
and on reducing high school dropout rates compared to the male results is consistent with the much steeper gradient of female employment and dropout rates with respect to changes in noncognitive skills compared to that of males. 


\section{References}

Araujo, A., D. Gottlieb, and H. Moreira (2004, December). A Model of Mixed Signals with Applications to Countersignaling and the GED. Working paper, Sociedade Brasileira de Econometria.

Arrow, K. J. (1973, July). Higher Education as a Filter. Journal of Public Economics 2(3), 193-216.

Biglan, A. (2004). Helping Adolescents at Risk: Prevention of Multiple Problem Behaviors. New York: Guilford Press.

Bonhomme, S. and J.-M. Robin (2004). Nonparametric Identification and Estimation of Independent Factor Models. Unpublished working paper, Sorbonne, Paris.

Bowles, S. and H. Gintis (1976). Schooling in Capitalist America: Educational Reform and the Contradictions of Economic Life. New York: Basic Books.

Bowles, S., H. Gintis, and M. Osborne (2001, December). The Determinants of Earnings: A Behavioral Approach. Journal of Economic Literature 39(4), 1137-1176.

Browning, M., L. P. Hansen, and J. J. Heckman (1999, December). Micro Data and General Equilibrium Models. In J. B. Taylor and M. Woodford (Eds.), Handbook of Macroeconomics, Volume 1A, Chapter 8, pp. 543-633. Elsevier.

Cameron, S. V. and J. J. Heckman (1998, April). Life Cycle Schooling and Dynamic Selection Bias: Models and Evidence for Five Cohorts of American Males. Journal of Political Economy 106(2), 262-333.

Cameron, S. V. and J. J. Heckman (2001, June). The Dynamics of Educational Attainment for Black, Hispanic, and White Males. Journal of Political Economy 109(3), 455-99.

Carneiro, P., K. Hansen, and J. J. Heckman (2003, May). Estimating Distributions of Treatment Effects with an Application to the Returns to Schooling and Measurement of the Effects of Uncertainty on College Choice. International Economic Review 44(2), 361-422. 2001 Lawrence R. Klein Lecture. 
Carneiro, P. and J. J. Heckman (2003). Human Capital Policy. In J. J. Heckman, A. B. Krueger, and B. M. Friedman (Eds.), Inequality in America: What Role for Human Capital Policies? Cambridge, MA: MIT Press.

Carneiro, P., J. J. Heckman, and D. V. Masterov (2005, April). Labor Market Discrimination and Racial Differences in Pre-Market Factors. Journal of Law and Economics 47(1), 1-39.

Cawley, J., J. J. Heckman, and E. J. Vytlacil (2001, September). Three Observations on Wages and Measured Cognitive Ability. Labour Economics 8(4), 419-442.

Cunha, F. and J. J. Heckman (2003). The Technology of Skill Formation. Unpublished manuscript, University of Chicago, presented at AEA meetings, January, 2003, San Diego, CA and Federal Reserve Bank of Minneapolis, October, 2004. Revised May, 2005 for presentation at the Society for Economic Dynamics and Control.

Cunha, F. and J. J. Heckman (2005). A Framework for the Analysis of Inequality. Journal of Macroeconomics, forthcoming.

Cunha, F., J. J. Heckman, L. J. Lochner, and D. V. Masterov (2006). Interpreting the Evidence on Life Cycle Skill Formation. In E. A. Hanushek and F. Welch (Eds.), Handbook of the Economics of Education. Amsterdam: North-Holland. forthcoming.

Cunha, F., J. J. Heckman, and S. Navarro (2005a, August). The Evolution of Earnings Risk in the US Economy. Presented at the 9th World Congress of the Econometric Society, London. Previously "Separating Heterogeneity from Uncertainty in an Aiyagari-Laitner Economy," presented at the Goldwater Conference on Labor Markets, Arizona State University, March 2004.

Cunha, F., J. J. Heckman, and S. Navarro (2005b, April). Separating Uncertainty from Heterogeneity in Life Cycle Earnings, The 2004 Hicks Lecture. Oxford Economic Papers 57(2), 191-261.

Cunha, F., J. J. Heckman, and S. Navarro (2006). Counterfactual Analysis of Inequality and Social Mobility. In S. L. Morgan, D. B. Grusky, and G. S. Fields (Eds.), Mobility and Inequality: Frontiers of Research from Sociology and Economics, Chapter 4. Palo Alto: Stanford University Press. forthcoming. 
Darity, W. A., A. Goldsmith, and J. Veum (1997, October). The Impact of Psychological and Human Capital on Wages. Economic Inquiry 35(4), 818-829.

Duckworth, A. L. and M. E. P. Seligman (2005, November). Self-Discipline Outdoes IQ in Predicting Academic Performance of Adolescents. Psychological Science 16(12), 939-944.

Edwards, R. C. (1976, Winter). Individual Traits and Organizational Incentives: What Makes a "Good" Worker? Journal of Human Resources 11(1), 51-68.

Ellwood, D. T. and T. J. Kane (2000). Who Is Getting a College Education? Family Background and the Growing Gaps in Enrollment. In S. Danziger and J. Waldfogel (Eds.), Securing the Future: Investing in Children from Birth to College, pp. 283-324. New York: Russell Sage Foundation.

Hansen, K. T., J. J. Heckman, and K. J. Mullen (2004, July-August). The Effect of Schooling and Ability on Achievement Test Scores. Journal of Econometrics 121(1-2), 39-98.

Heckman, J. J. (1981). Statistical Models for Discrete Panel Data. In C. Manski and D. McFadden (Eds.), Structural Analysis of Discrete Data with Econometric Applications, pp. 114-178. Cambridge, MA: MIT Press.

Heckman, J. J. (1995, October). Lessons from The Bell Curve. Journal of Political Economy 103(5), 1091.

Heckman, J. J. (2005). Invited Comments. In L. J. Schweinhart, J. Montie, Z. Xiang, W. S. Barnett, C. R. Belfield, and M. Nores (Eds.), Lifetime Effects: The High/Scope Perry Preschool Study Through Age 40, pp. 229-233. Ypsilanti, MI: High/Scope Press. Monographs of the High/Scope Educational Research Foundation, 14.

Heckman, J. J., M. I. Larenas, and S. Urzua (2004). Accounting for the Effect of Schooling and Abilities in the Analysis of Racial and Ethnic Disparities in Achievement Test Scores. Unpublished manuscript, University of Chicago, Department of Economics.

Heckman, J. J., L. J. Lochner, and P. E. Todd (2006). Earnings Equations and Rates of Return: The Mincer Equation and Beyond. In E. A. Hanushek and F. Welch (Eds.), Handbook of the Economics of Education. Amsterdam: North-Holland. forthcoming. 
Heckman, J. J. and D. V. Masterov (2004, September). The Productivity Argument for Investing in Young Children. Technical Report Working Paper No. 5, Committee on Economic Development.

Heckman, J. J. and S. Navarro (2006). Dynamic Discrete Choice and Dynamic Treatment Effects. Journal of Econometrics, forthcoming.

Heckman, J. J. and Y. Rubinstein (2001, May). The Importance of Noncognitive Skills: Lessons from the GED Testing Program. American Economic Review 91(2), 145-149.

Heckman, J. J., J. Stixrud, and S. Urzua (2006). The Effects of Cognitive and Noncognitive Skills on Racial and Ethnic Wage Gaps. Unpublished manuscript, University of Chicago, Department of Economics.

Heckman, J. J., S. Urzua, and E. J. Vytlacil (2004). Understanding Instrumental Variables in Models with Essential Heterogeneity. Unpublished manuscript, University of Chicago, Department of Economics. Review of Economics and Statistics Lecture, 2002. Under review, Review of Economics and Statistics.

Heckman, J. J. and E. J. Vytlacil (2005, May). Structural Equations, Treatment Effects and Econometric Policy Evaluation. Econometrica 73(3), 669-738.

Herrnstein, R. J. and C. A. Murray (1994). The Bell Curve: Intelligence and Class Structure in American Life. New York: Free Press.

Herrnstein, R. J. and J. Q. Wilson (1985). Crime and Human Nature: The Definitive Study of the Causes of Crime. New York: Simon and Schuster.

Jencks, C. (1979). Who Gets Ahead? The Determinants of Economic Success in America. New York: Basic Books.

Jensen, A. R. (1998). The g Factor: The Science of Mental Ability. Westport, CT: Praeger.

Jöreskog, K. G. (1977). Structural Equations Models in the Social Sciences: Specification, Estimation and Testing. In P. Krishnaiah (Ed.), Applications of Statistics, pp. 265-287. New York: North-Holland. 
Jöreskog, K. G. and A. S. Goldberger (1975, September). Estimation of a Model with Multiple Indicators and Multiple Causes of a Single Latent Variable. Journal of the American Statistical Association 70(351), 631-639.

Klein, R., R. Spady, and A. Weiss (1991, October). Factors Affecting the Output and Quit Propensities of Production Workers. Review of Economic Studies 58(5), 929-953.

Neal, D. A. and W. R. Johnson (1996, October). The Role of Premarket Factors in Black-White Wage Differences. Journal of Political Economy 104(5), 869-895.

Osborne-Groves, M. (2004, March). How Important is Your Personality? Labor Market Returns to Personality for Women in the US and UK. Unpublished manuscript, Towson University, Department of Economics. In press at Journal of Economic Psychology.

Rosenberg, M. (1965). Society and the Adolescent Self-Image. Princeton, NJ: Princeton University Press.

Rotter, J. B. (1966). Generalized Expectancies for Internal versus External Control of Reinforcement. Washington DC: American Psychological Association.

Segal, C. (2005). Misbehavior, Education, and Labor Market Outcomes. Unpublished Manuscript, Stanford University.

Spence, A. M. (1973, August). Job Market Signaling. Quarterly Journal of Economics 87(3), $355-374$.

Wolfe, R. N. and S. D. Johnson (1995, April). Personality as a Predictor of College Performance. Educational And Psychological Measurement 55(2), 177-185. 
Table 1- Estimated Coefficients from Log Hourly Wage Regressions NLSY79 - Males and Females at Age $30^{(a)}$

\begin{tabular}{|c|c|c|c|c|}
\hline \multirow[b]{2}{*}{ Variables $^{(b)}$} & \multicolumn{2}{|c|}{ Males } & \multicolumn{2}{|c|}{ Females ${ }^{(e)}$} \\
\hline & (A) & (B) & (A) & (B) \\
\hline GED & $\begin{array}{c}0.017 \\
(0.048)\end{array}$ & & $\begin{array}{l}-0.002 \\
(0.056)\end{array}$ & \\
\hline HS Graduate & $\begin{array}{c}0.087 \\
(0.035)\end{array}$ & & $\begin{array}{c}0.059 \\
(0.044)\end{array}$ & \\
\hline Some College, No Degree & $\begin{array}{c}0.146 \\
(0.044)\end{array}$ & & $\begin{array}{c}0.117 \\
(0.052)\end{array}$ & \\
\hline 2-Year College Degree & $\begin{array}{c}0.215 \\
(0.058)\end{array}$ & & $\begin{array}{c}0.233 \\
(0.058)\end{array}$ & \\
\hline 4-Year College Degree & $\begin{array}{c}0.292 \\
(0.046)\end{array}$ & & $\begin{array}{c}0.354 \\
(0.054)\end{array}$ & \\
\hline Cognitive Measure $^{(c)}$ & $\begin{array}{c}0.121 \\
(0.016)\end{array}$ & $\begin{array}{l}0.1900 \\
(0.013)\end{array}$ & $\begin{array}{c}0.169 \\
(0.017)\end{array}$ & $\begin{array}{c}0.251 \\
(0.014)\end{array}$ \\
\hline Noncognitive Measure ${ }^{(\mathrm{d})}$ & $\begin{array}{c}0.042 \\
(0.011)\end{array}$ & $\begin{array}{c}0.052 \\
(0.012)\end{array}$ & $\begin{array}{c}0.028 \\
(0.013)\end{array}$ & $\begin{array}{c}0.041 \\
(0.013)\end{array}$ \\
\hline Constant & $\begin{array}{c}2.558 \\
(0.057)\end{array}$ & $\begin{array}{c}2.690 \\
(0.050)\end{array}$ & $\begin{array}{c}2.178 \\
(0.063)\end{array}$ & $\begin{array}{c}2.288 \\
(0.052) \\
\end{array}$ \\
\hline
\end{tabular}

Notes: (a) We exclude the oversample of blacks, Hispanics and poor whites, the military sample, and those currently enrolled in college; (b) The model includes a set of cohort dummies, local labor market conditions (unemployment rate), the region of residence, and race. Column A presents the estimates obtained from OLS. Column B presents the results from an OLS model in which the schooling dummies are excluded; (c) The cognitive measure represents the standardized average over the ASVAB scores (arithmetic reasoning, word knowledge, paragraph comprehension, math knowledge and coding speed); (d) The noncognitive measure is computed as a (standardized) average of the Rosenberg Self-Esteem Scale and Rotter Internal-External Locus of Control Scale. Standard errors in parentheses; (e) For females we also estimate the equations correcting for selection into the labor force. The results presented in this table are robust to this correction. 
Table 2A. Variables in the empirical implementation of the model

Outcome Equations

\begin{tabular}{|c|c|c|c|c|c|c|c|c|}
\hline \multirow[b]{2}{*}{ Variables } & \multirow{2}{*}{$\begin{array}{c}\text { Log of Hourly Wage }{ }^{(2)}, \\
\text { Employment }{ }^{(b)} \text { and } \\
\text { Occupational Choice }{ }^{(c)} \text { Models }\end{array}$} & \multicolumn{6}{|c|}{$\begin{array}{c}\text { Educational Choice Model }{ }^{(\mathrm{d})} \\
\text { (Multinomial Probit) }\end{array}$} & \multirow{2}{*}{$\begin{array}{l}\text { Behavioral Outcomes }^{(e)} \\
\text { Work Experience }{ }^{(t)} \text { and } \\
\text { Fertililty Choice Model }^{(g)}\end{array}$} \\
\hline & & HS Dropouts & GED & HS Graduates & Some College, No Degree & 2 -yr. degree & 4-yr. degree & \\
\hline Black (Dummy) & Yes & Yes & Yes & Yes & Yes & Yes & - & Yes \\
\hline Hispanic (Dummy) & Yes & Yes & Yes & Yes & Yes & Yes & - & Yes \\
\hline Region of Residence (Dummy Variables) & Yes & - & & - & - & - & - & - \\
\hline Urban Residence (Dummy) & Yes & - & & & - & & & \\
\hline Local Unemployment Rate at age 30 & Yes & - & & - & - & - & - & - \\
\hline Living in a Urban area at age 14 (Dummy) & - & Yes & Yes & Yes & Yes & Yes & - & Yes \\
\hline Living in the South at age 14 (Dummy) & - & Yes & Yes & Yes & Yes & Yes & - & Yes \\
\hline Family income in 1979 & - & Yes & Yes & Yes & Yes & Yes & - & Yes \\
\hline Broken home at Age 14 (Dummy) & - & Yes & Yes & Yes & Yes & Yes & & Yes \\
\hline Number of Siblings at Age 17 (Dummy) & - & Yes & Yes & Yes & Yes & Yes & - & Yes \\
\hline Mother's Highest Grade Completed at Age 17 & - & Yes & Yes & Yes & Yes & Yes & - & Yes \\
\hline Father's Highest Grade Completed at Age 17 & - & Yes & Yes & Yes & Yes & Yes & - & Yes \\
\hline Local Wage of High School Dropouts at Age 17 & - & Yes & - & - & - & - & - & - \\
\hline Local Unemployment Rate of High School Dropouts at Age 17 & - & Yes & & & - & & & \\
\hline Local Wage of High School Graduates at Age 17 & - & - & - & Yes & - & - & - & - \\
\hline Local Unemployment Rate of High School Graduates at Age 17 & - & - & - & Yes & - & - & - & - \\
\hline Local Wage of Attendees of Some College at Age 17 & - & - & - & - & Yes & - & - & - \\
\hline Local Unemployment Rate of Attendees of Some College at Age 17 & - & - & - & - & Yes & - & - & - \\
\hline Local Wage for College Graduates at Age 17 & - & - & & & - & & Yes & \\
\hline Local Unemployment Rate for College Graduates at Age 17 & & & - & & - & - & Yes & \\
\hline Tuition at Two Year College at Age 17 & - & - & - & - & - & Yes & - & - \\
\hline Tuition at Four Year College at Age 17 & & - & - & - & - & - & Yes & - \\
\hline GED Costs & - & - & Yes & - & - & - & - & - \\
\hline Cohort Dummies & Yes & Yes & Yes & Yes & Yes & Yes & - & Yes \\
\hline \multicolumn{9}{|l|}{ Factors } \\
\hline Cognitive Factor & Yes & Yes & & Yes & Yes & Yes & & Yes \\
\hline Noncognitive Factor & Yes & Yes & & Yes & Yes & Yes & - & Yes \\
\hline
\end{tabular}

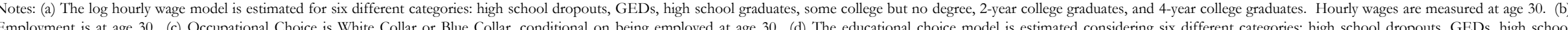

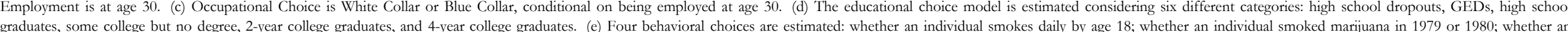

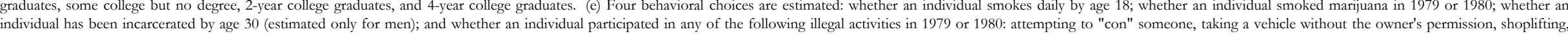

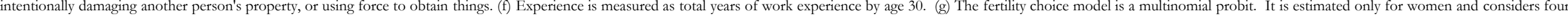
choices for marital/fertility status by age 18: single with child, single with no child, married with child, and married with no child. 


\section{Table 2B. Variables in the empirical implementation of the model}

\section{Auxiliary Measures}

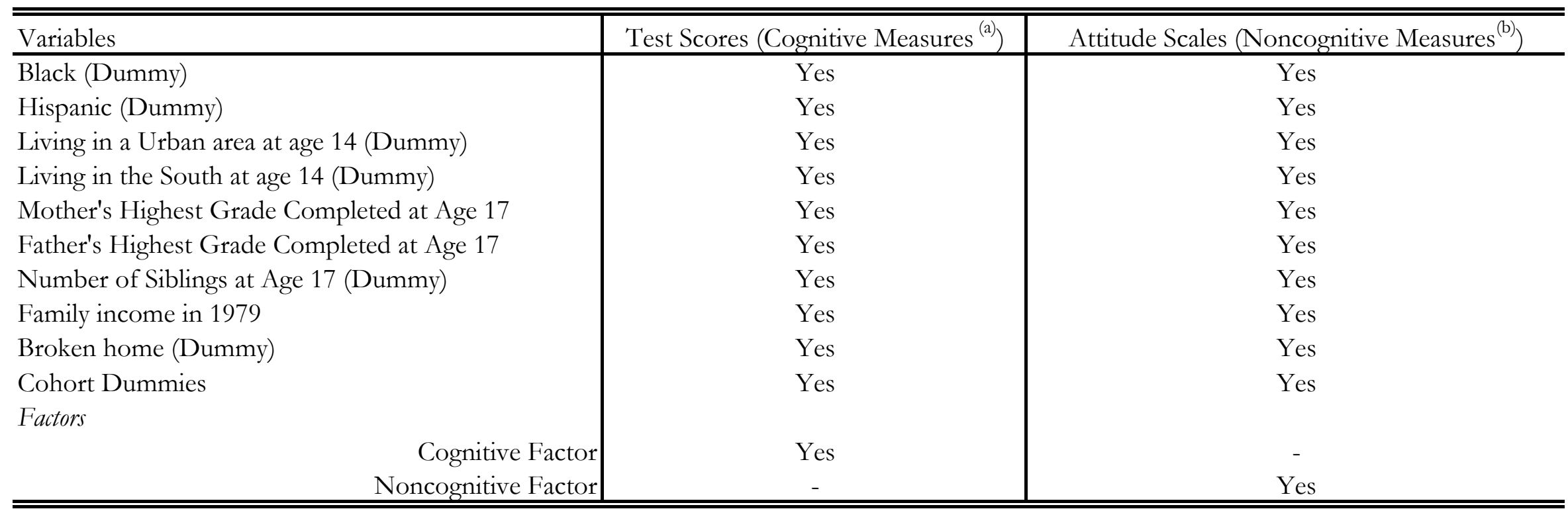

Notes: (a) Test scores are standardized to have within-sample mean 0, variance 1. The included cognitive measures are Arithmetic Reasoning, Word Knowledge, Paragraph Comprehension, Math Knowledge, and Coding Speed. ; (b) The included noncognitive measures are Rotter Locus of Control Scale and Rosenberg Self-Esteem Scale. The locus of control scale is based on the four-item abbreviated version of the Rotter InternalExternal Locus of Control Scale. This scale is designed to measure the extent to which individuals believe they have control over their lives through self-motivation or self-determination (internal control) as opposed to the extent that the enviroment controls their lives (external control). The selfesteem scale is based on the 10-item Rosenberg Self-Esteem Scale. This scale describes a degree of approval or disapproval toward oneself. In both cases, we standardize the test scores to have within-sample mean 0 and variance 1, after taking averages over the respective sets of scales. 
Table 3A. Estimated Coefficients of the Cognitive and Noncognitive Factors for the Log Hourly Wage Model ${ }^{(a),(b),(c),(d)}$

Sample from NLSY79-Males at Age 30

\begin{tabular}{|c|c|c|}
\hline \multirow{2}{*}{ Schooling Level } & \multirow[b]{2}{*}{ Cognitive } & \multirow[b]{2}{*}{ Noncognitive } \\
\hline & & \\
\hline \multirow[t]{2}{*}{ HS Dropout } & 0.113 & 0.424 \\
\hline & $(0.076)$ & $(0.092)$ \\
\hline \multirow[t]{2}{*}{ GED } & 0.175 & 0.357 \\
\hline & $(0.107)$ & $(0.117)$ \\
\hline \multirow[t]{2}{*}{ HS Graduate } & 0.259 & 0.360 \\
\hline & $(0.041)$ & $(0.059)$ \\
\hline \multirow[t]{2}{*}{ Some College, No Degree } & 0.069 & 0.401 \\
\hline & $(0.086)$ & $(0.110)$ \\
\hline \multirow[t]{2}{*}{ 2-Year College Degree } & 0.039 & 0.368 \\
\hline & $(0.138)$ & $(0.209)$ \\
\hline \multirow[t]{2}{*}{ 4-Year College Degree } & 0.296 & -0.060 \\
\hline & $(0.075)$ & $(0.175)$ \\
\hline
\end{tabular}

Notes: (a) The cognitive measure represents the standardized average over the raw ASVAB scores (arithmetic reasoning, word knowledge, paragraph comprehension, math knowledge and coding speed); (b) The noncognitive measure is computed as a (standardized) average of the Rosenberg Self-Esteem Scale and Rotter Internal-External Locus of Control Scale; (c) We exclude the oversample of blacks, Hispanics and poor whites, the military sample, and those currently enrolled in college. Standard errors in parentheses. (d) The model also includes a set of cohort dummies, local labor market conditions (unemployment rate), and the region of residence. 
Table 3B. Estimated Coefficients of the Cognitive and Noncognitive Factors for the Log Hourly Wage Model ${ }^{(a),(b),(c),(d)}$

Sample from NLSY79-Females at Age 30

\begin{tabular}{|c|c|c|}
\hline \multirow{2}{*}{ Schooling Level } & \multirow[b]{2}{*}{ Cognitive } & \multirow[b]{2}{*}{ Noncognitive } \\
\hline & & \\
\hline \multirow[t]{2}{*}{ HS Dropout } & 0.322 & 0.208 \\
\hline & $(0.125)$ & $(0.103)$ \\
\hline \multirow[t]{2}{*}{ GED } & 0.020 & 0.242 \\
\hline & $(0.137)$ & $(0.153)$ \\
\hline \multirow[t]{2}{*}{ HS Graduate } & 0.341 & 0.564 \\
\hline & $(0.049)$ & $(0.056)$ \\
\hline \multirow[t]{2}{*}{ Some College, No Degree } & 0.093 & 0.569 \\
\hline & $(0.084)$ & $(0.116)$ \\
\hline \multirow[t]{2}{*}{ 2-Year College Degree } & 0.206 & 0.279 \\
\hline & $(0.096)$ & $(0.145)$ \\
\hline \multirow[t]{2}{*}{ 4-Year College Degree } & 0.290 & 0.379 \\
\hline & $(0.066)$ & $(0.103)$ \\
\hline
\end{tabular}

Notes: (a) The cognitive measure represents the standardized average over the raw ASVAB scores (arithmetic reasoning, word knowledge, paragraph comprehension, math knowledge and coding speed); (b) The noncognitive measure is computed as a (standardized) average of the Rosenberg Self-Esteem Scale and Rotter Internal-External Locus of Control Scale; (c) We exclude the oversample of blacks, Hispanics and poor whites, the military sample, and those currently enrolled in college. Standard errors in parentheses. (d) The model also includes a set of cohort dummies, local labor market conditions (unemployment rate), and the region of residence. 
Table 4. Standarized OLS Coefficients of Cognitive and Noncognitive Skills from Log Hourly Wage Regressions ${ }^{\text {(a) }}$

by Different Skill Measures: Measured Test Scores, Corrected Test Scores and Latent Abilities (Factors)

Sample from the NLSY79--Males at age 30

\begin{tabular}{|c|c|c|c|c|c|c|}
\hline \multirow[b]{2}{*}{ Schooling Level } & \multicolumn{3}{|c|}{ Cognitive Ability } & \multicolumn{3}{|c|}{ Noncognitive Ability } \\
\hline & (i) & (ii) & (iii) & (iv) & (v) & (vi) \\
\hline HS Dropout & 0.047 & 0.019 & 0.039 & 0.072 & 0.023 & 0.133 \\
\hline GED & 0.074 & 0.068 & 0.101 & 0.018 & 0.056 & 0.157 \\
\hline HS Graduate & 0.087 & 0.064 & 0.102 & 0.035 & 0.016 & 0.113 \\
\hline Some College, No Degree & -0.018 & -0.012 & 0.024 & 0.041 & 0.03 & 0.131 \\
\hline 2-Year College Degree & 0.04 & -0.047 & 0.01 & 0.022 & 0.056 & 0.133 \\
\hline 4-Year College Degree & 0.12 & 0.113 & 0.124 & 0.054 & -0.002 & -0.005 \\
\hline Overall (Including Schooling Dummies) & 0.107 & 0.066 & 0.097 & 0.043 & 0.021 & 0.112 \\
\hline Overall (Excluding Schooling Dummies) & 0.177 & 0.143 & 0.134 & 0.055 & 0.043 & 0.135 \\
\hline
\end{tabular}

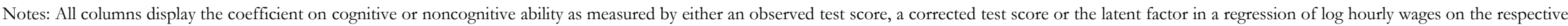

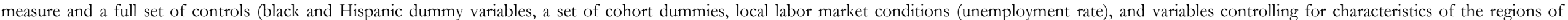

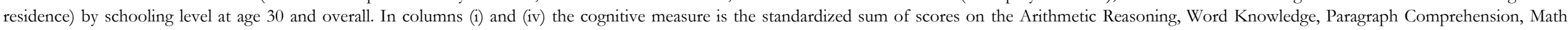

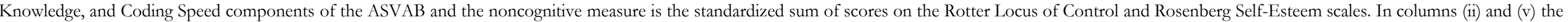

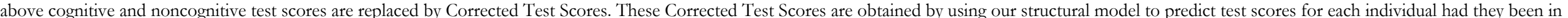

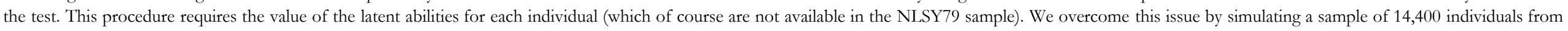

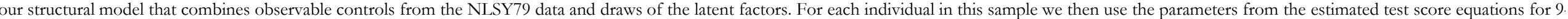

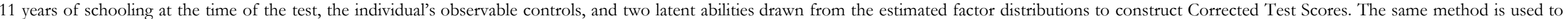

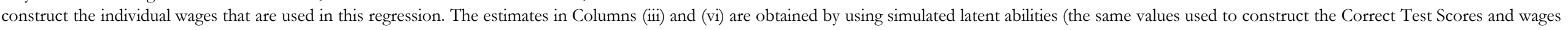

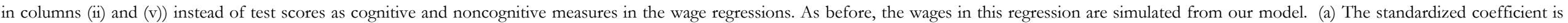
obtained by multiplying the original coefficient by the standard deviation of the variable to which it is associated. This allows us to make comparisons across columns. 


\section{Figure 1}

\section{Perry Preschool Program: IQ, by Age and Treatment Group}

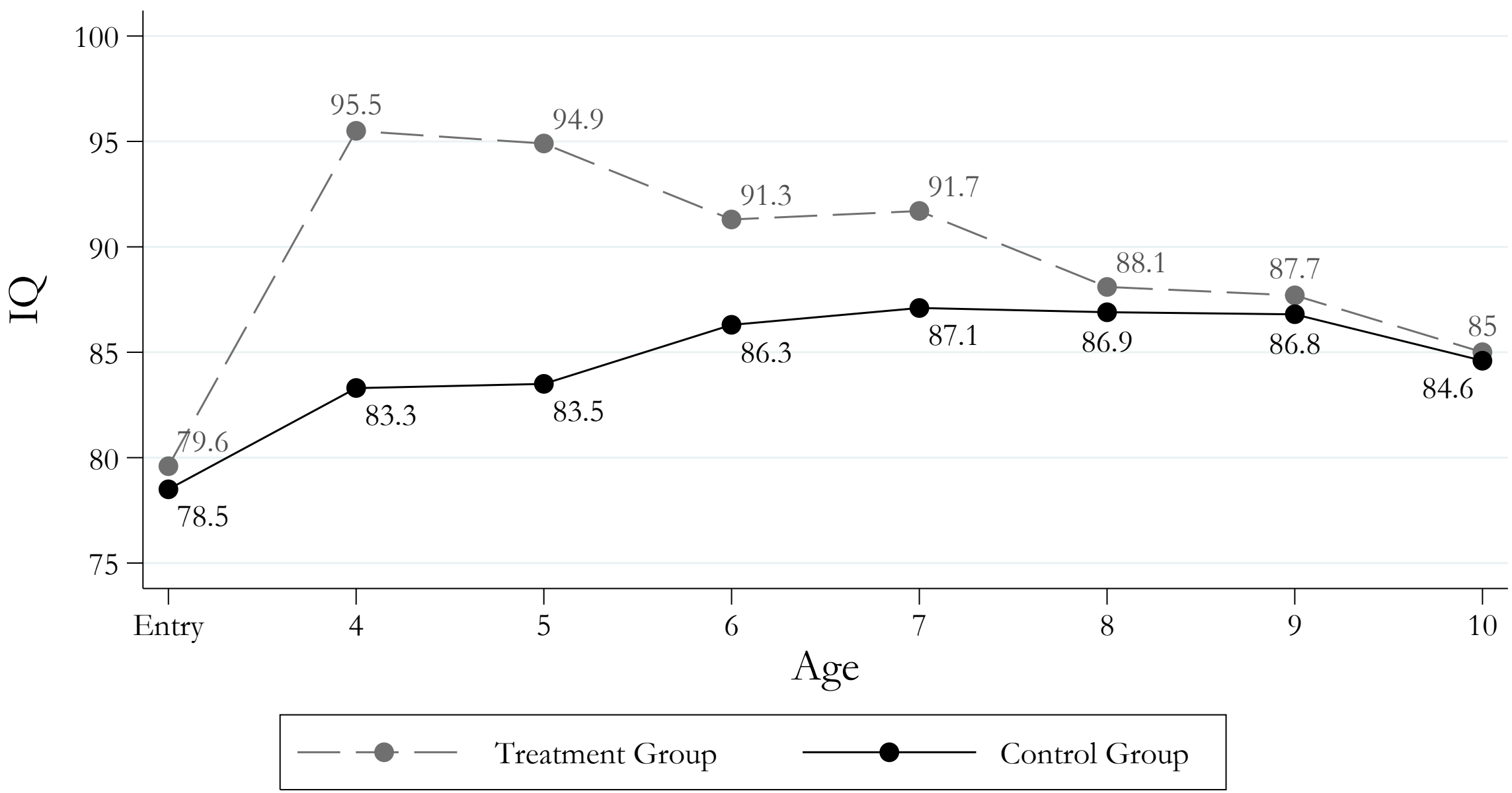

Source: Perry Preschool Program. IQ measured on the Stanford-Binet Intelligence Scale (Terman \& Merrill, 1960). Test was administered at program entry and each of the ages indicated. 
Figure 2. Distribution of Test Scores by Gender and Schooling Level
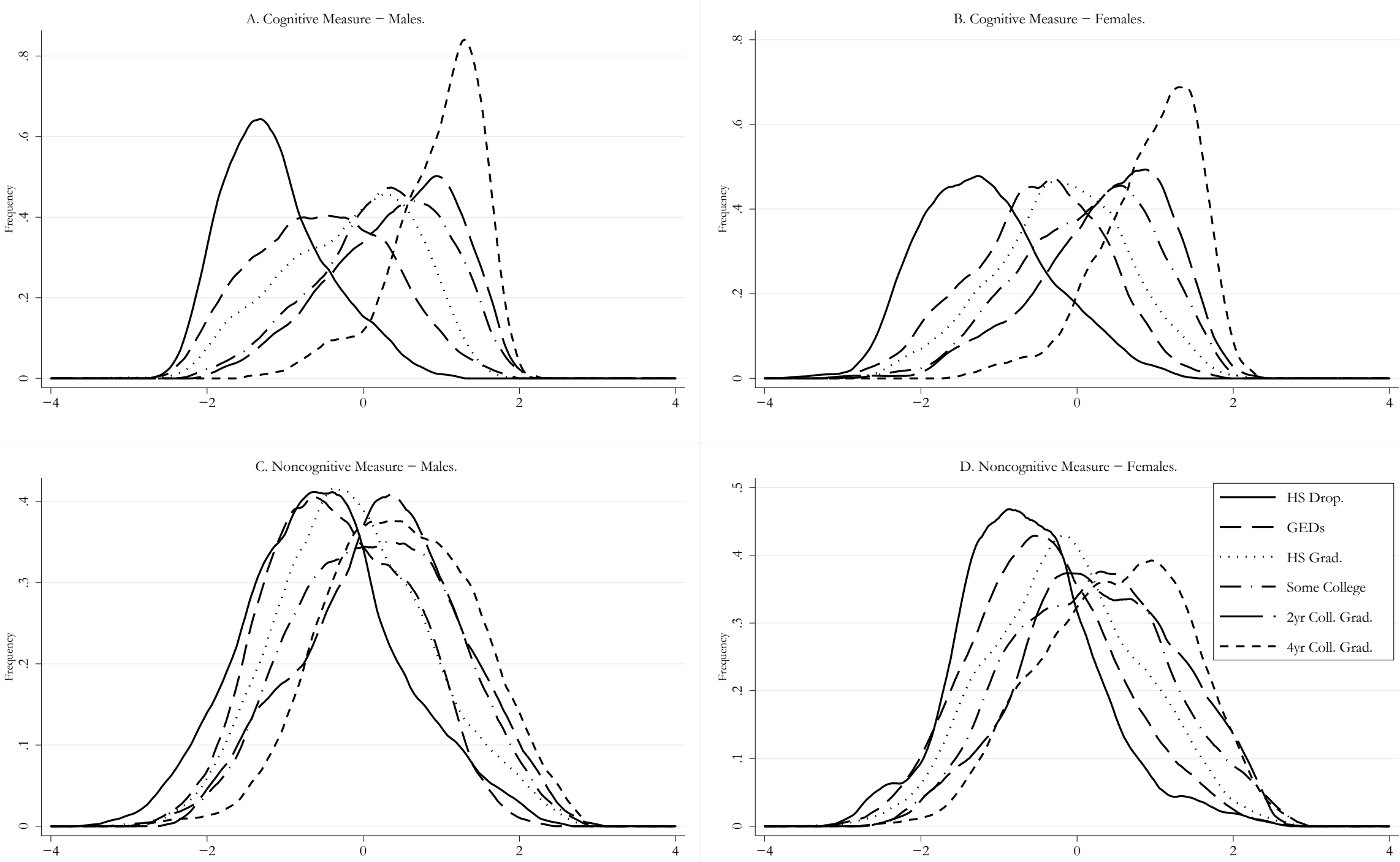

Notes: The cognitive measure represents the standardized average over the ASVAB scores (arithmetic reasoning, word knowledge, paragraph comprehension, numerical operations and coding speed). The noncognitive measure is computed as a (standardized) average of the Rosenberg Self-Esteem Scale and Rotter Internal-External Locus of Control Scale. The schooling levels represent the observed schooling level by age 30 in the NLSY79 sample (See Web Appendix A for details). 
Figure 3. Distribution of Factors by Gender and Schooling Level
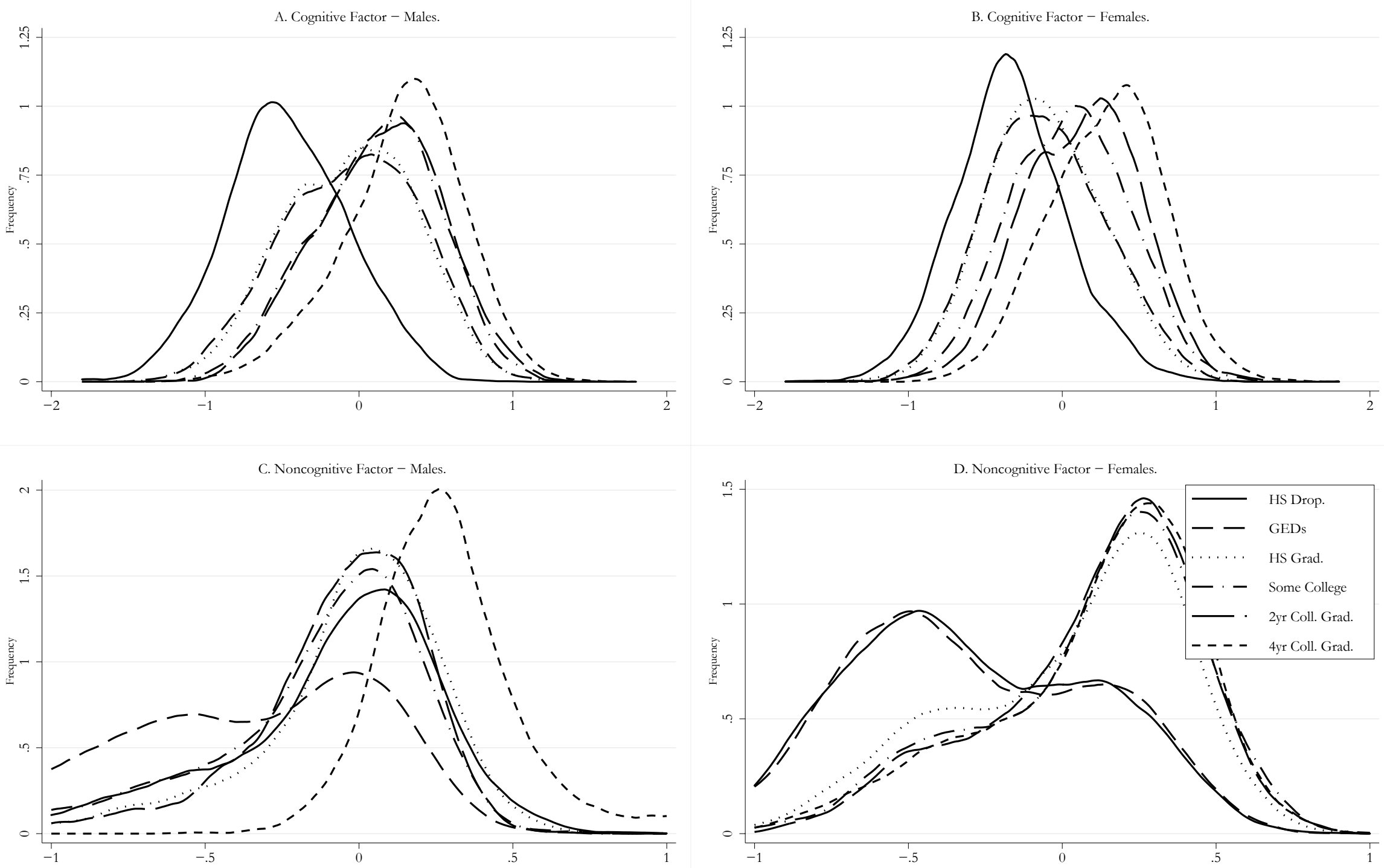

Notes: The factors are simulated from the estimates of the model. The schooling levels represent the predicted schooling level by age 30 . These schooling levels

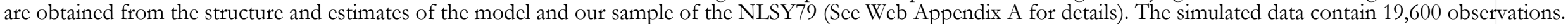


Figure 4A. Effect of schooling on ASVAB Components for person with average ability with $95 \%$ confidence bands--Males
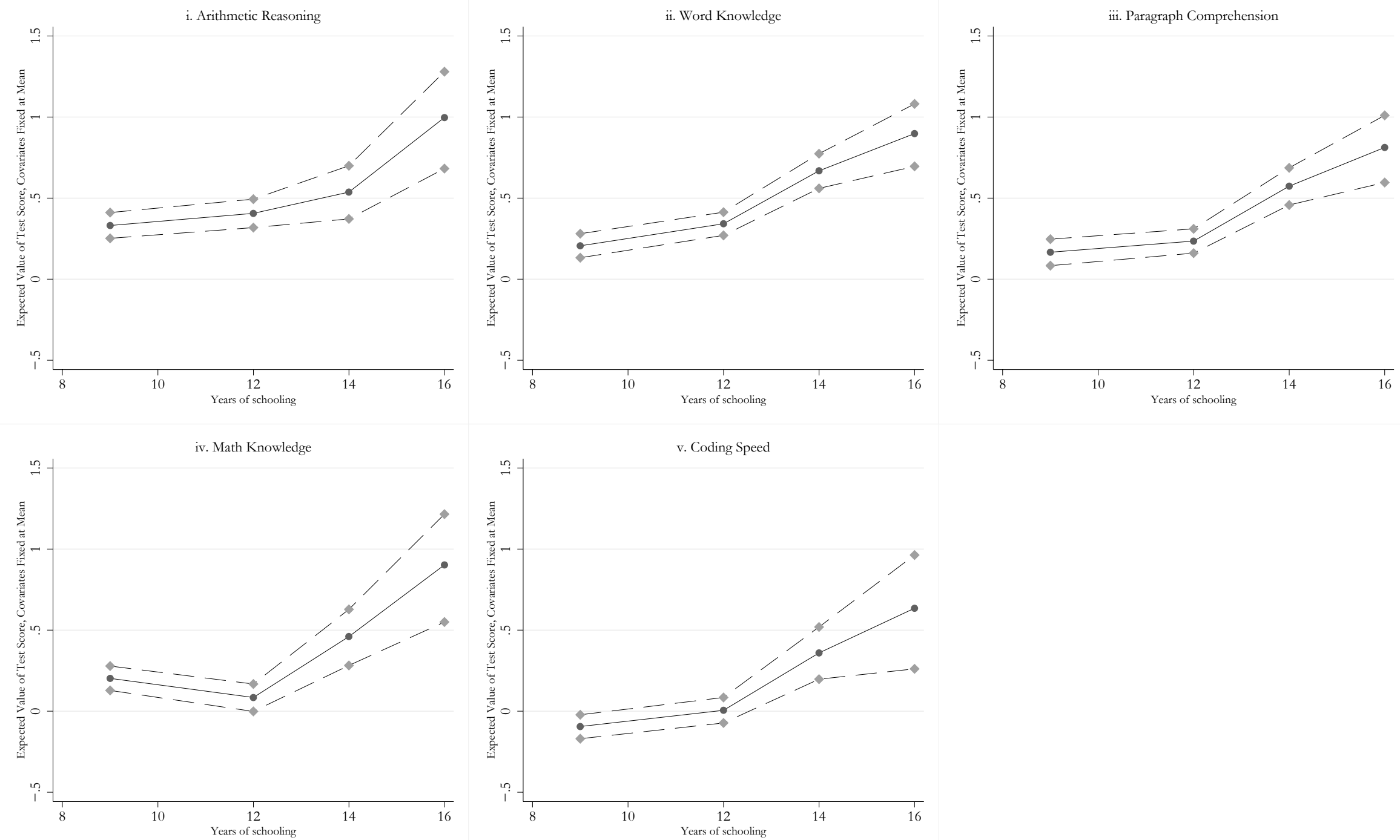

Notes: We standardize the test scores to have within-sample mean 0, variance 1. The model is estimated using the Age 30 NLSY79 Sample (See Web Appendix A for details). 


\section{Figure 4B. Effect of schooling on Noncognitive scales for person with average ability}

with $95 \%$ confidence bands -- Males
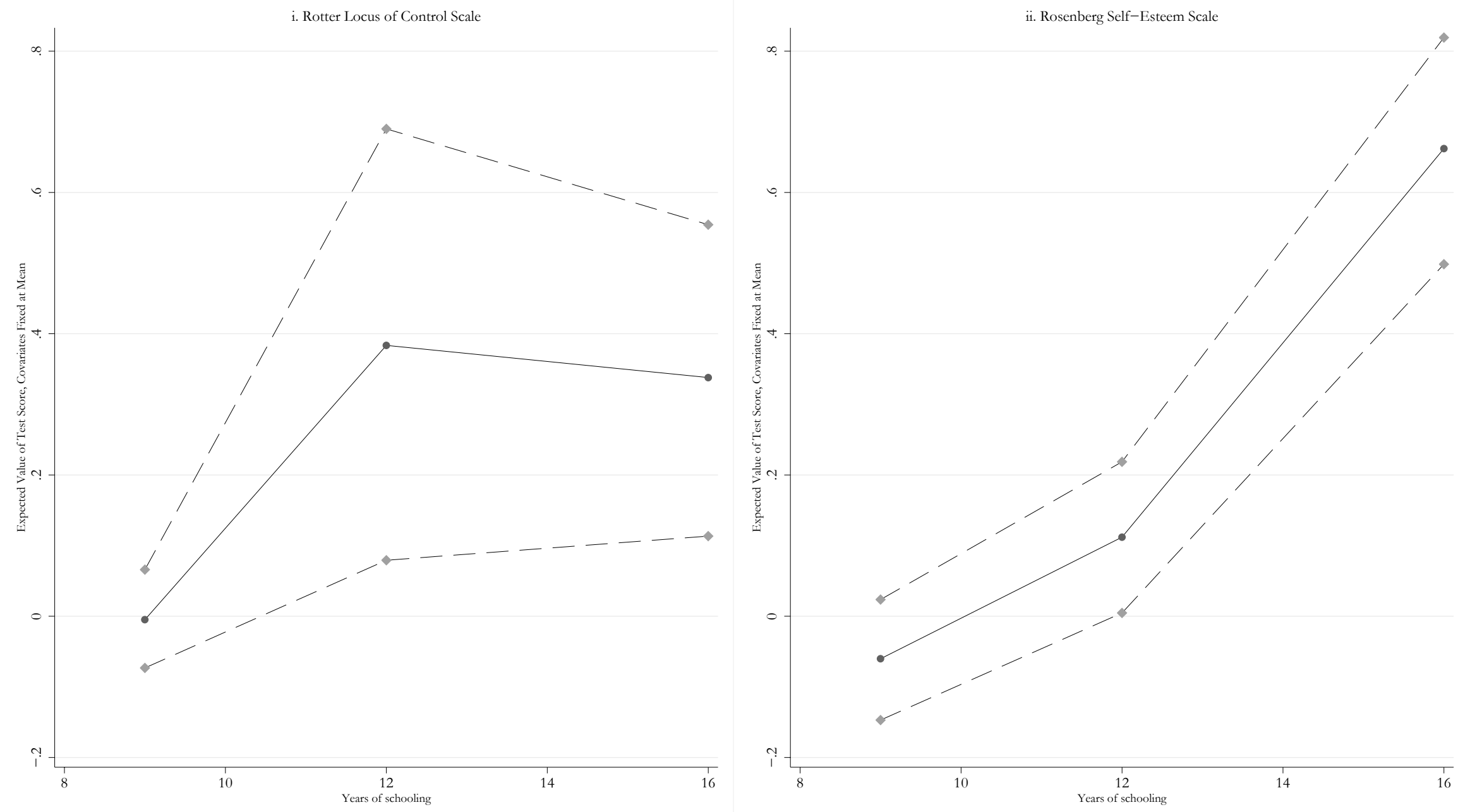

Notes: The locus of control scale is based on the four-item abbreviated version of the Rotter Internal-External Locus of Control Scale. This scale is designed to measure the extent to which individuals believe they have control over their lives through self-motivation or self-determination (internal control) as opposed to the extent that the enviroment controls their lives (external control). The self-esteem scale is based on the 10-item Rosenberg Self-Esteem Scale. This scale describes a degree of approval or disapproval toward oneself. In both cases, we standardize the test scores to have within-sample mean 0 and variance 1 , after taking averages over the respective sets of scales. The model is estimated using the Age 30 NLSY79 Sample (See Web Appendix A for details). 
Figure 5A. Mean Log Wages by Age 30 - Males

i. By Decile of Cognitive and Noncognitive Factors

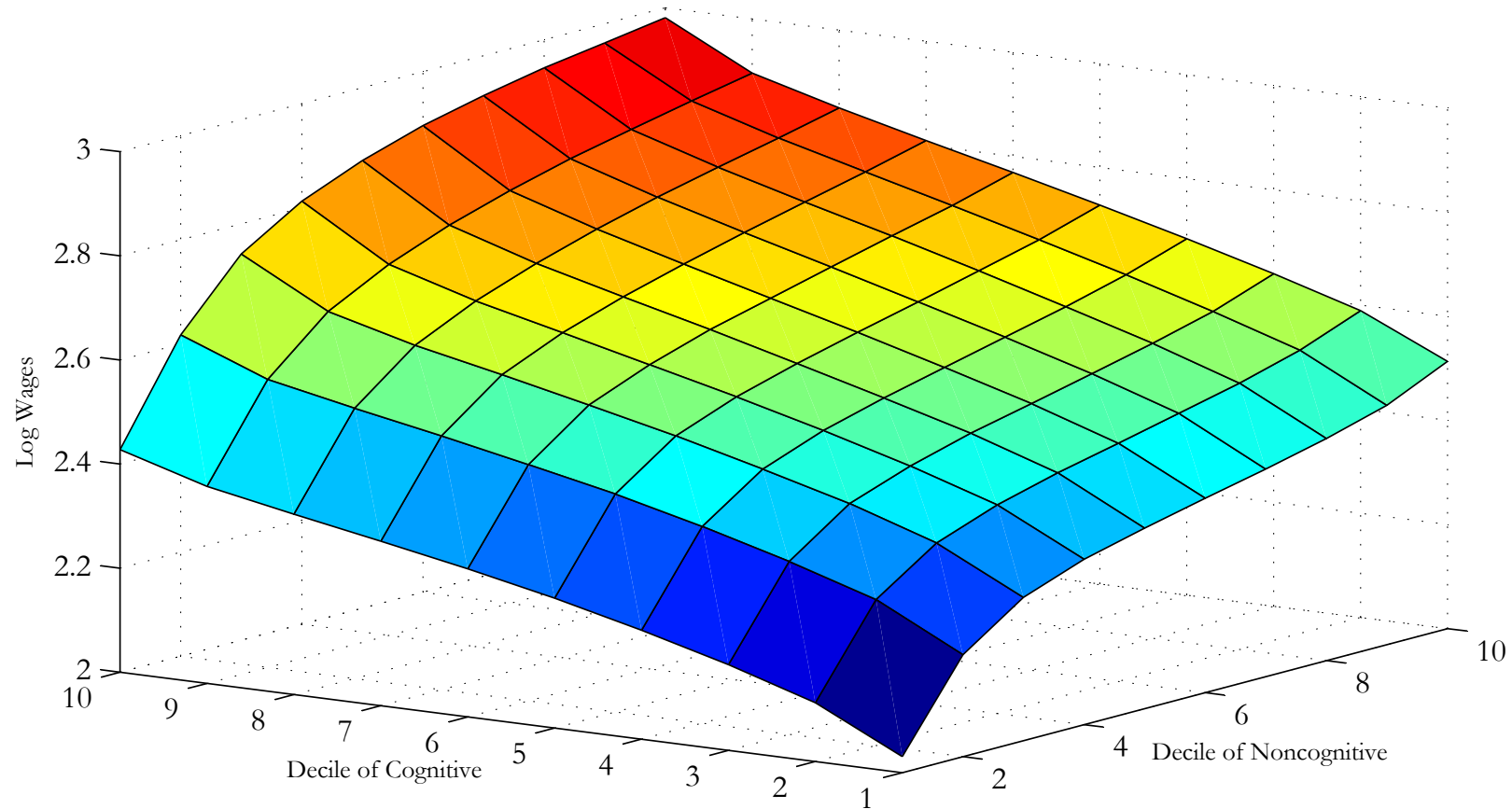

ii. By Decile of Cognitive Factor

iii. By Decile of Noncognitive Factor
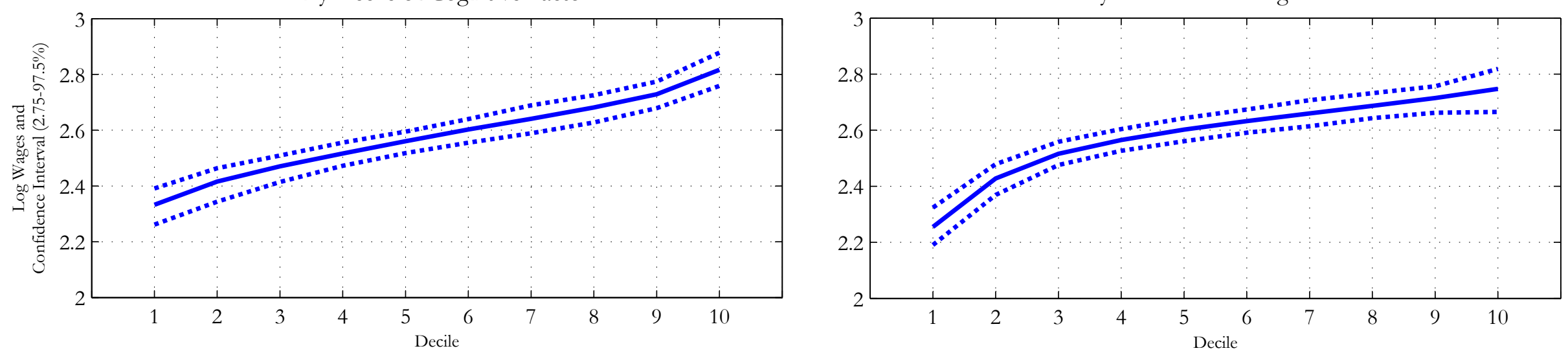

Notes: The data are simulated from the estimates of the model and our NLSY79 sample. We use the standard convention that higher deciles are associated with higher values of the variable. The confidence intervals are computed using bootstrapping (200 draws). 
Figure 5B. Mean Log Wages by Age 30 - Females

i. By Decile of Cognitive and Noncognitive Factors

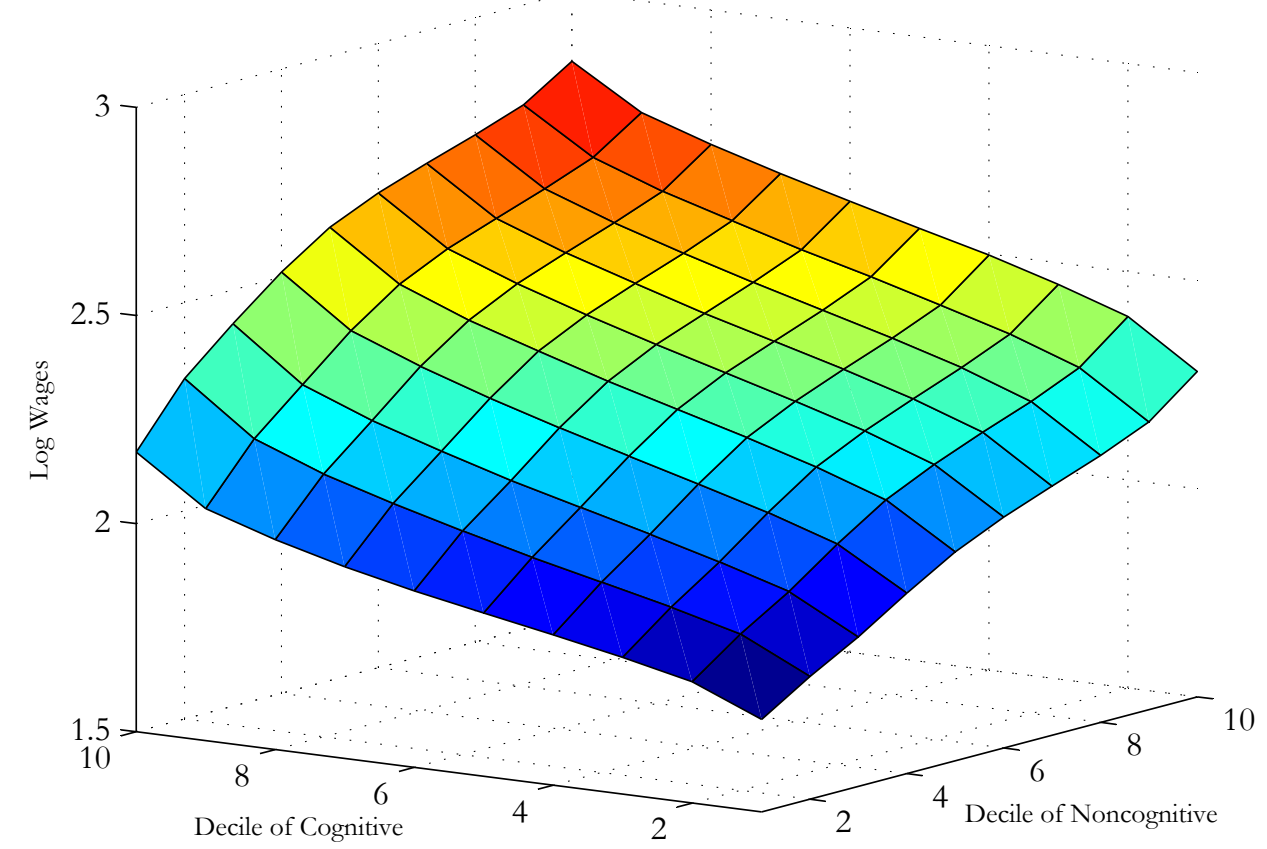

ii. By Decile of Cognitive Factor
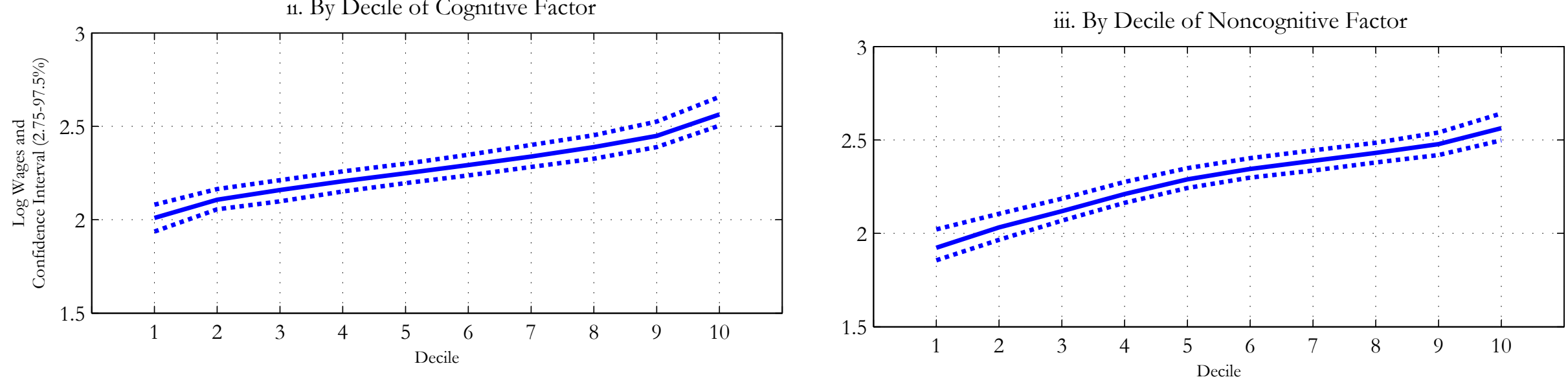

Notes: The data are simulated from the estimates of the model and our NLSY79 sample. We use the standard convention that higher deciles are associated with higher values of the variable. The confidence intervals are computed using bootstrapping (200 draws). 
Figure 6A. Mean Log Wages of High School Dropouts by Age 30 - Males i. By Decile of Cognitive and Noncognitive Factors

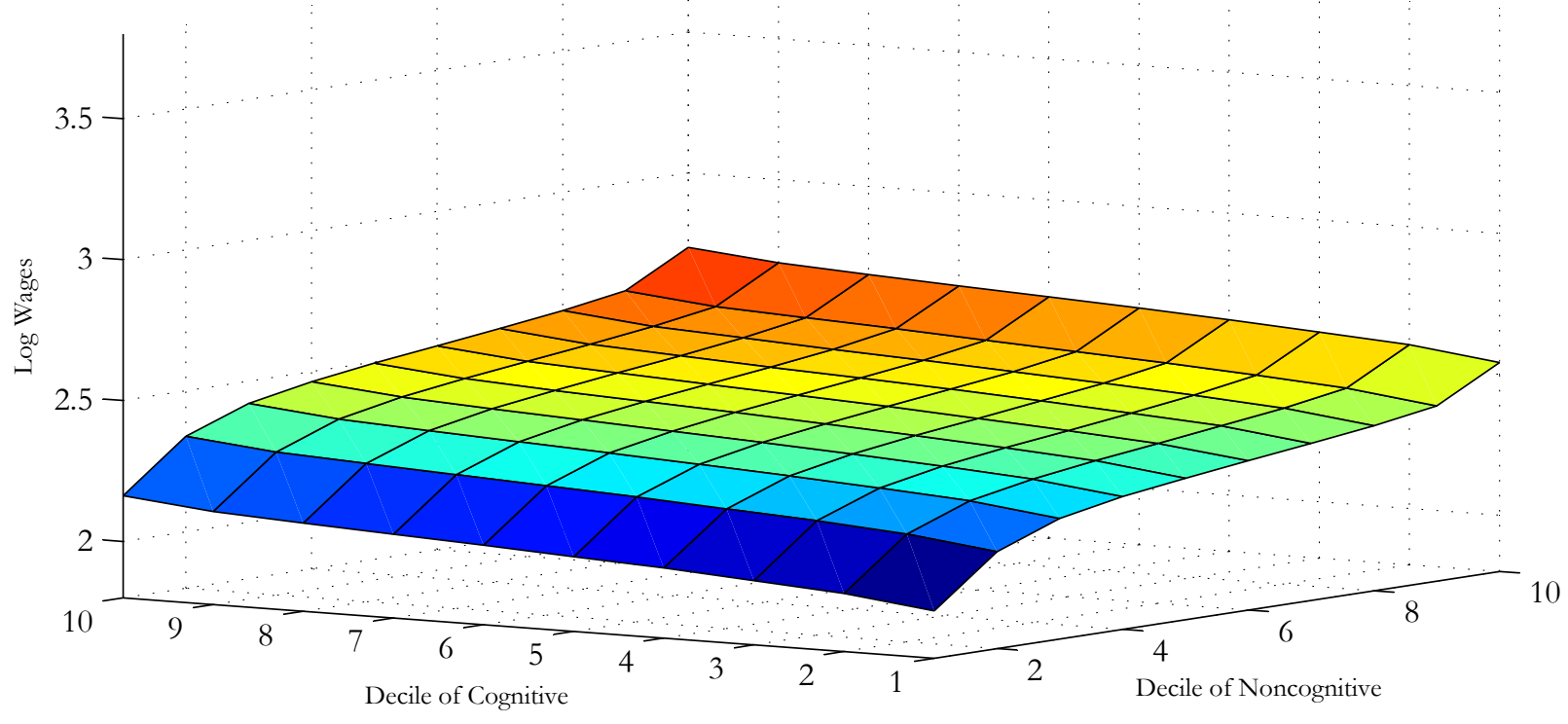

ii. By Decile of Cognitive Factor

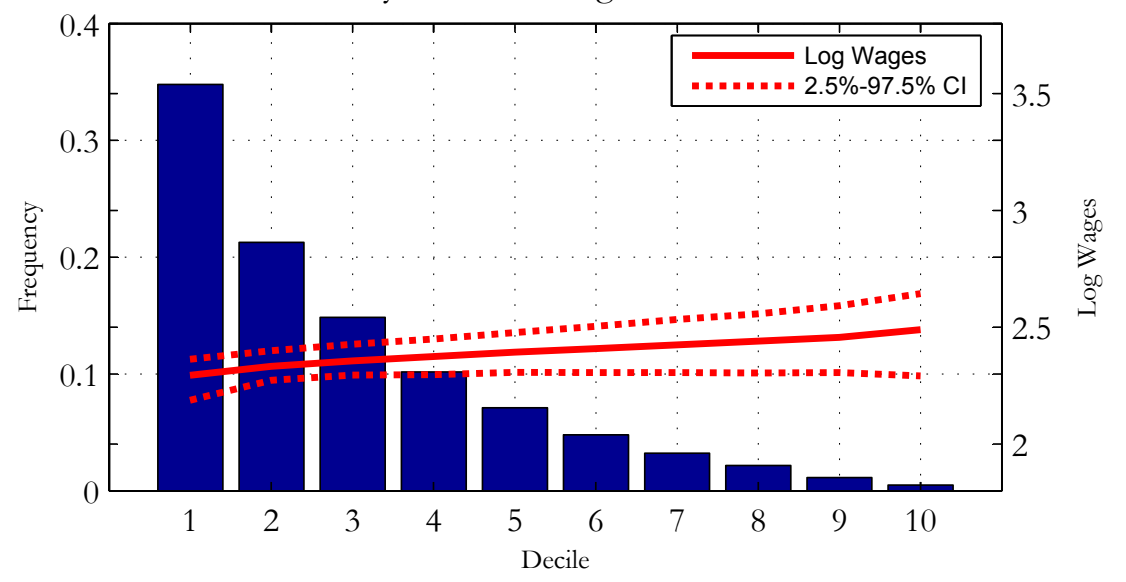

iii. By Decile of Noncognitive Factor

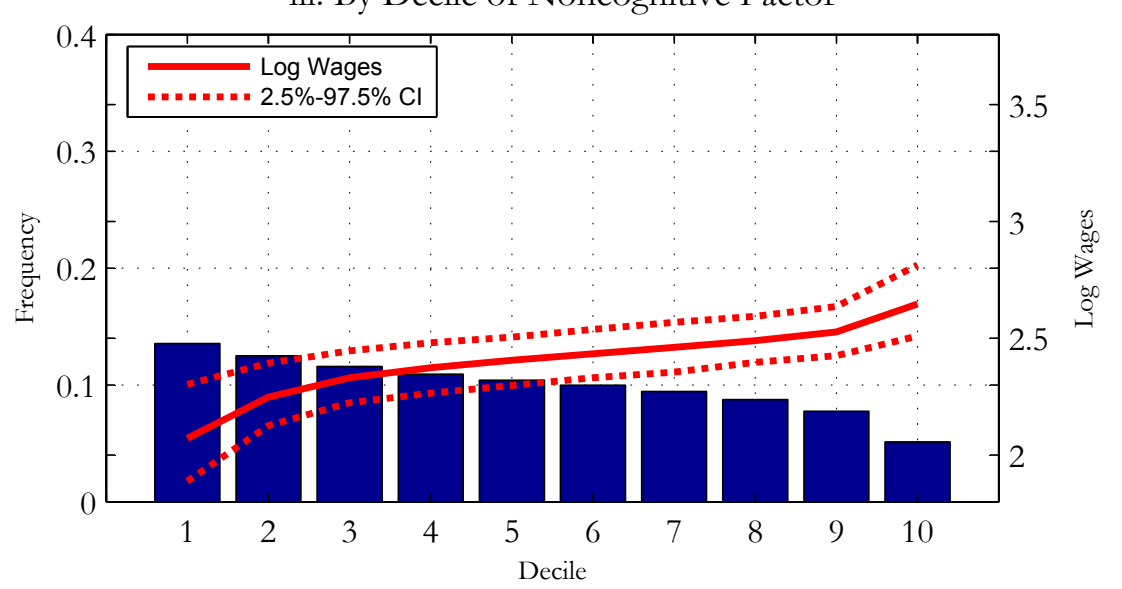

Notes: The data are simulated from the estimates of the model and our NLSY79 sample. We use the standard convention that higher deciles are associated with higher values of the variable. The confidence intervals are computed using bootstrapping (200 draws). Frequency indicates proportion of individuals with the indicated level of education whose abilities lie in the indicated decile of the distribution. 
Figure 6B. Mean Log Wages of High School Dropouts by Age 30 - Females

i. By Decile of Cognitive and Noncognitive Factors

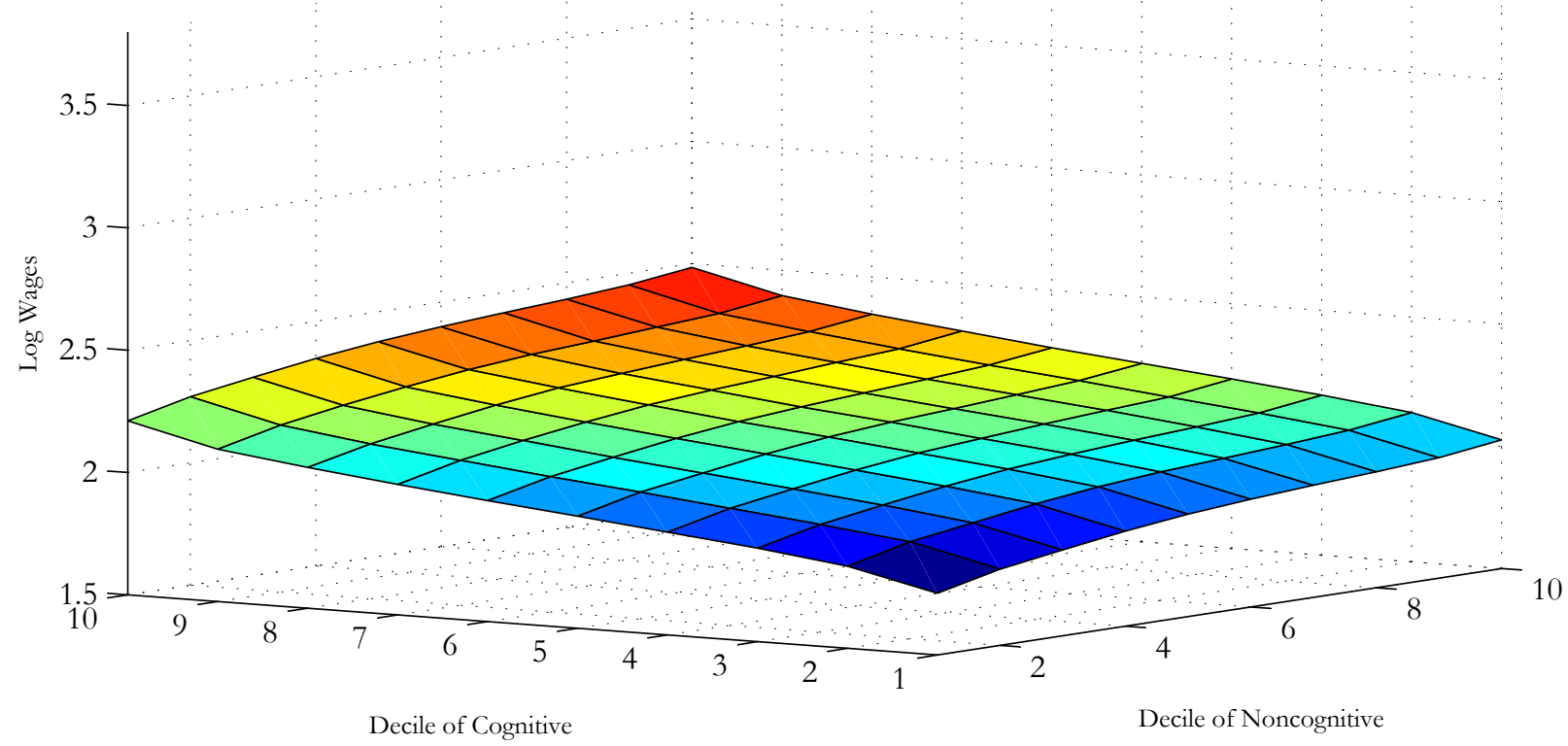

ii. By Decile of Cognitive Factor
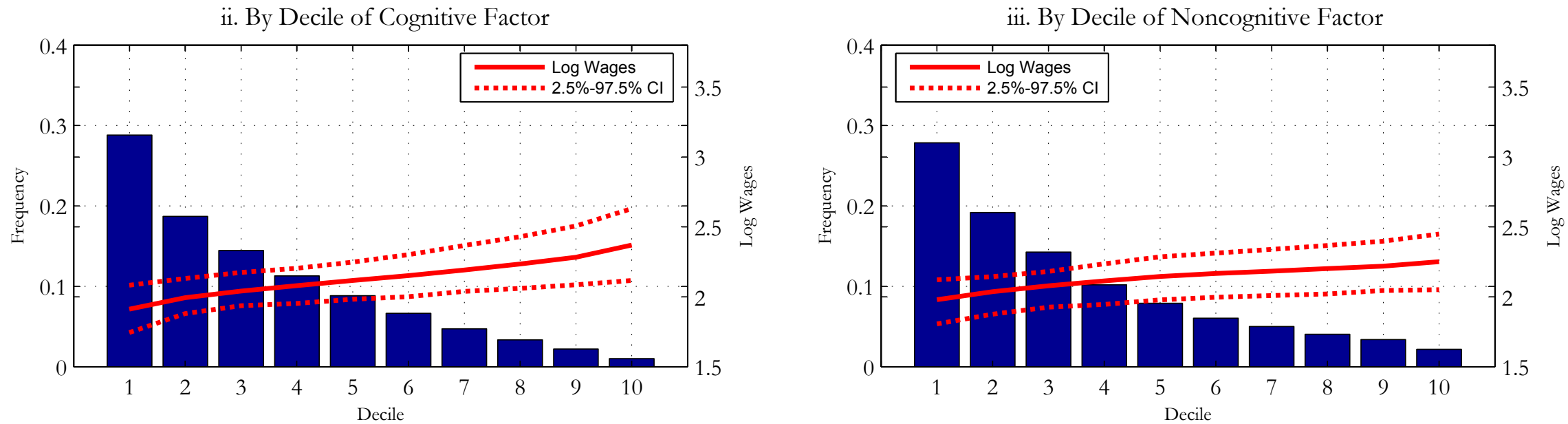

Notes: The data are simulated from the estimates of the model and our NLSY79 sample. We use the standard convention that higher deciles are associated with higher values of the variable. The confidence intervals are computed using bootstrapping ( 200 draws). Frequency indicates proportion of individuals with the indicated level of education whose abilities lie in the indicated decile of the distribution. 
Figure 7A. Mean Log Wages of GEDs by Age 30 - Males

i. By Decile of Cognitive and Noncognitive Factors

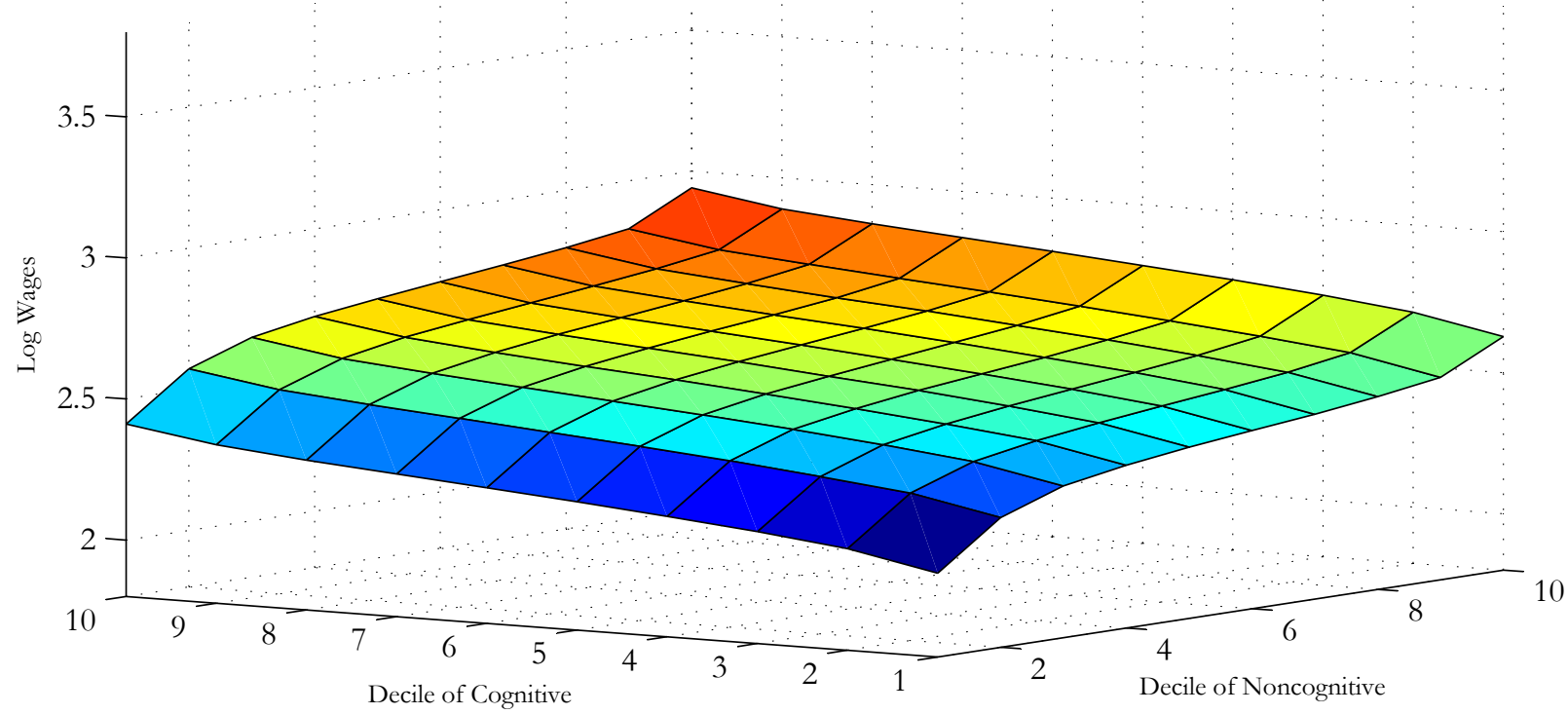

ii. By Decile of Cognitive Factor
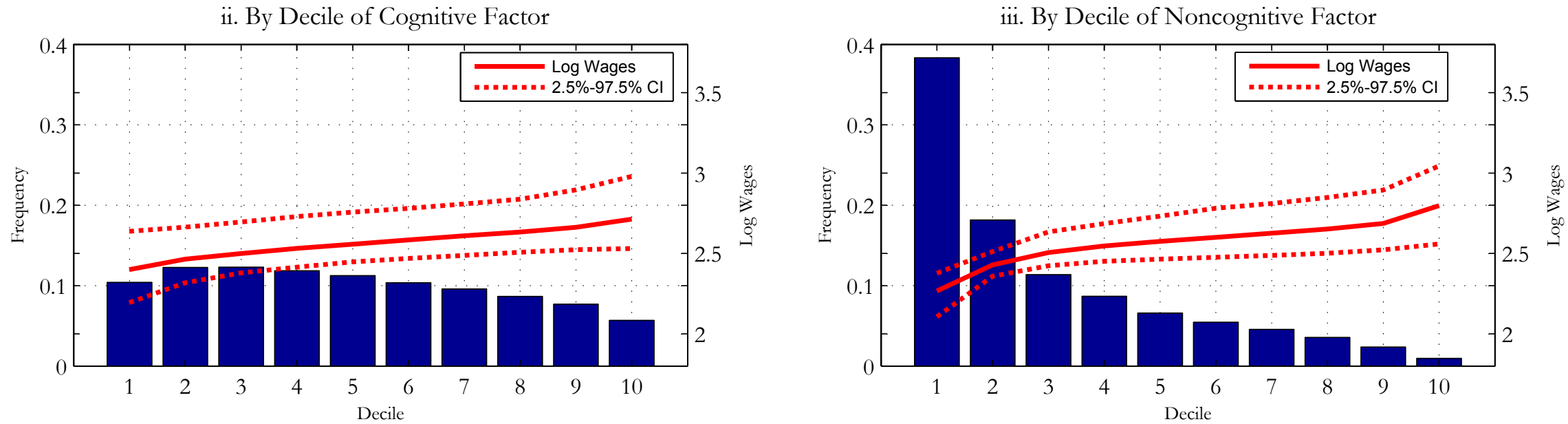

Notes: The data are simulated from the estimates of the model and our NLSY79 sample. We use the standard convention that higher deciles are associated with higher values of the variable. The confidence intervals are computed using bootstrapping ( $200 \mathrm{draws})$. Frequency indicates proportion of individuals with the indicated level of education whose abilities lie in the indicated decile of the distribution. 
Figure 7B. Mean Log Wages of GEDs by Age 30 - Females

i. By Decile of Cognitive and Noncognitive Factors

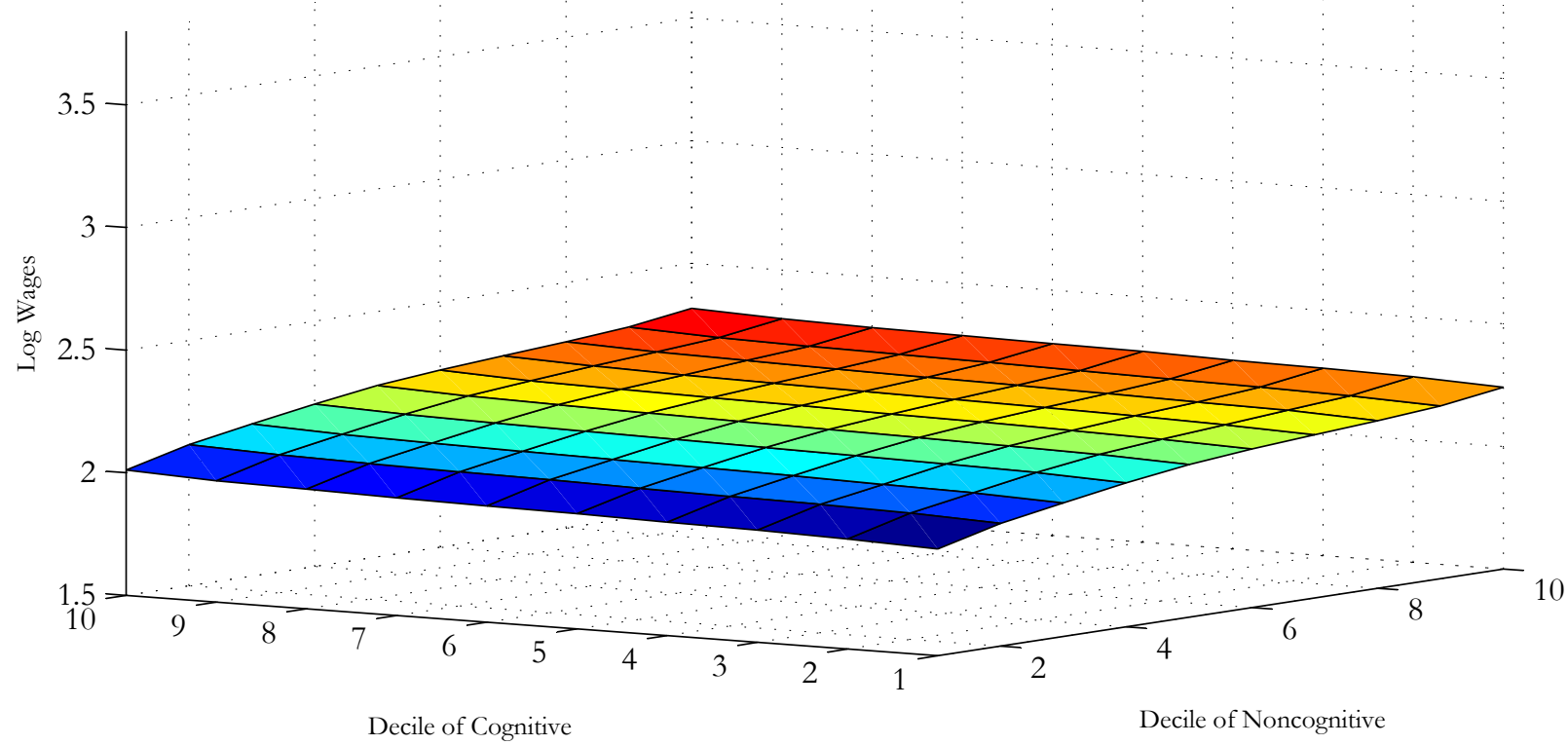

ii. By Decile of Cognitive Factor
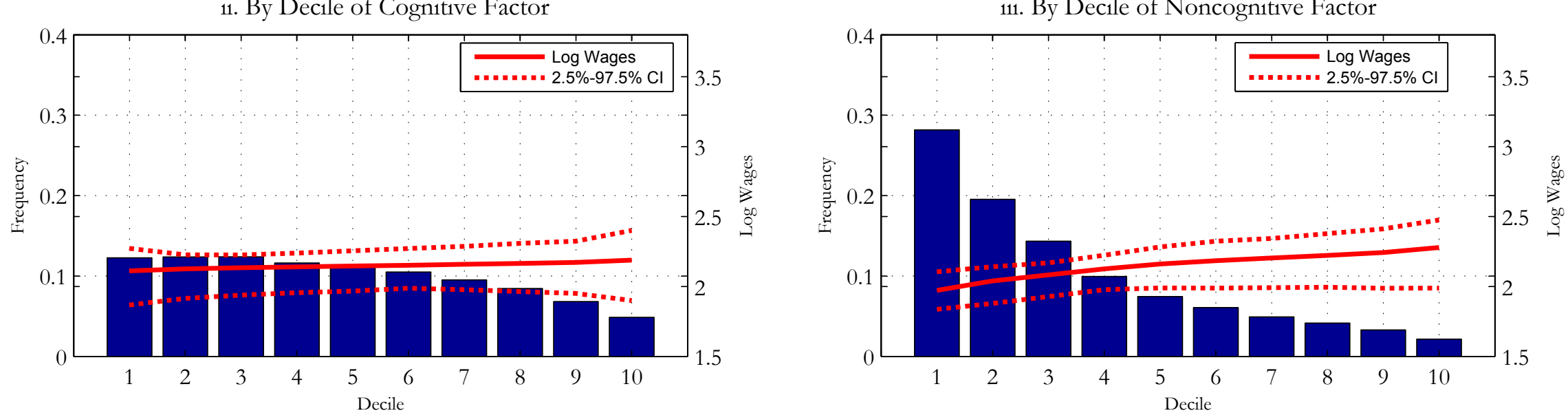

Notes: The data are simulated from the estimates of the model and our NLSY79 sample. We use the standard convention that higher deciles are associated with higher values of the variable. The confidence intervals are computed using bootstrapping ( 200 draws). Frequency indicates proportion of individuals with the indicated level of education whose abilities lie in the indicated decile of the distribution. 
Figure 8A. Mean Log Wages of High School Graduates by Age 30 - Males i. By Decile of Cognitive and Noncognitive Factors

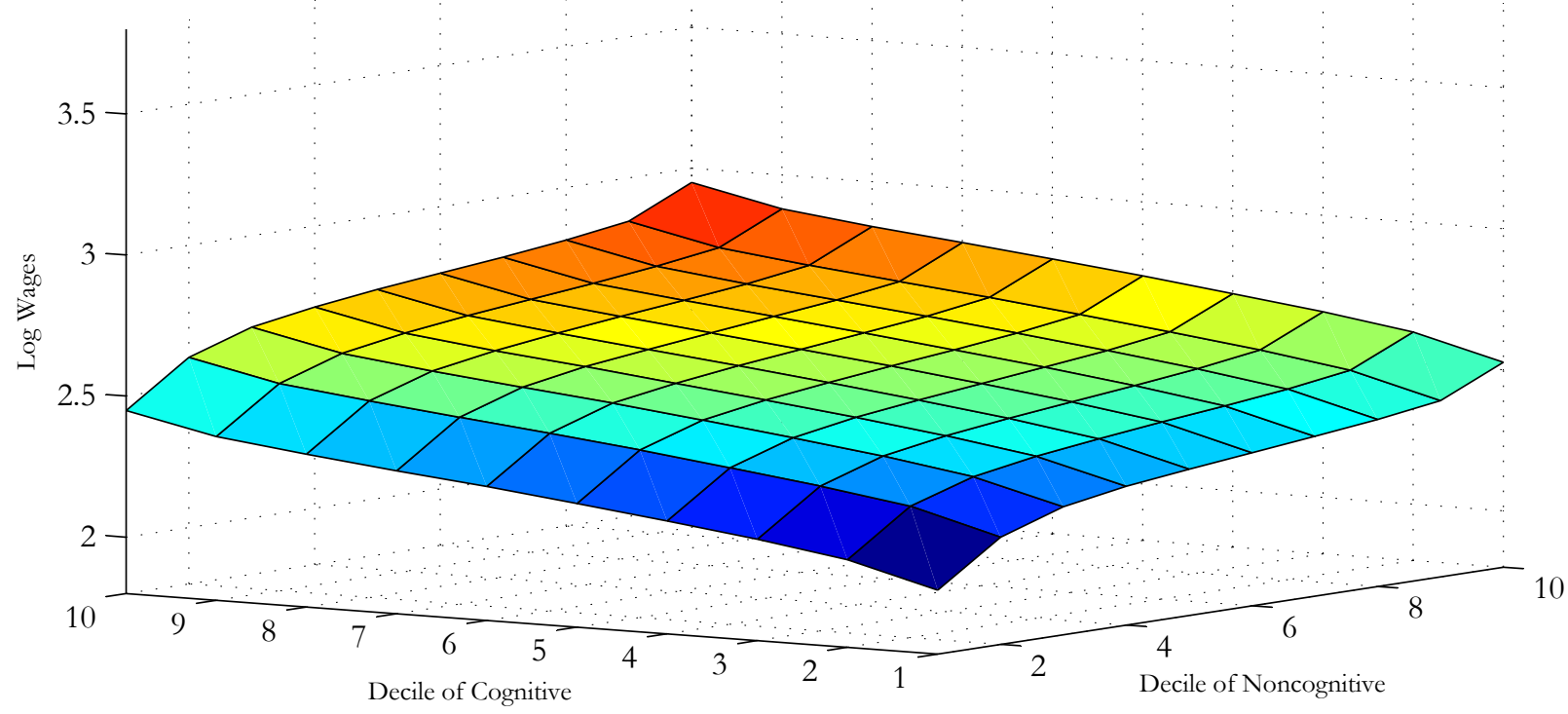

ii. By Decile of Cognitive Factor

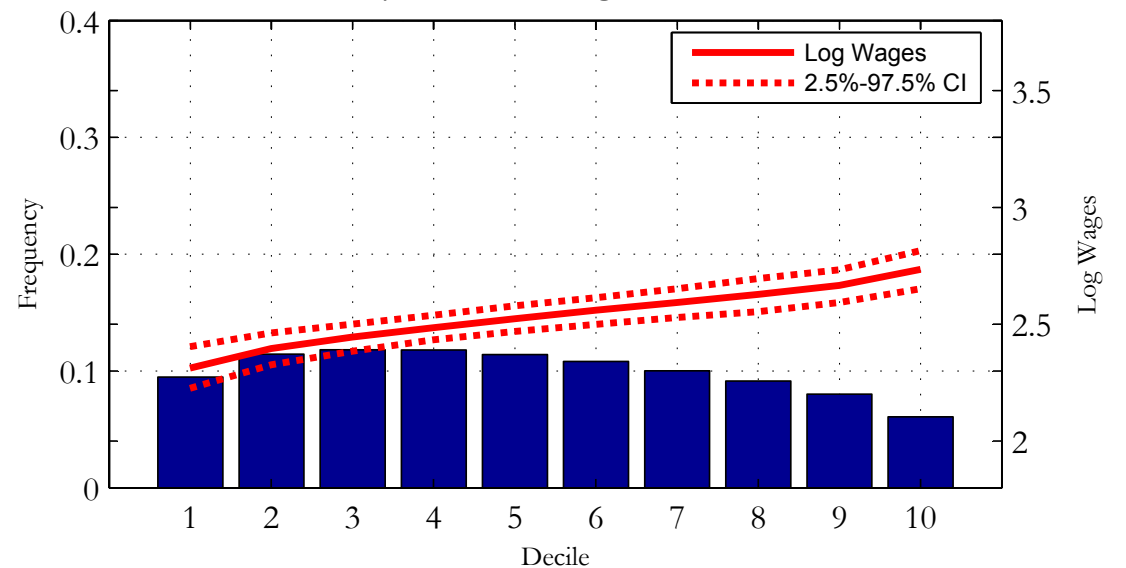

iii. By Decile of Noncognitive Factor

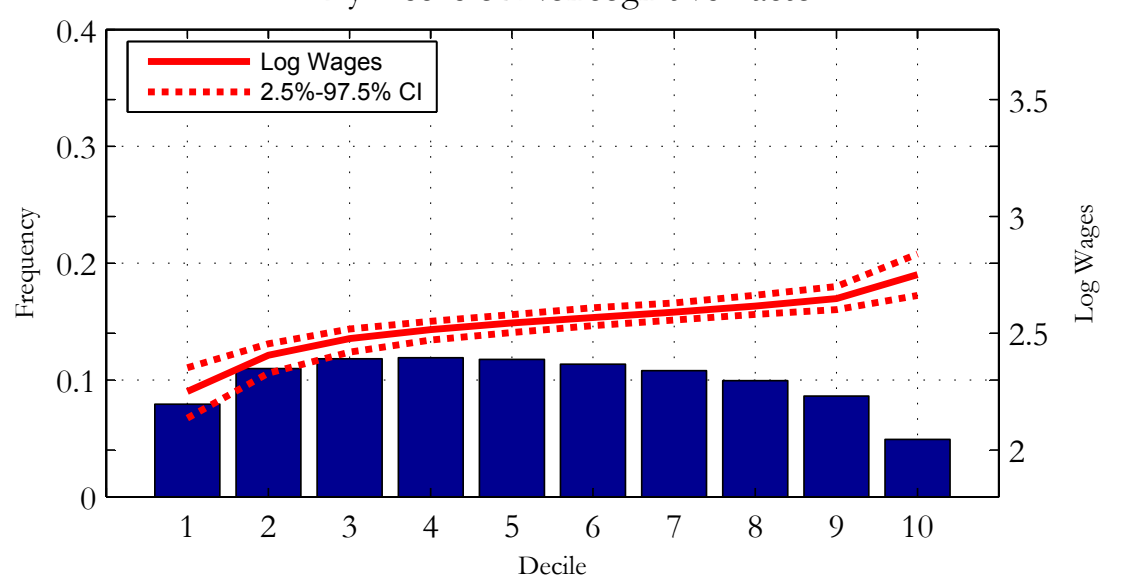

Notes: The data are simulated from the estimates of the model and our NLSY79 sample. We use the standard convention that higher deciles are associated with higher values of the variable. The confidence intervals are computed using bootstrapping (200 draws). Frequency indicates proportion of individuals with the indicated level of education whose abilities lie in the indicated decile of the distribution. 
Figure 8B. Mean Log Wages of High School Graduates by Age 30 - Females i. By Decile of Cognitive and Noncognitive Factors

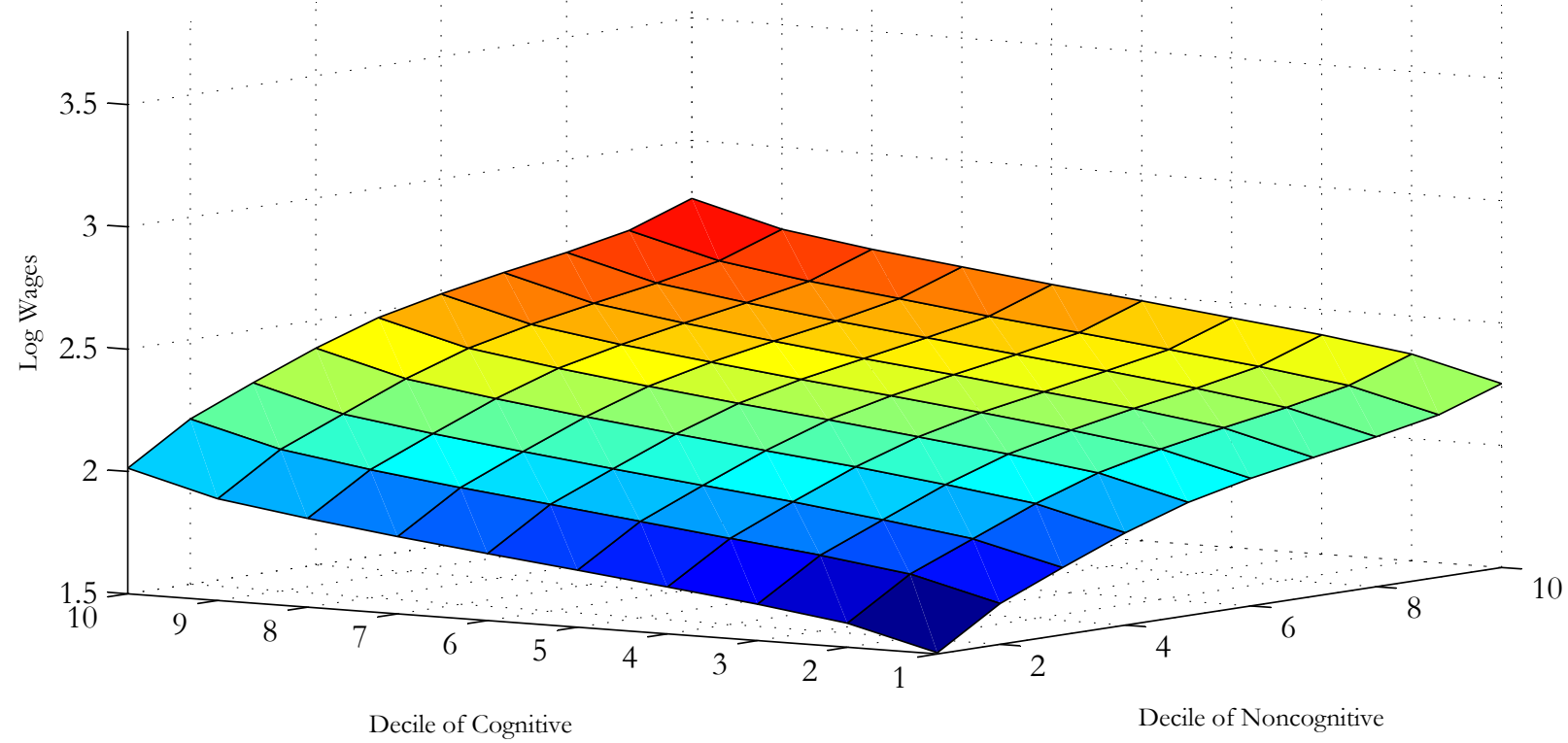

ii. By Decile of Cognitive Factor

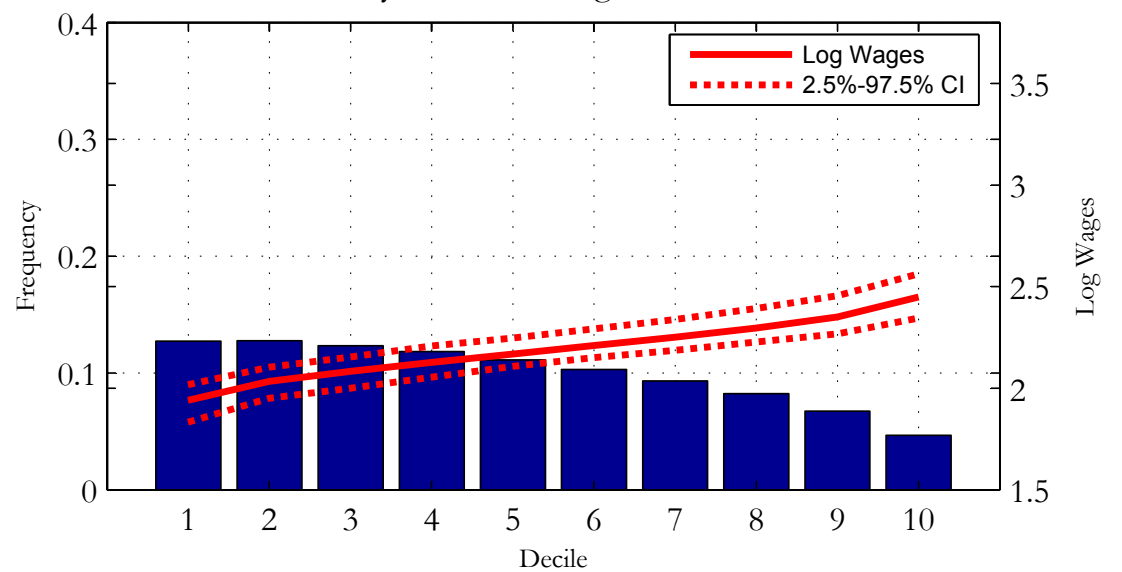

iii. By Decile of Noncognitive Factor

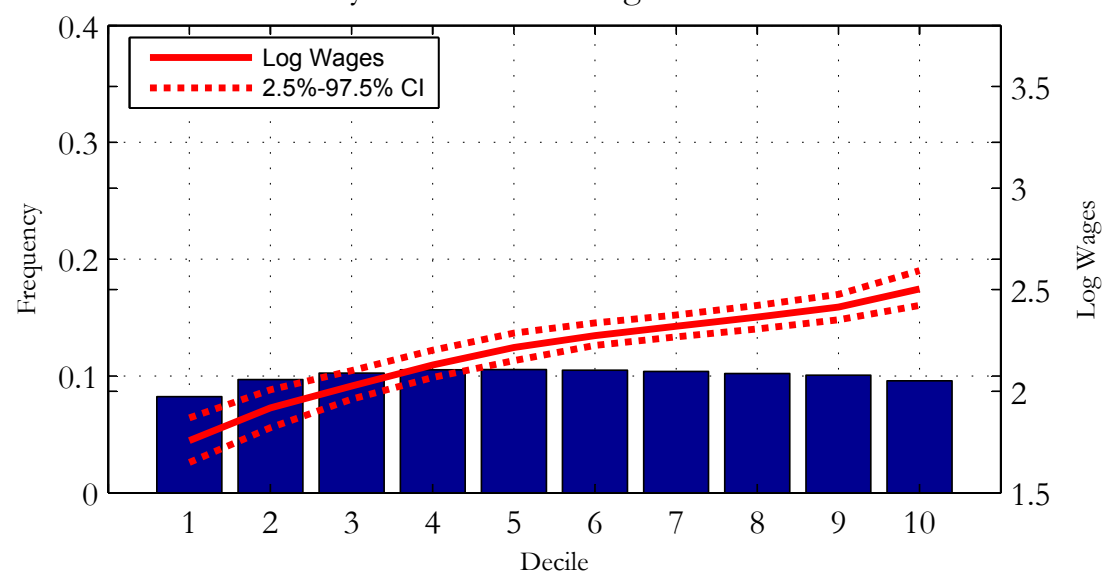

Notes: The data are simulated from the estimates of the model and our NLSY79 sample. We use the standard convention that higher deciles are associated with higher values of the variable. The confidence intervals are computed using bootstrapping ( $200 \mathrm{draws})$. Frequency indicates proportion of individuals with the indicated level of education whose abilities lie in the indicated decile of the distribution. 
Figure 9A. Mean Log Wages of Some College Attenders by Age 30 - Males i. By Decile of Cognitive and Noncognitive Factors

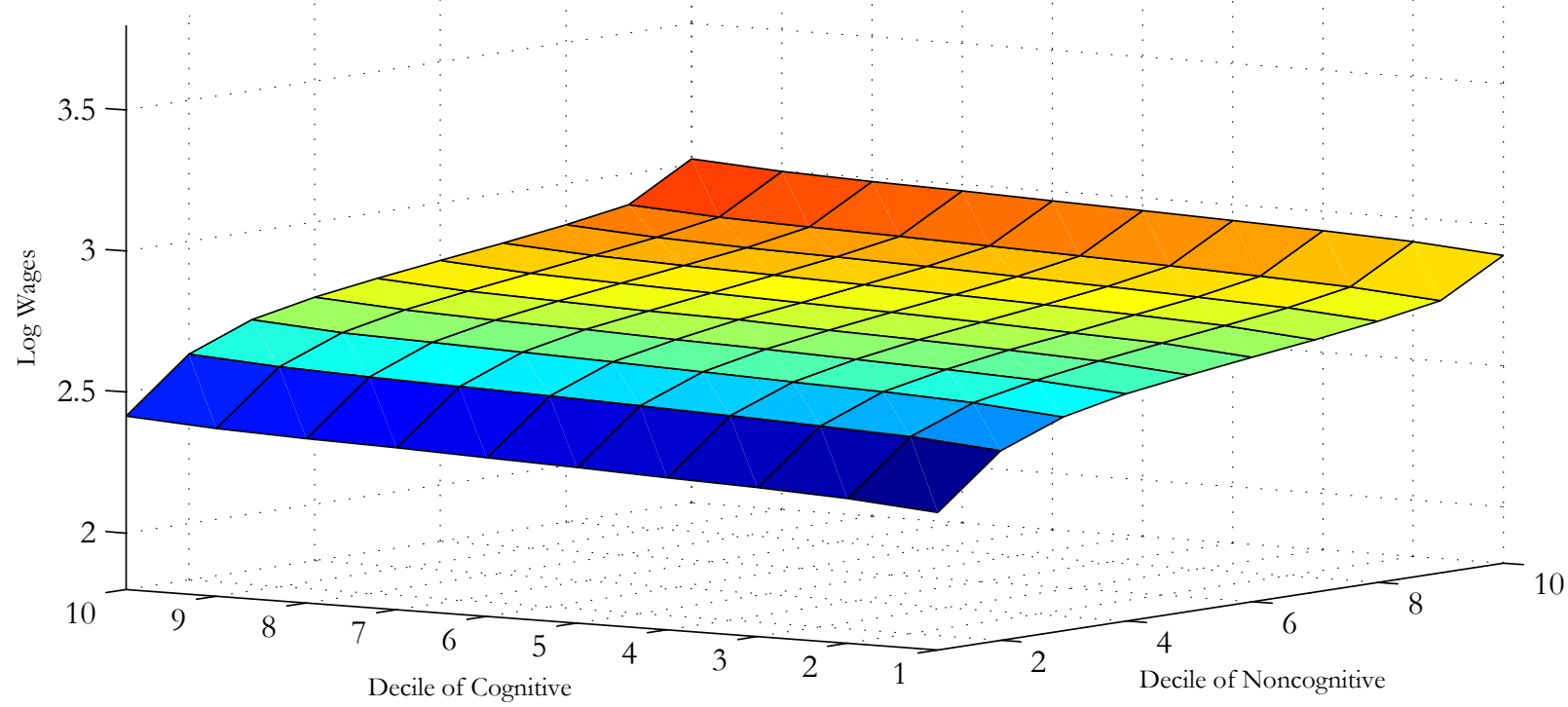

ii. By Decile of Cognitive Factor
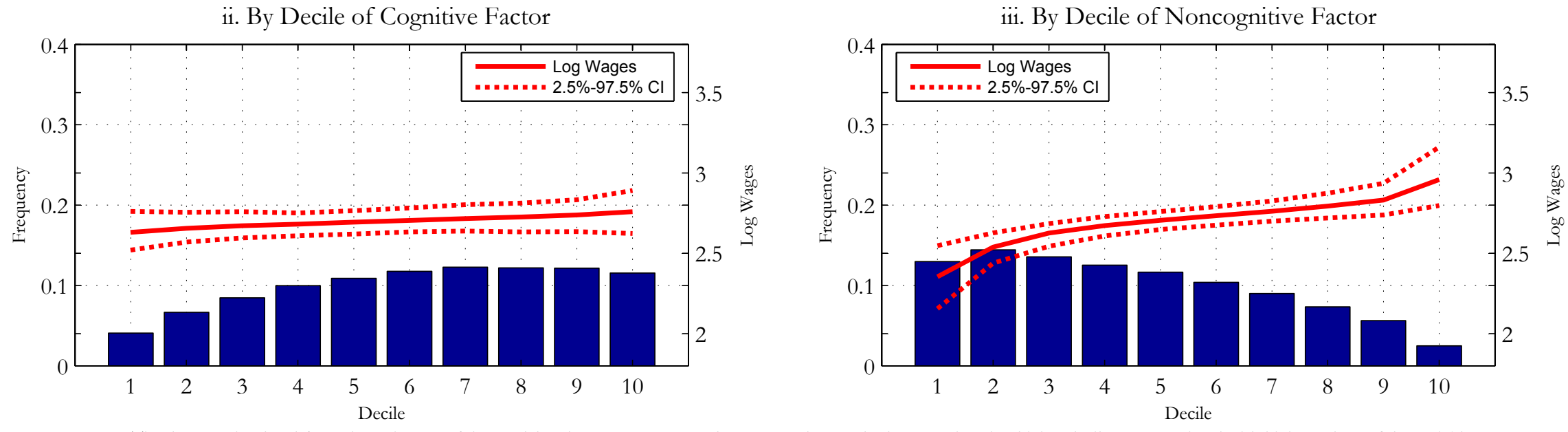

Notes: The data are simulated from the estimates of the model and our NI SY79 sample. We use the standard convention that higher deciles are associated with higher values of the variable. The confidence intervals are computed using bootstrapping ( $200 \mathrm{draws})$. Frequency indicates proportion of individuals with the indicated level of education whose abilities lie in the indicated decile of the distribution. 
Figure 9B. Mean Log Wages of Some College Attenders by Age 30 - Females i. By Decile of Cognitive and Noncognitive Factors

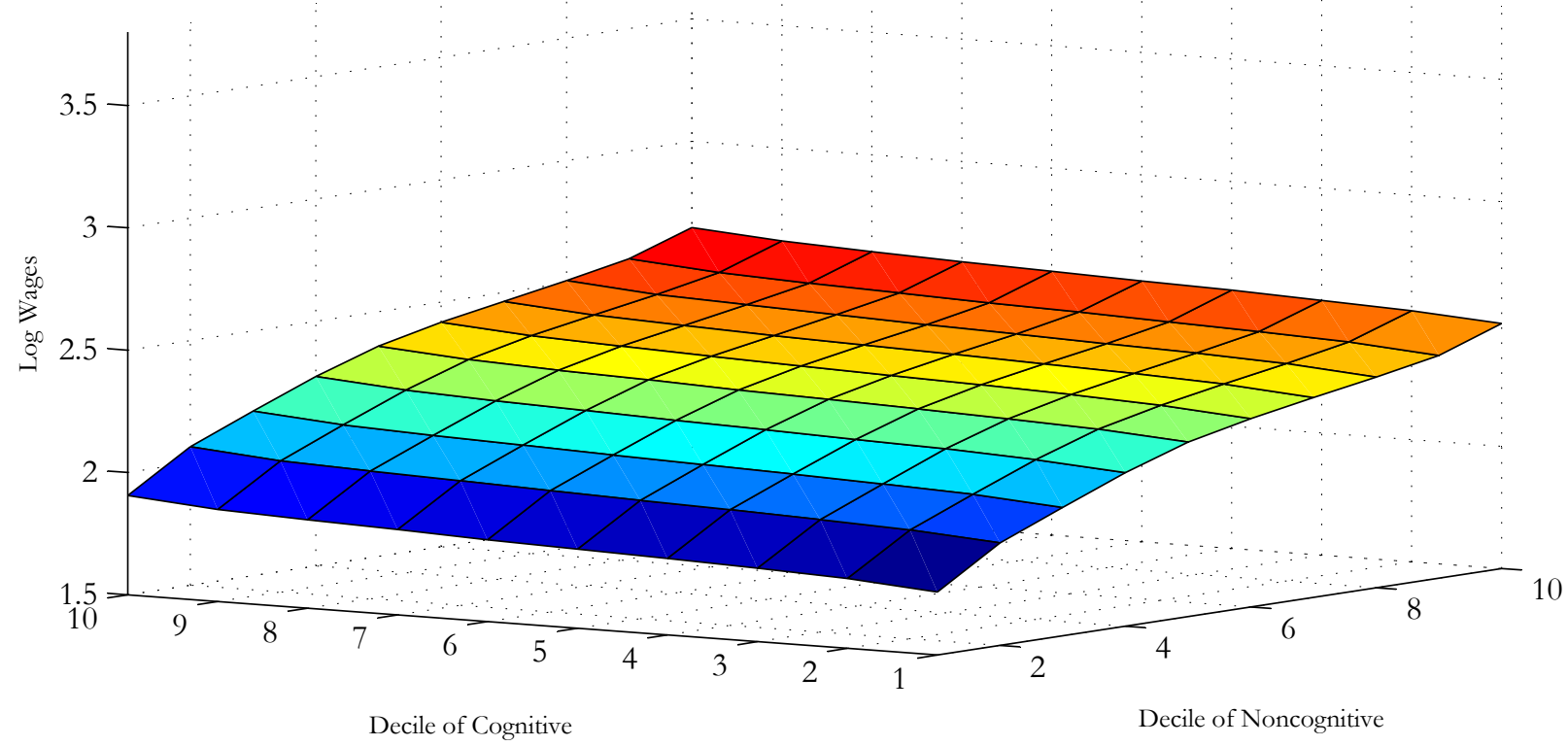

ii. By Decile of Cognitive Factor
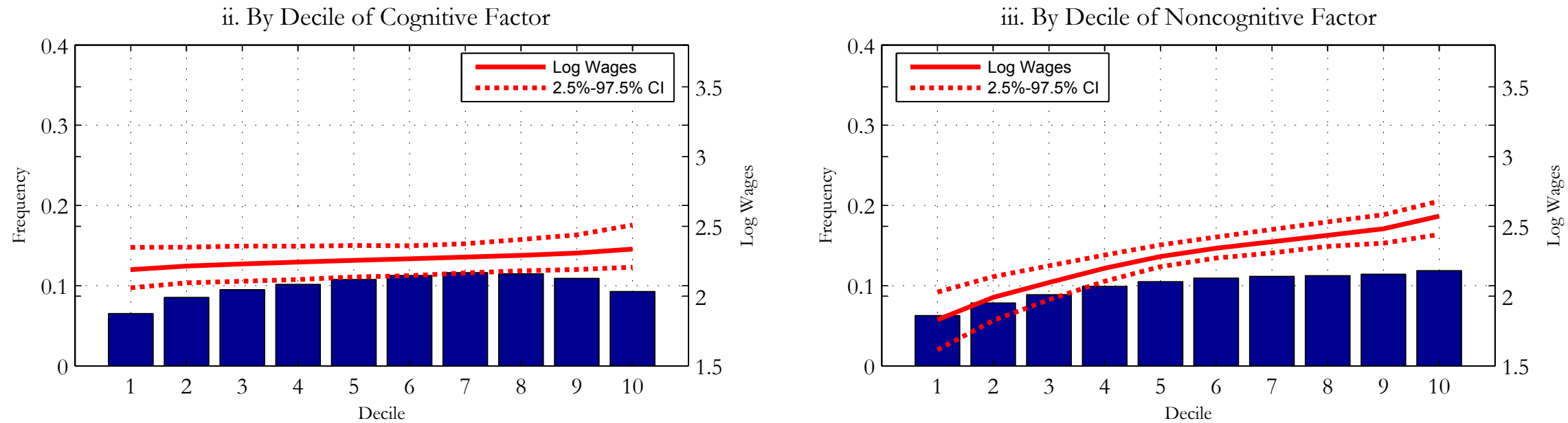

Notes: The data are simulated from the estimates of the model and our NLSY79 sample. We use the standard convention that higher deciles are associated with higher values of the variable. The confidence intervals are computed using bootstrapping (200 draws). Frequency indicates proportion of individuals with the indicated level of education whose abilities lie in the indicated decile of the distribution. 
Figure 10A. Mean Log Wages of 2-yr College Graduates by Age 30 - Males i. By Decile of Cognitive and Noncognitive Factors

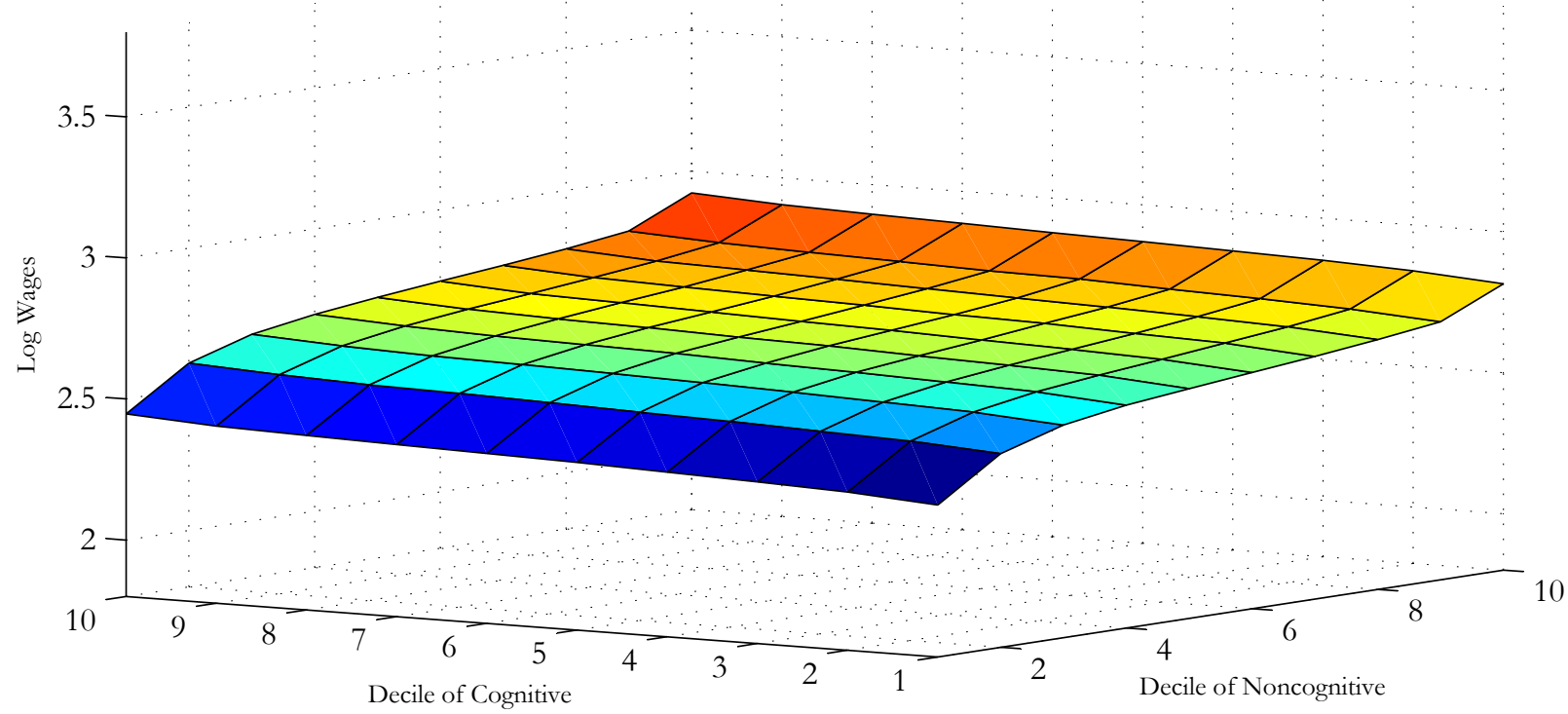

ii. By Decile of Cognitive Factor

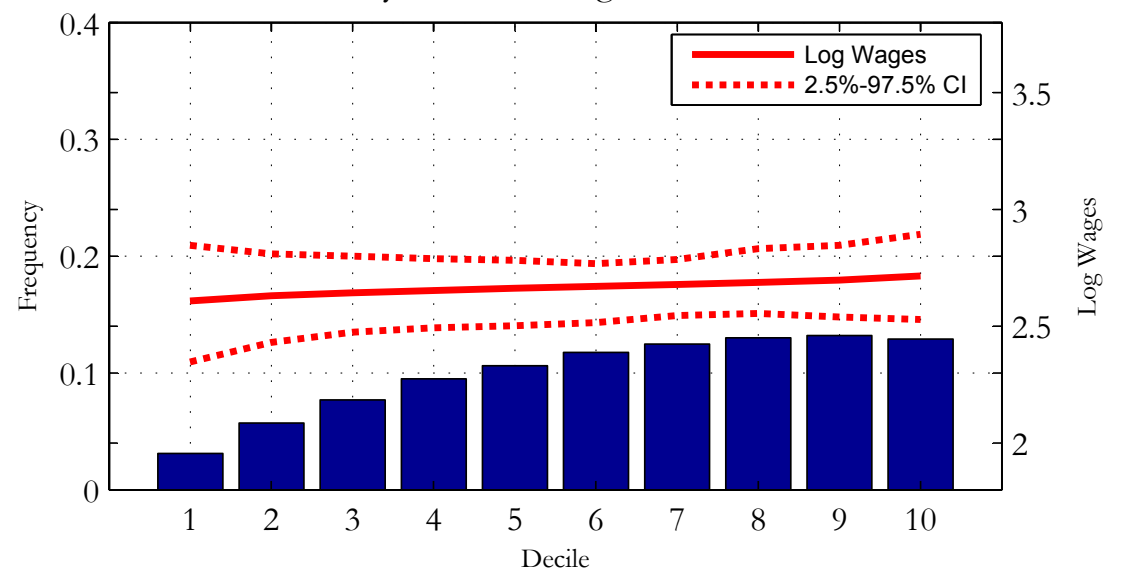

iii. By Decile of Noncognitive Factor

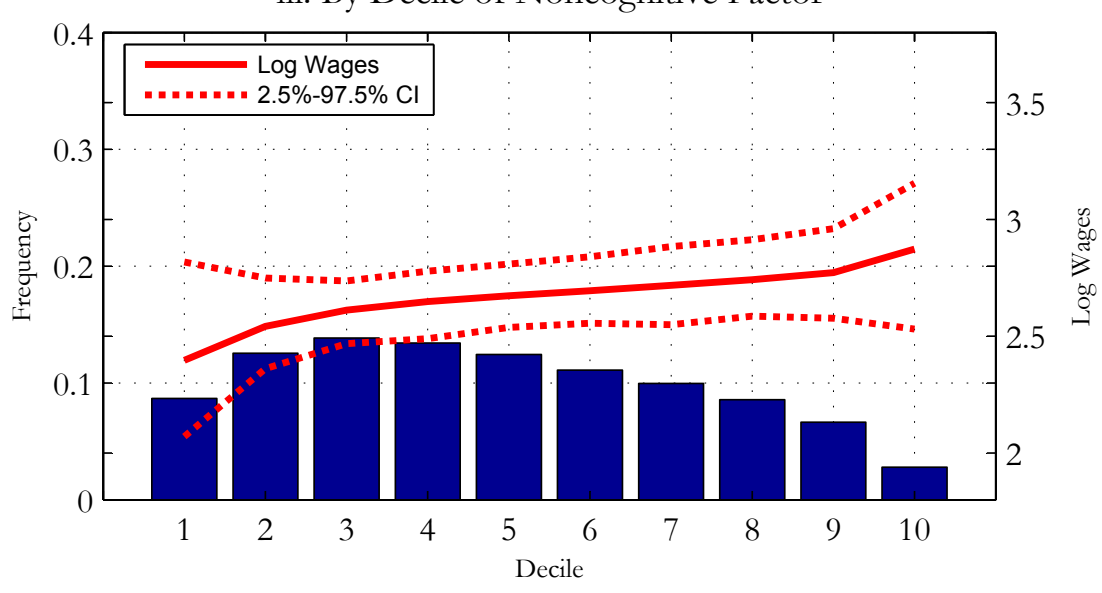

Notes: The data are simulated from the estimates of the model and our NLSY79 sample. We use the standard convention that higher deciles are associated with higher values of the variable. The confidence intervals are computed using bootstrapping (200 draws). Frequency indicates proportion of individuals with the indicated level of education whose abilities lie in the indicated decile of the distribution. 
Figure 10B. Mean Log Wages of 2-yr College Graduates by Age 30 - Females i. By Decile of Cognitive and Noncognitive Factors

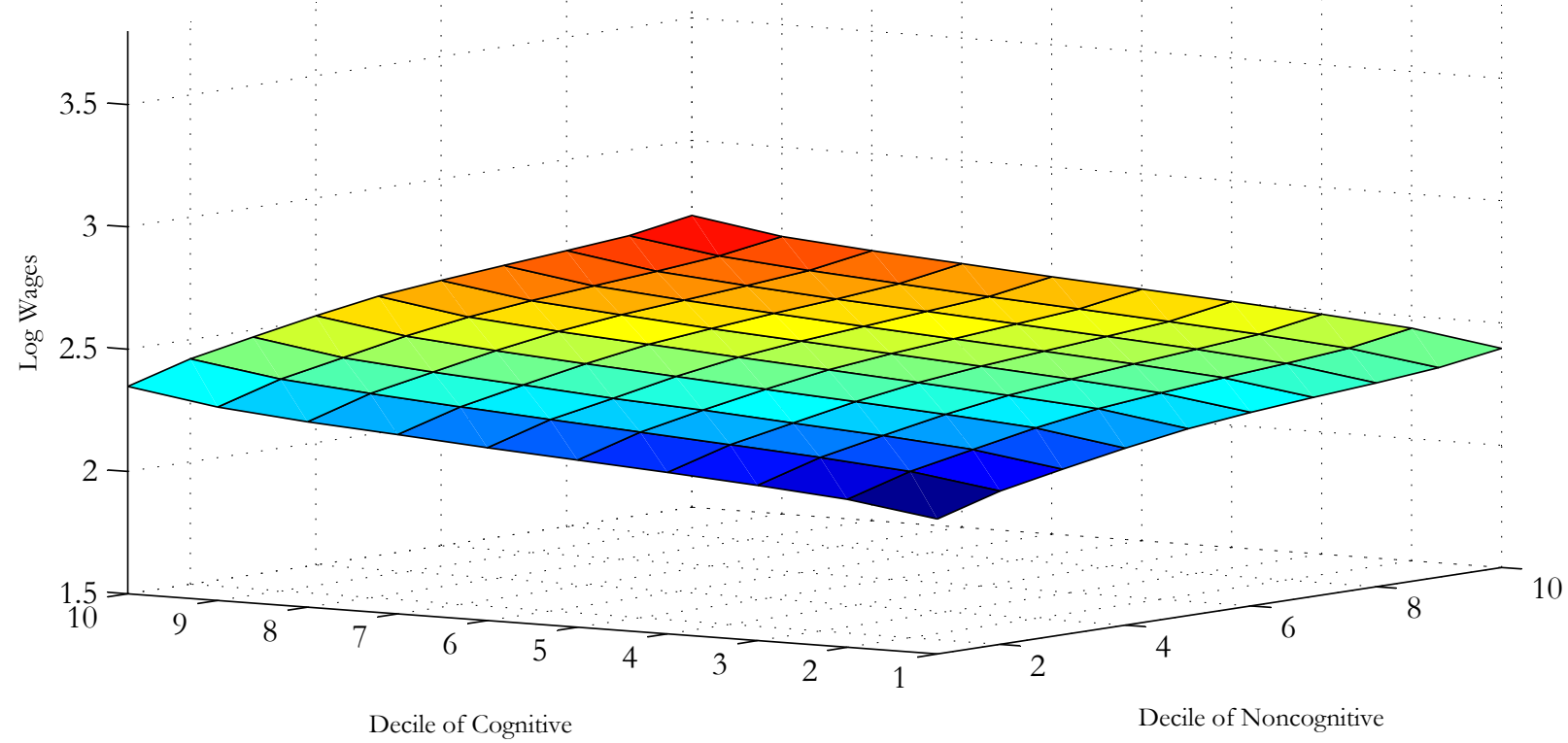

ii. By Decile of Cognitive Factor
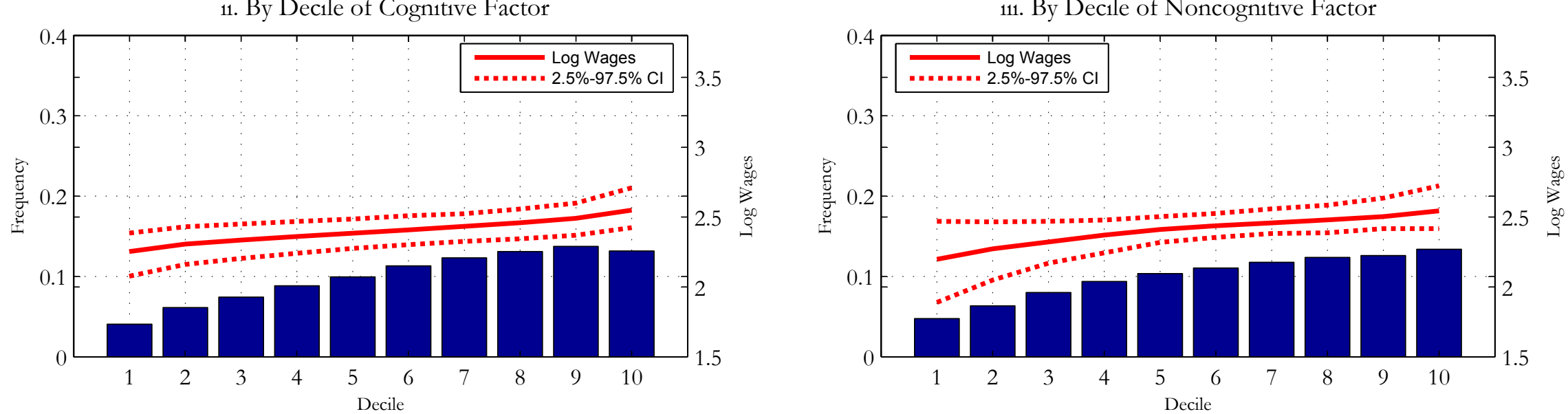

Notes: The data are simulated from the estimates of the model and our NLSY79 sample. We use the standard convention that higher deciles are associated with higher values of the variable. The confidence intervals are computed using bootstrapping (200 draws). Frequency indicates proportion of individuals with the indicated level of education whose abilities lie in the indicated decile of the distribution. 
Figure 11A. Mean Log Wages of 4-yr College Graduates by Age 30 - Males

i. By Decile of Cognitive and Noncognitive Factors

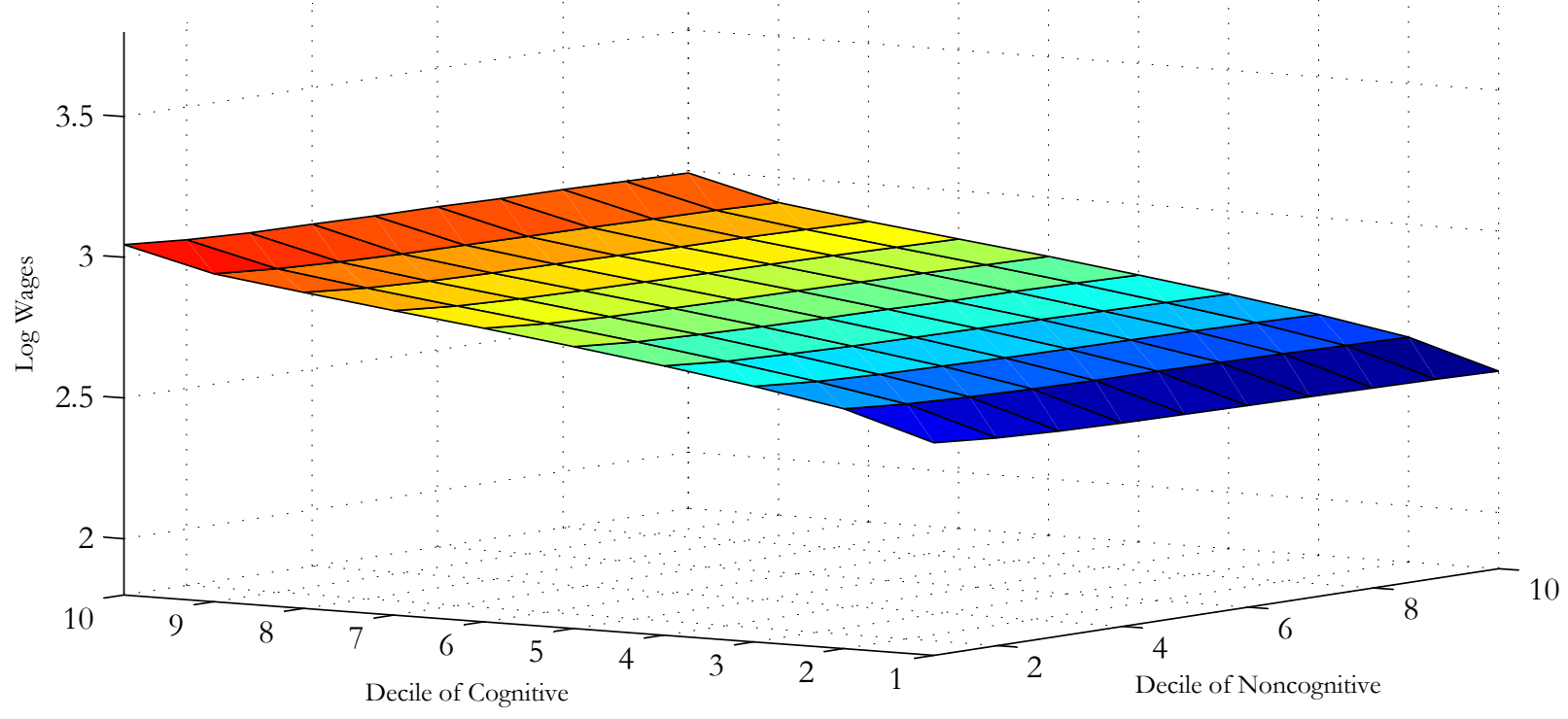

ii. By Decile of Cognitive Factor

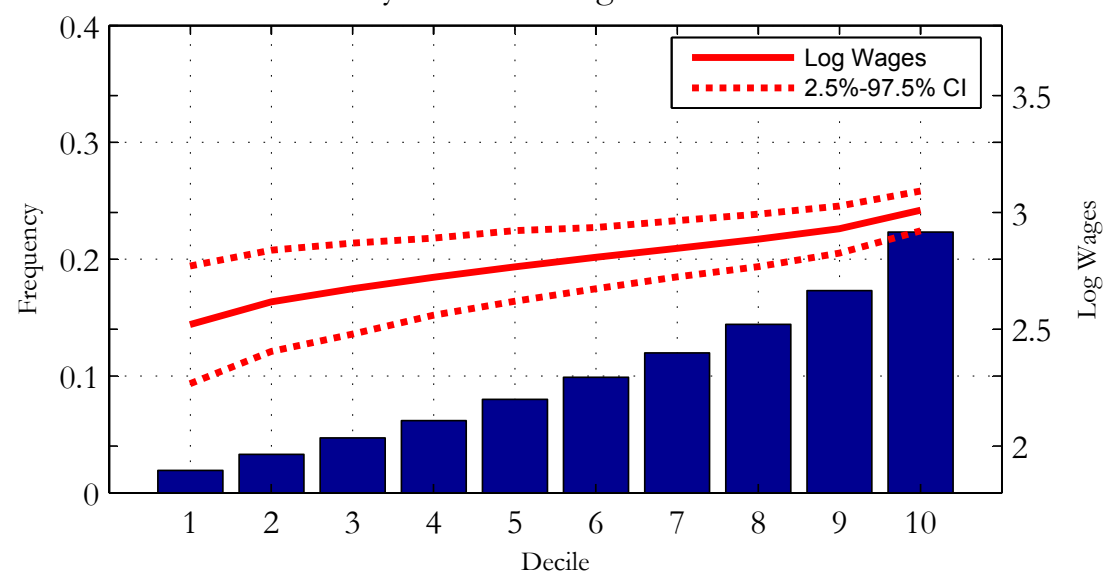

iii. By Decile of Noncognitive Factor

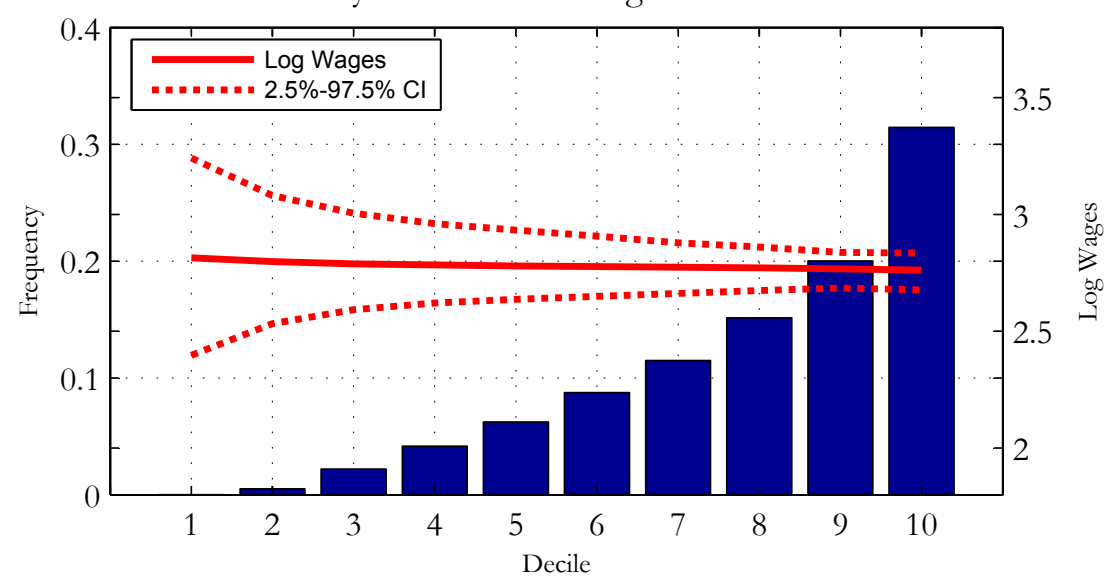

Notes: The data are simulated from the estimates of the model and our NLSY79 sample. We use the standard convention that higher deciles are associated with higher values of the variable. The confidence intervals are computed using bootstrapping ( $200 \mathrm{draws})$. Frequency indicates proportion of individuals with the indicated level of education whose abilities lie in the indicated decile of the distribution. 
Figure 11B. Mean Log Wages of 4-yr College Graduates by Age 30 - Females i. By Decile of Cognitive and Noncognitive Factors

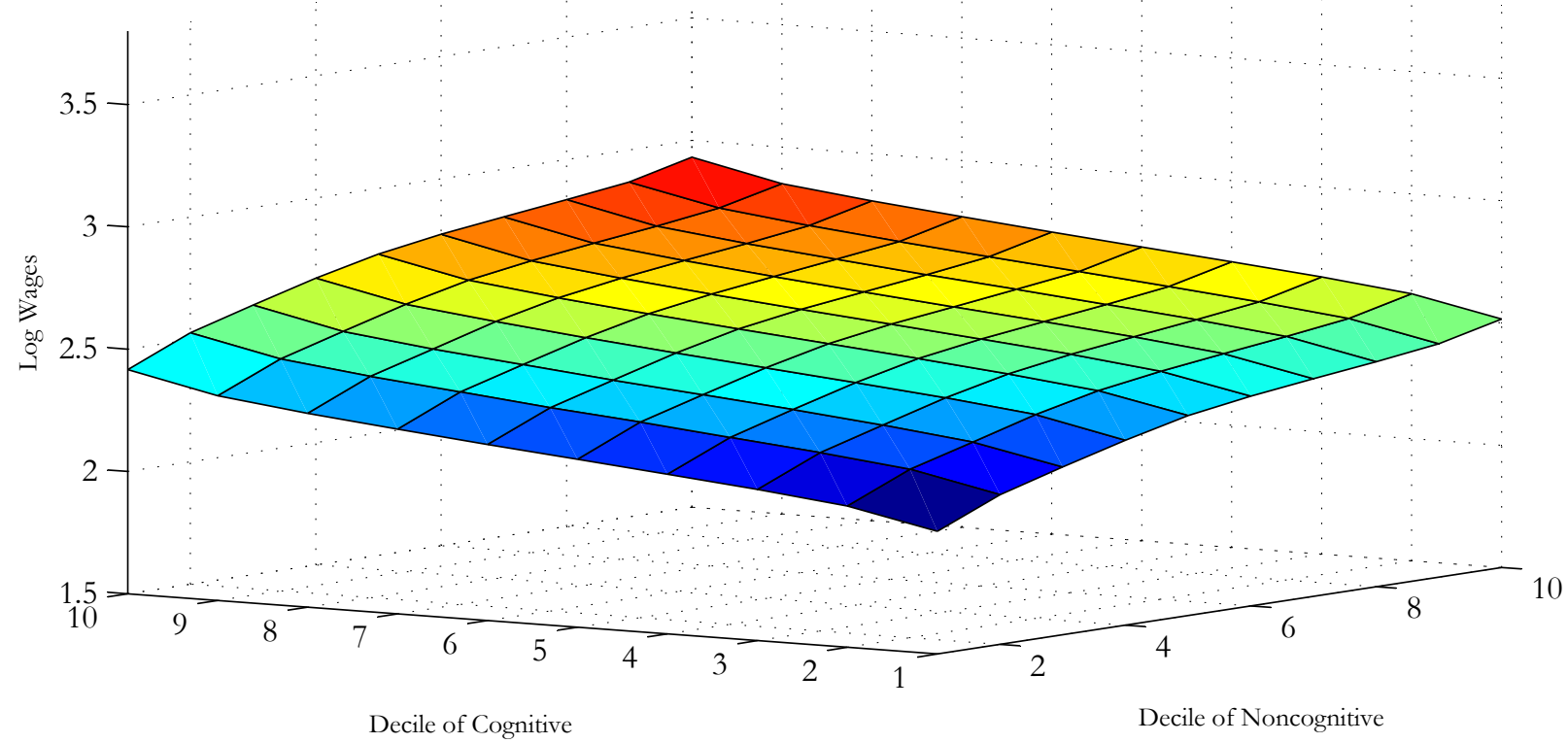

ii. By Decile of Cognitive Factor

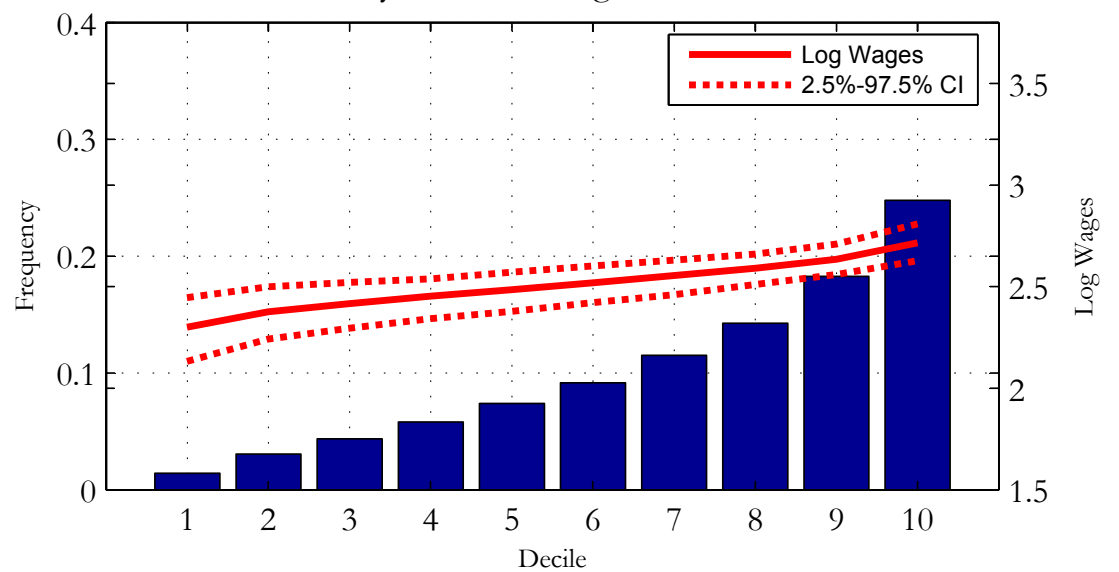

iii. By Decile of Noncognitive Factor

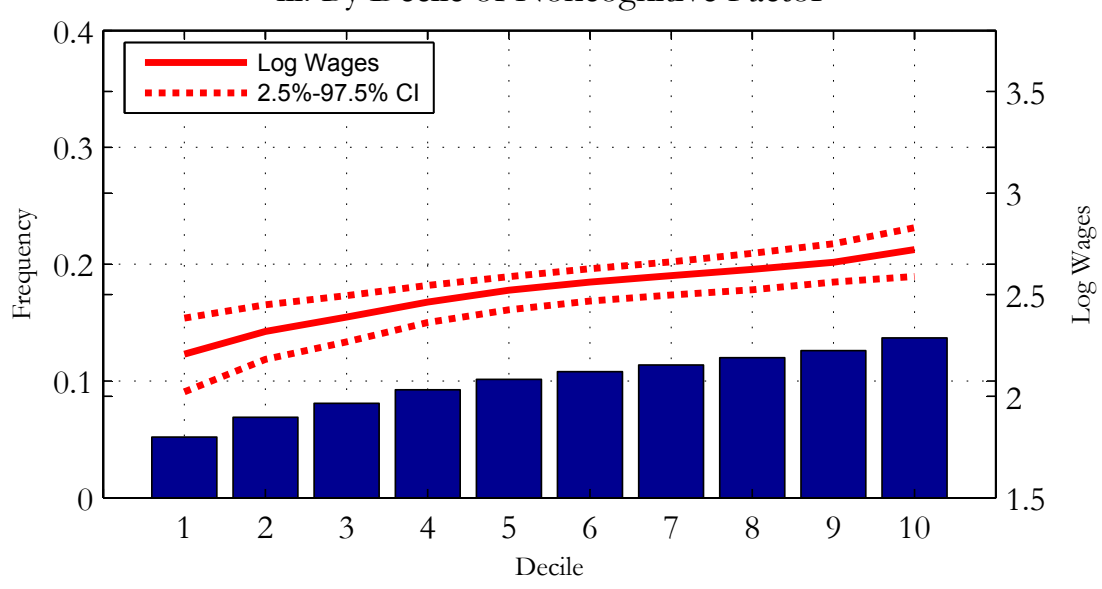

Notes: The data are simulated from the estimates of the model and our NLSY79 sample. We use the standard convention that higher deciles are associated with higher values of the variable. The confidence intervals are computed using bootstrapping (200 draws). Frequency indicates proportion of individuals with the indicated level of education whose abilities lie in the indicated decile of the distribution. 
Figure 12A. Probability of Employment at Age 30 - Males

i. By Decile of Cognitive and Noncognitive Factor

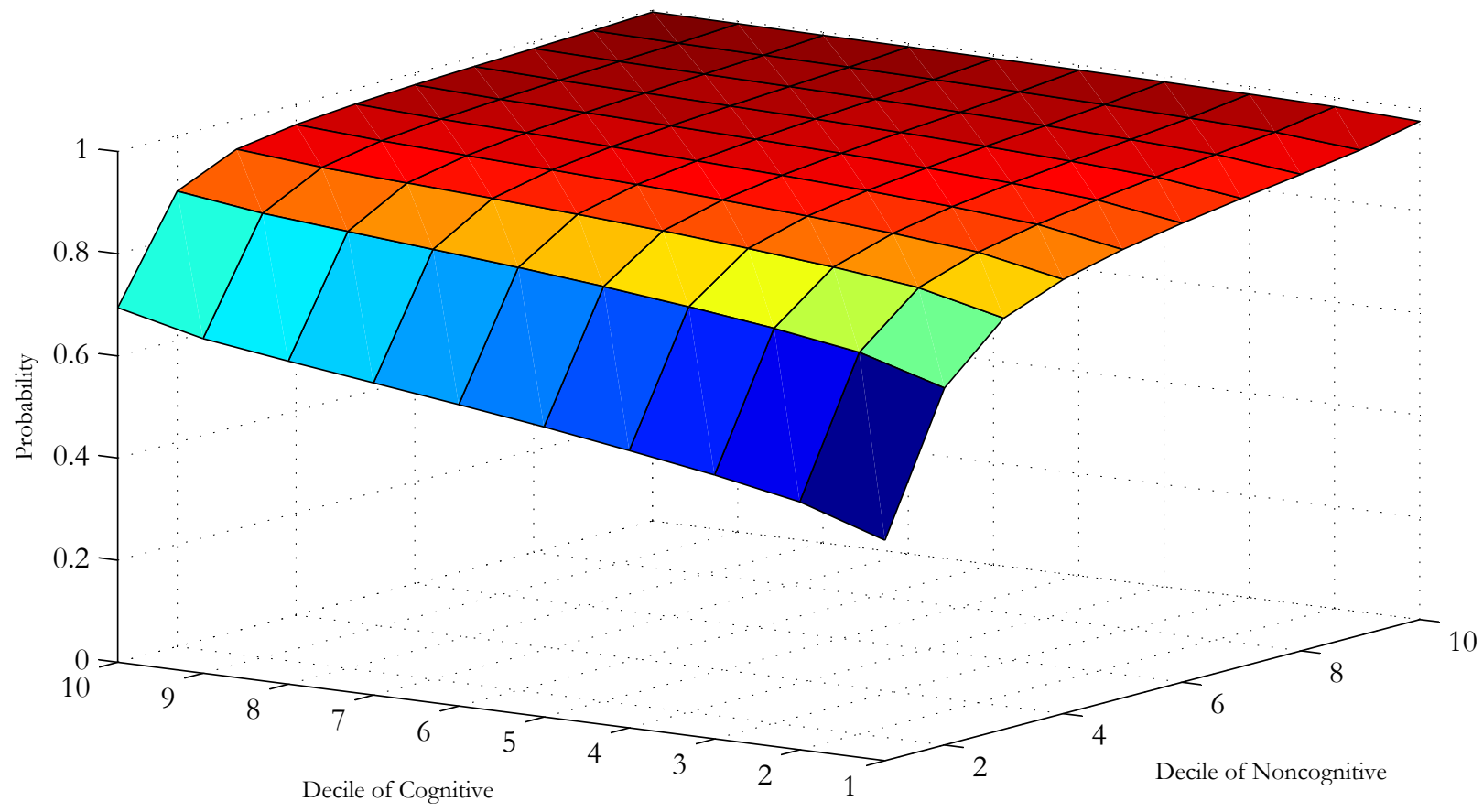

ii. By Decile of Cognitive Factor

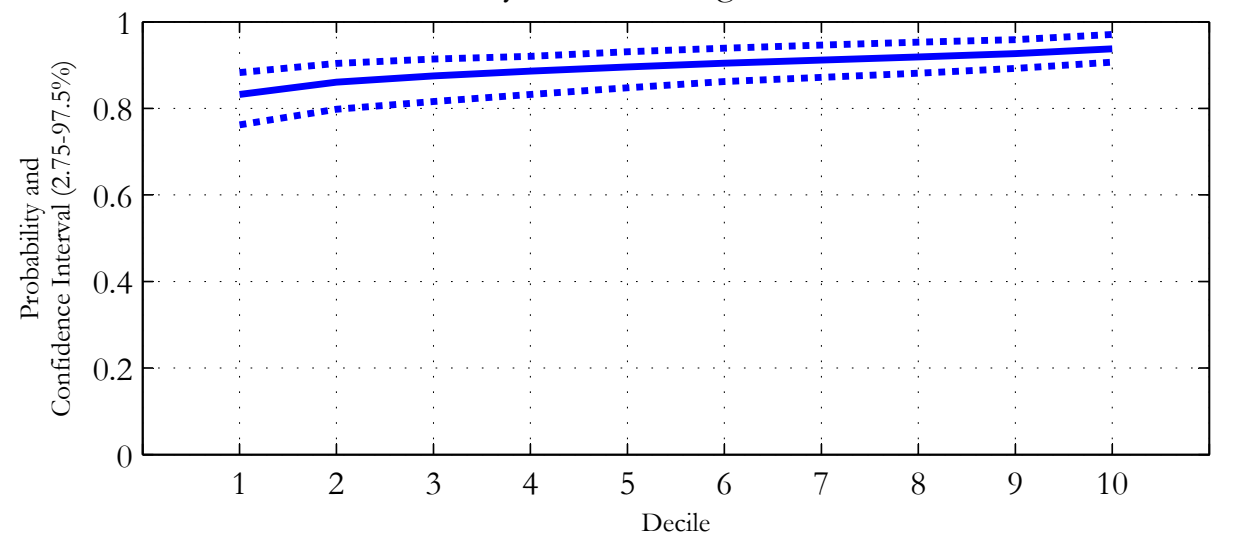

iii. By Decile of Noncognitive Factor

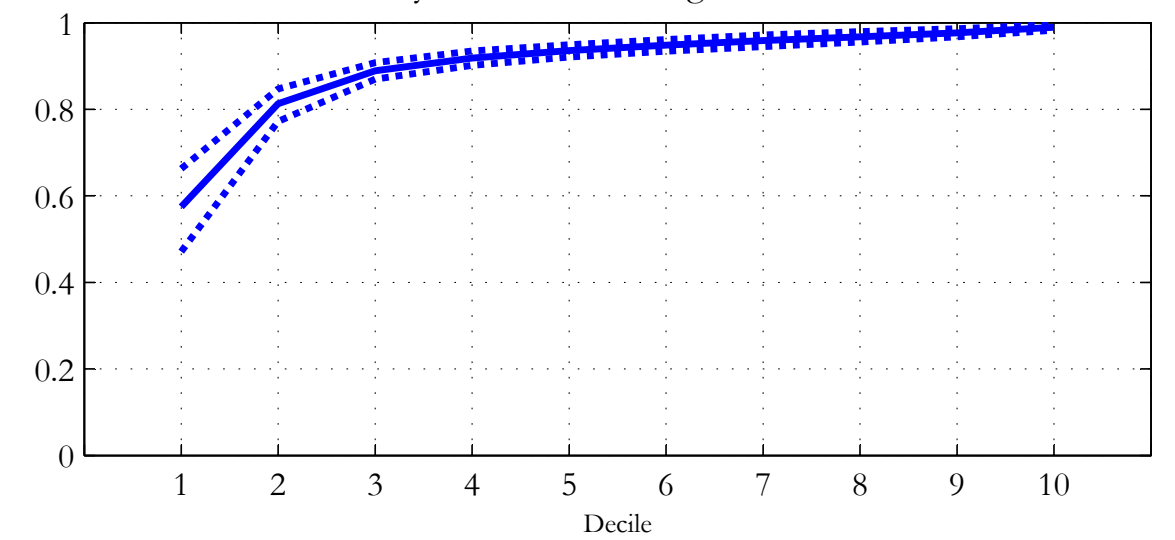

Notes: The data are simulated from the estimates of the model and our NLSY79 sample. We use the standard convention that higher deciles are associated with higher values of the variable. The confidence intervals are computed using bootstrapping (200 draws). 
Figure 12B. Probability of Employment at Age 30 - Females

i. By Decile of Cognitive and Noncognitive Factor

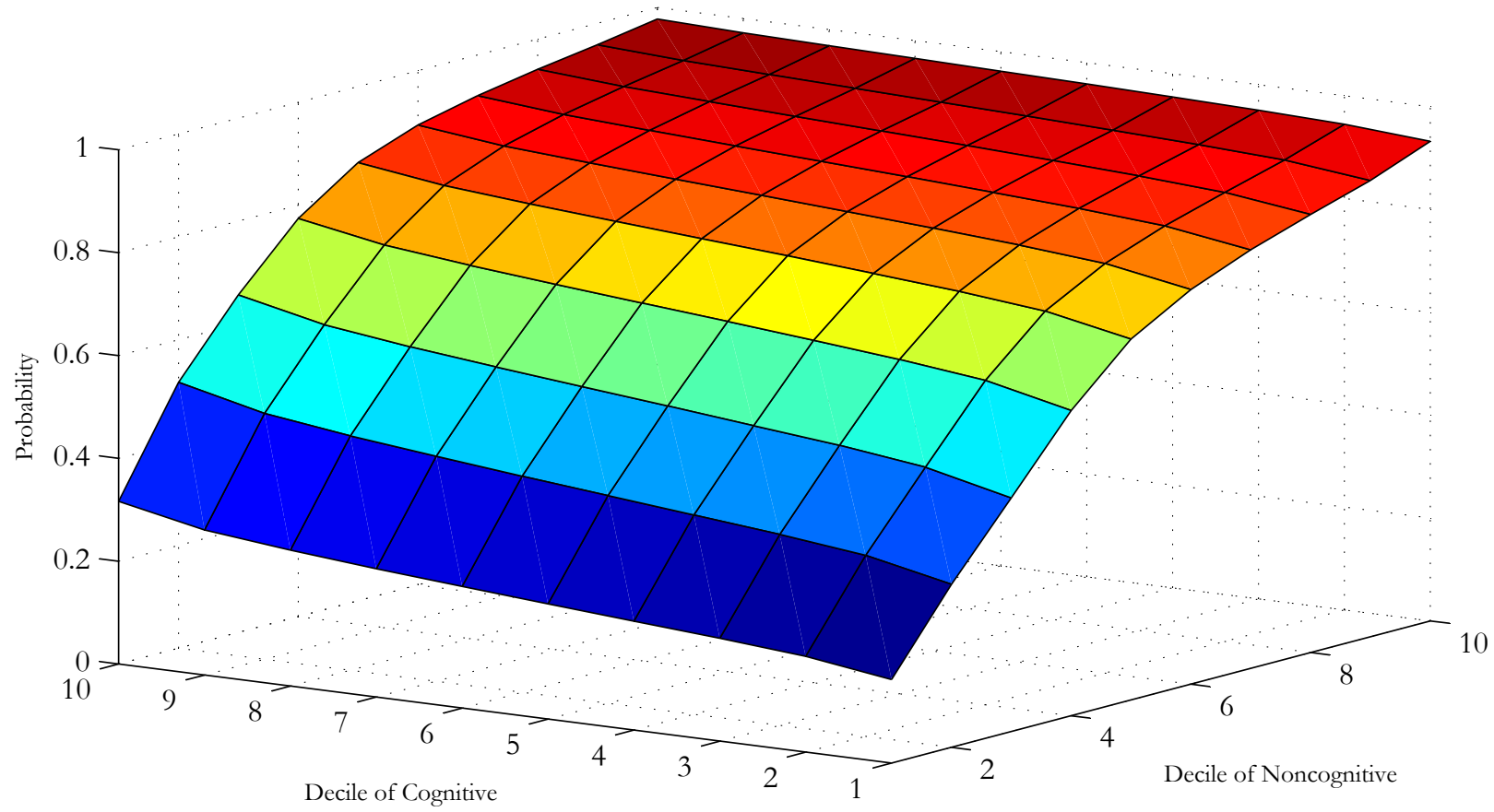

ii. By Decile of Cognitive Factor

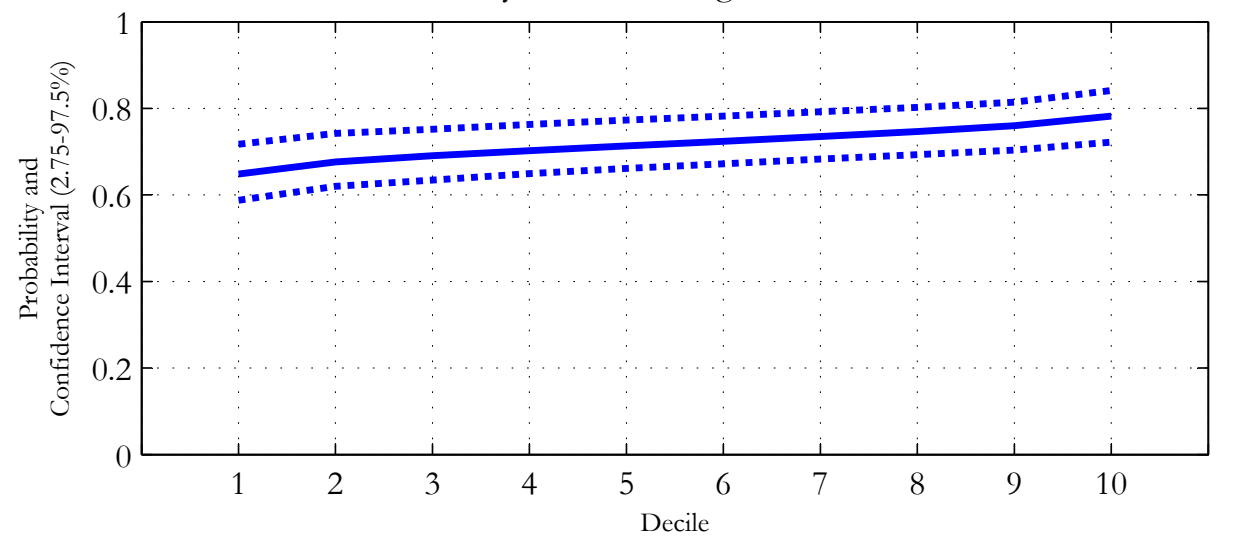

iii. By Decile of Noncognitive Factor

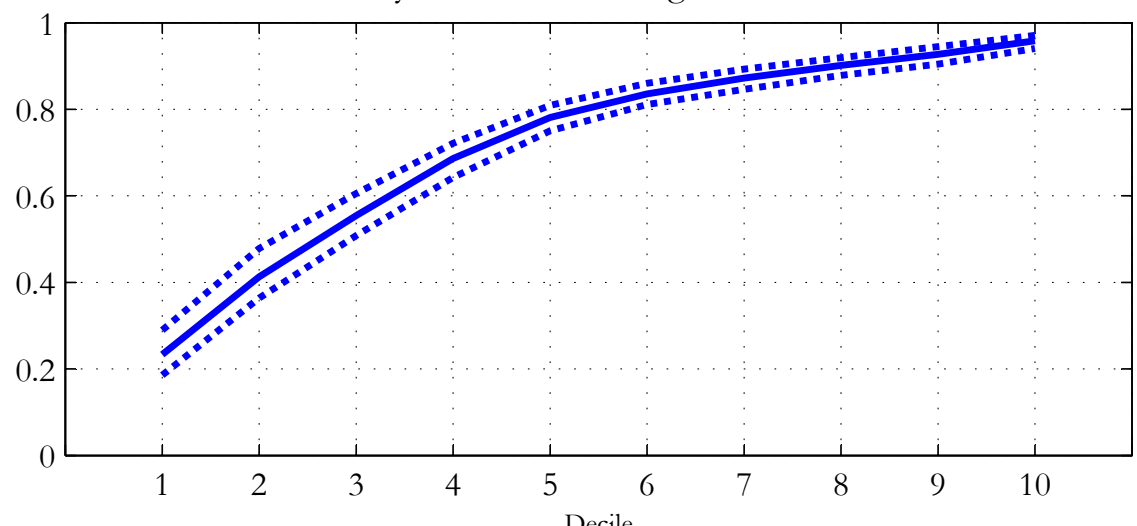

Notes: The data are simulated from the estimates of the model and our NLSY79 sample. We use the standard convention that higher deciles are associated with higher values of the variable. The confidence intervals are computed using bootstrapping (200 draws). 
Figure 13A. Mean Work Experience of High School Dropouts by Age 30 - Males i. By Decile of Cognitive and Noncognitive Factors

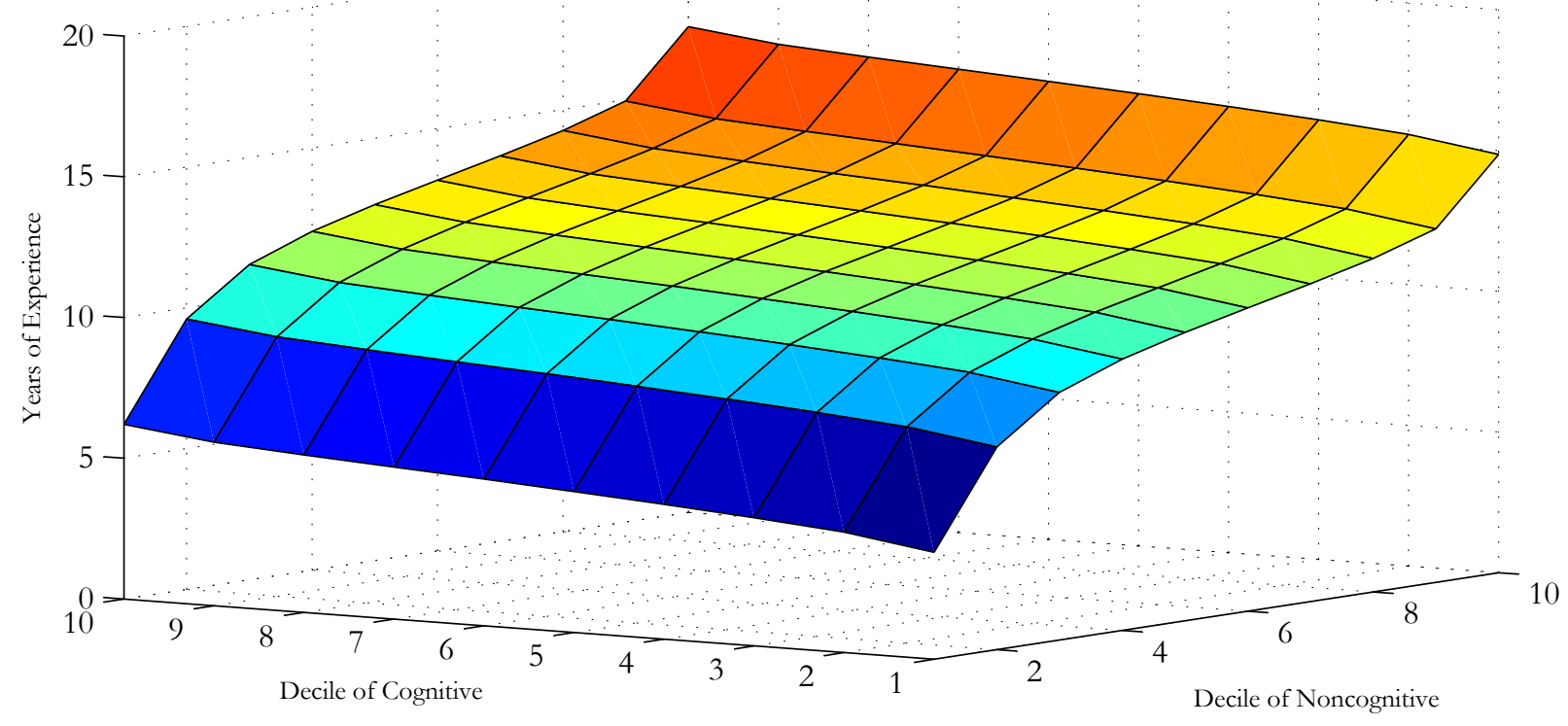

ii. By Decile of Cognitive Factor

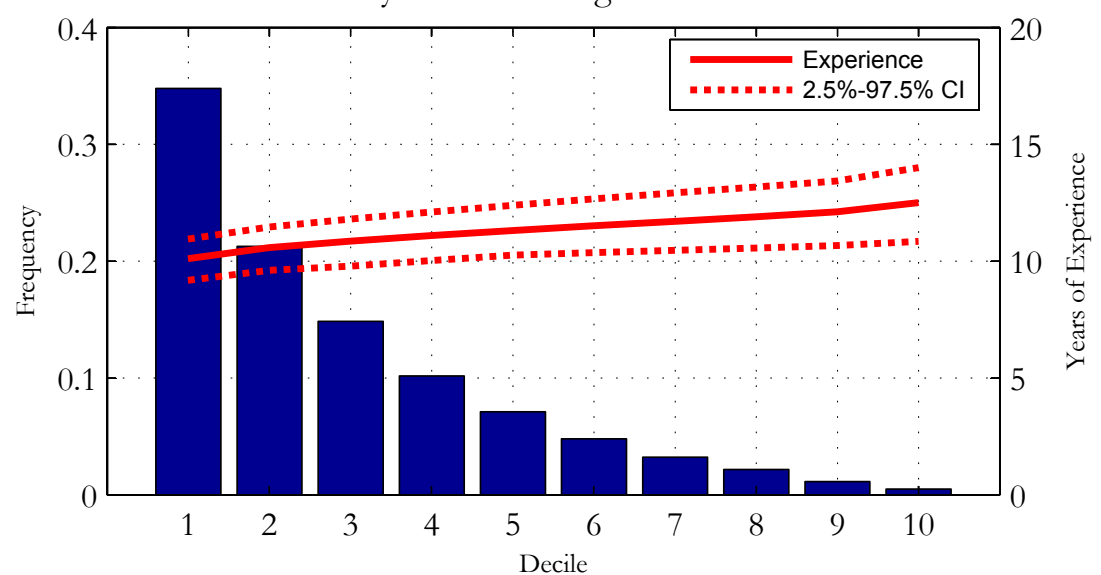

iii. By Decile of Noncognitive Factor

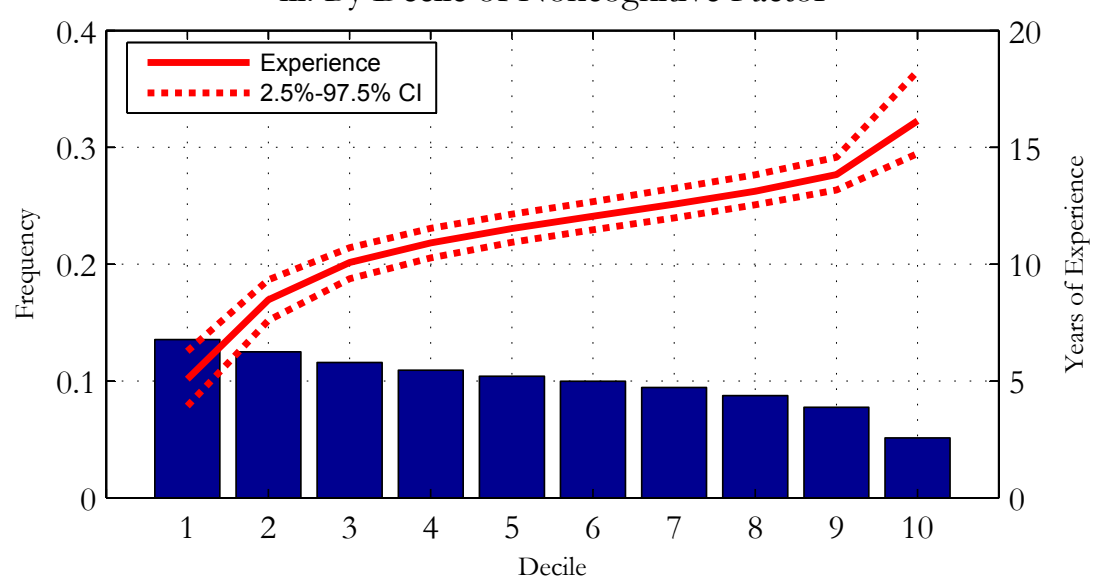

Notes: The data are simulated from the estimates of the model and our NLSY79 sample. We use the standard convention that higher deciles are associated with higher values of the variable. The confidence intervals are computed using bootstrapping (200 draws). Frequency indicates proportion of individuals with the indicated level of education whose abilities lie in the indicated decile of the distribution. 
Figure 13B. Mean Work Experience of GEDs by Age 30 - Males

i. By Decile of Cognitive and Noncognitive Factors

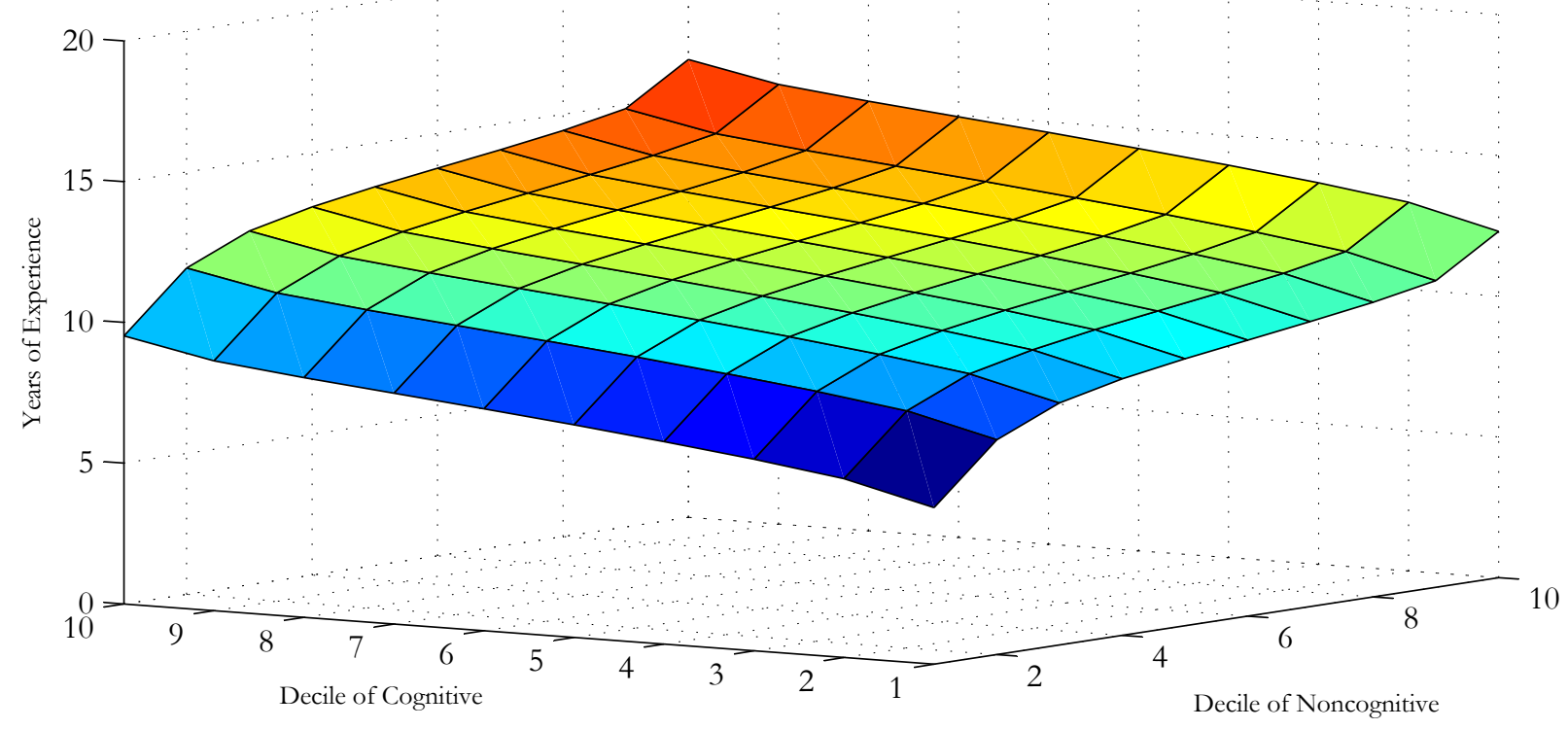

ii. By Decile of Cognitive Factor

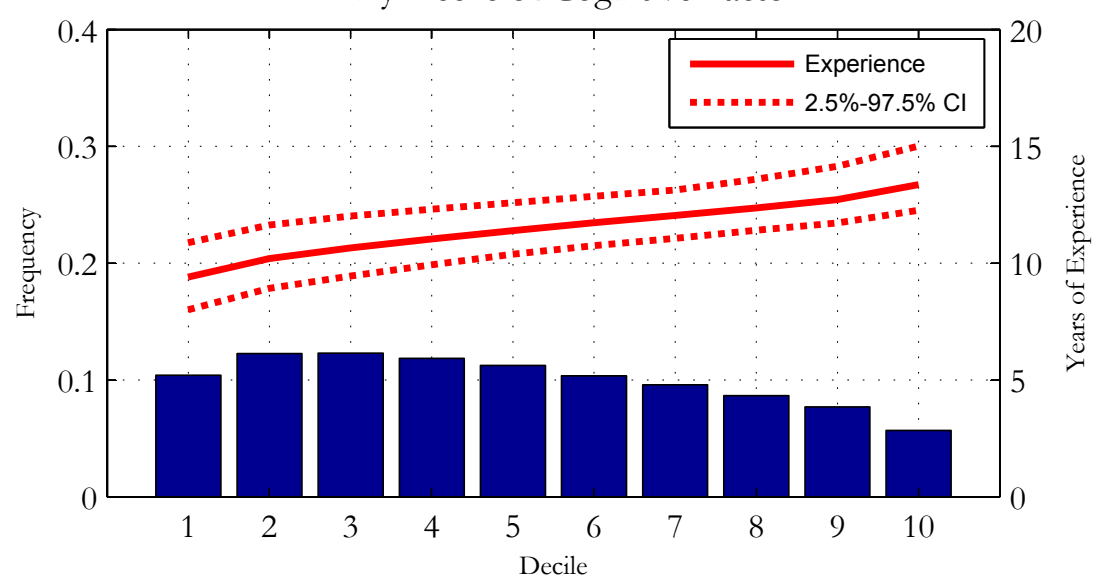

iii. By Decile of Noncognitive Factor

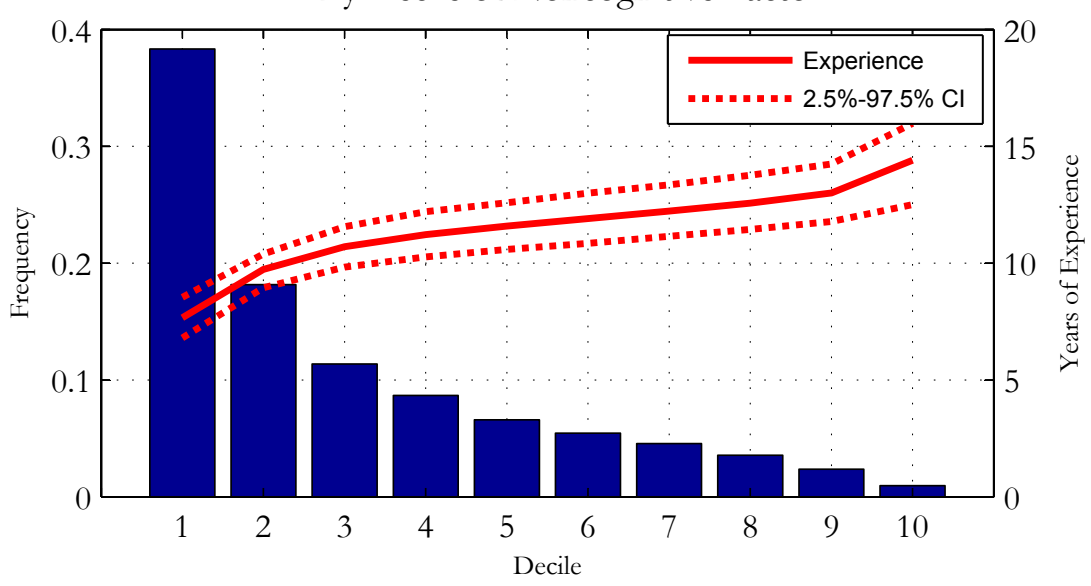

Notes: The data are simulated from the estimates of the model and our NLSY79 sample. We use the standard convention that higher deciles are associated with higher values of the variable. The confidence intervals are computed using bootstrapping ( 200 draws). Frequency indicates proportion of individuals with the indicated level of education whose abilities lie in the indicated decile of the distribution. 
Figure 13C. Mean Work Experience of High School Graduates by Age 30 - Males i. By Decile of Cognitive and Noncognitive Factors

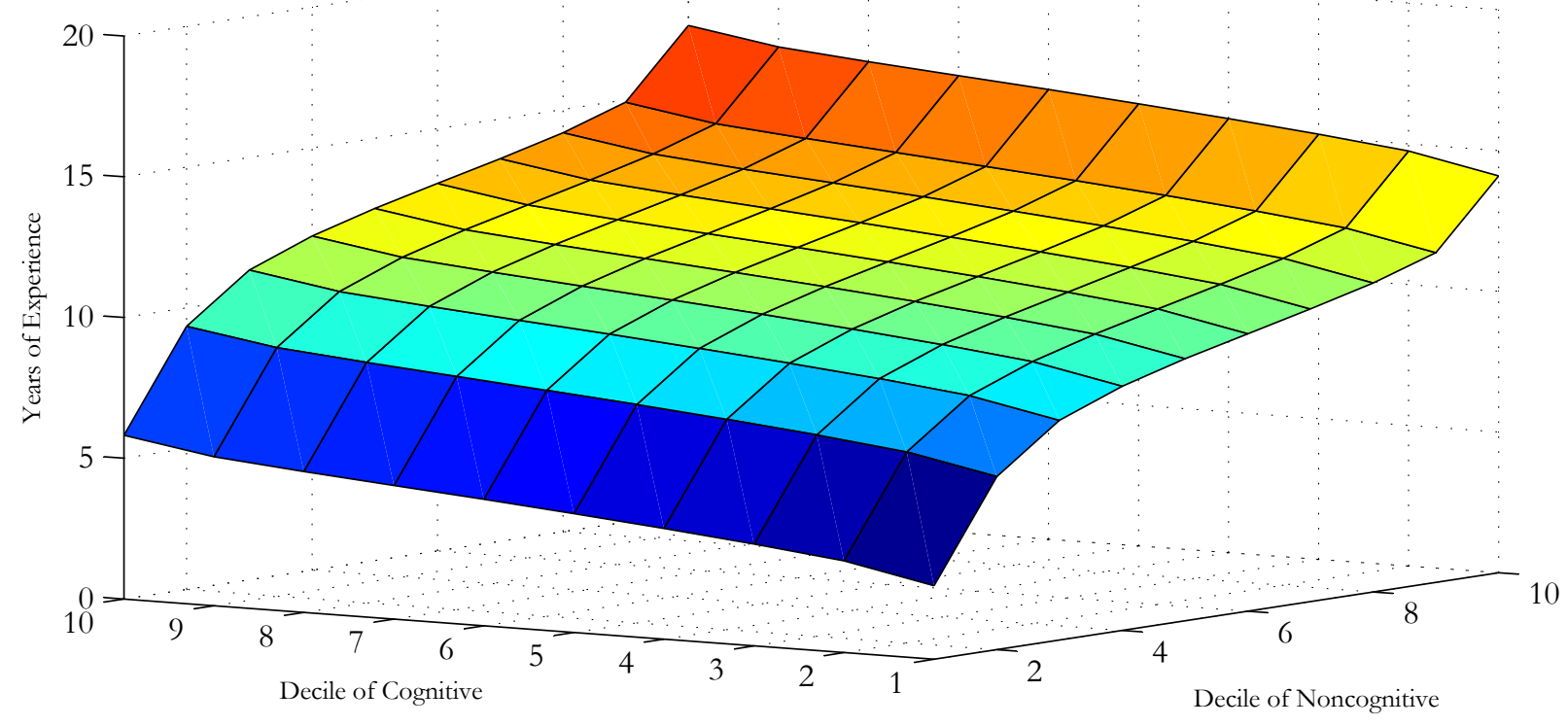

ii. By Decile of Cognitive Factor

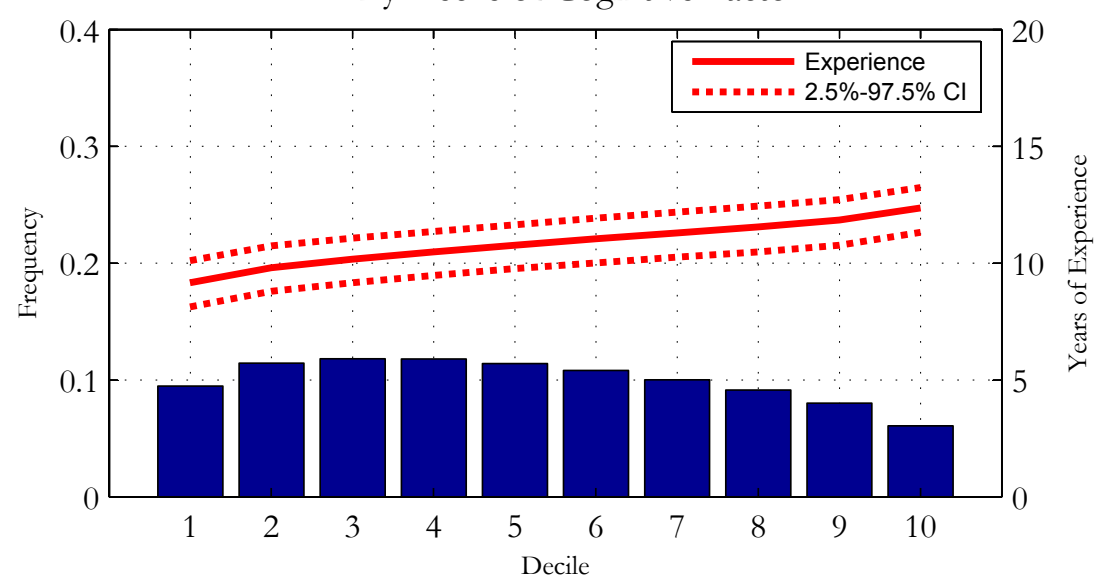

iii. By Decile of Noncognitive Factor

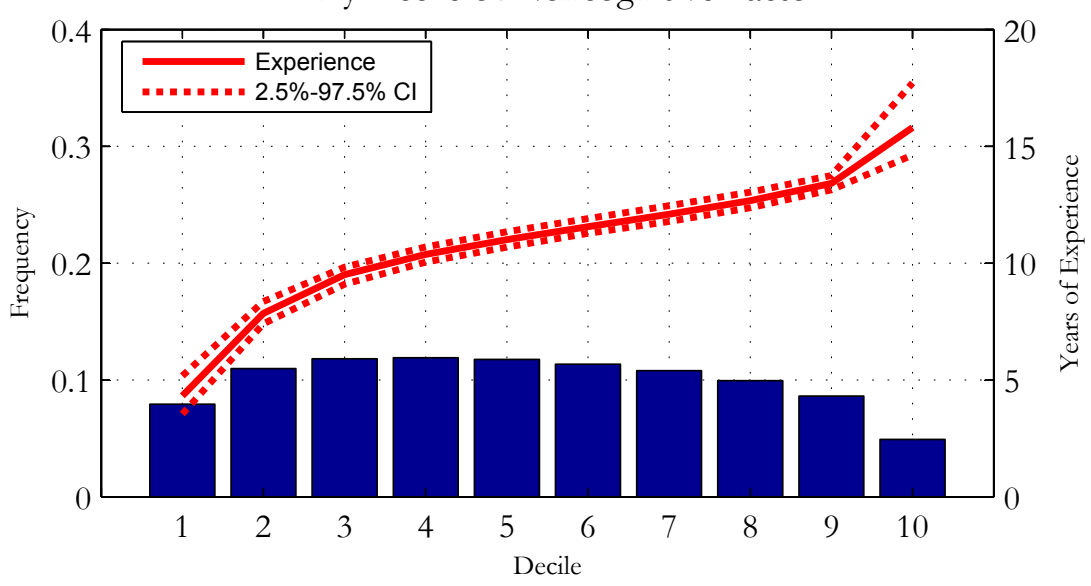

Notes: The data are simulated from the estimates of the model and our NLSY79 sample. We use the standard convention that higher deciles are associated with higher values of the variable. The confidence intervals are computed using bootstrapping (200 draws). Frequency indicates proportion of individuals with the indicated level of education whose abilities lie in the indicated decile of the distribution. 
Figure 13D. Mean Work Experience of 4-yr College Graduates by Age 30 - Males i. By Decile of Cognitive and Noncognitive Factors

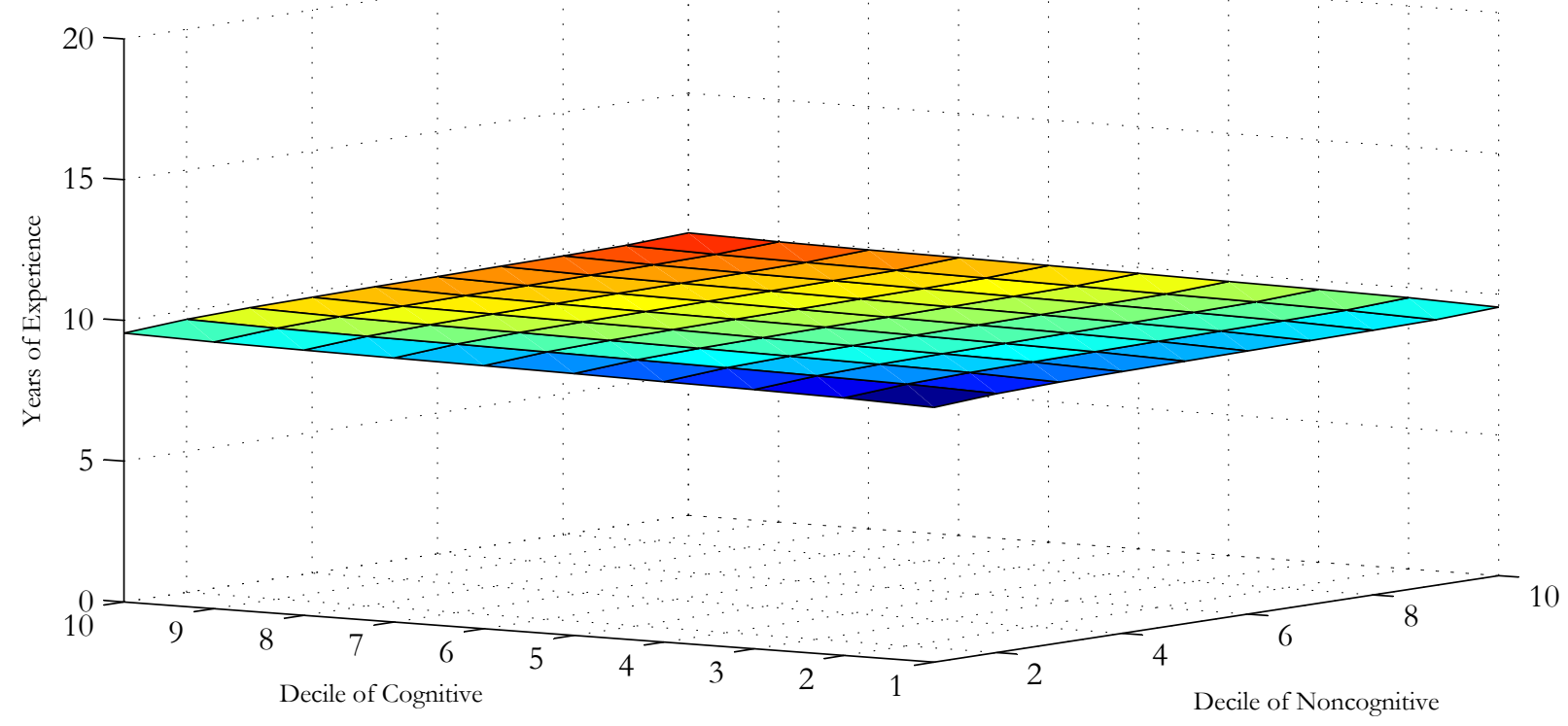

ii. By Decile of Cognitive Factor

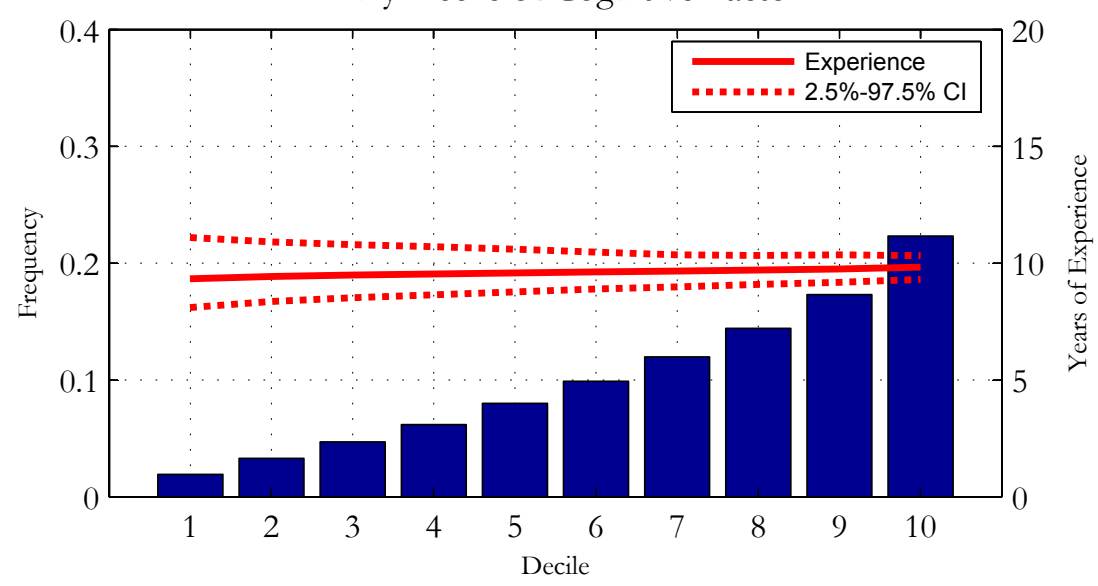

iii. By Decile of Noncognitive Factor

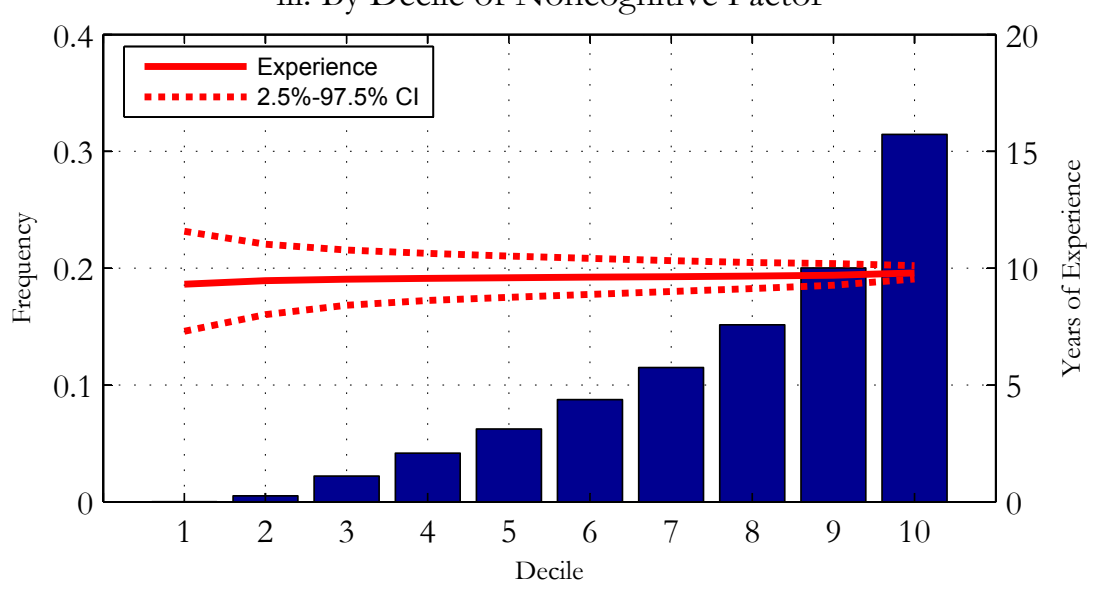

Notes: The data are simulated from the estimates of the model and our NLSY79 sample. We use the standard convention that higher deciles are associated with higher values of the variable. The confidence intervals are computed using bootstrapping (200 draws). Frequency indicates proportion of individuals with the indicated level of education whose abilities lie in the indicated decile of the distribution. 
Figure 14A. Probability Of Being a White Collar Worker by Age 30 - Males

i. By Decile of Cognitive and Noncognitive Factor

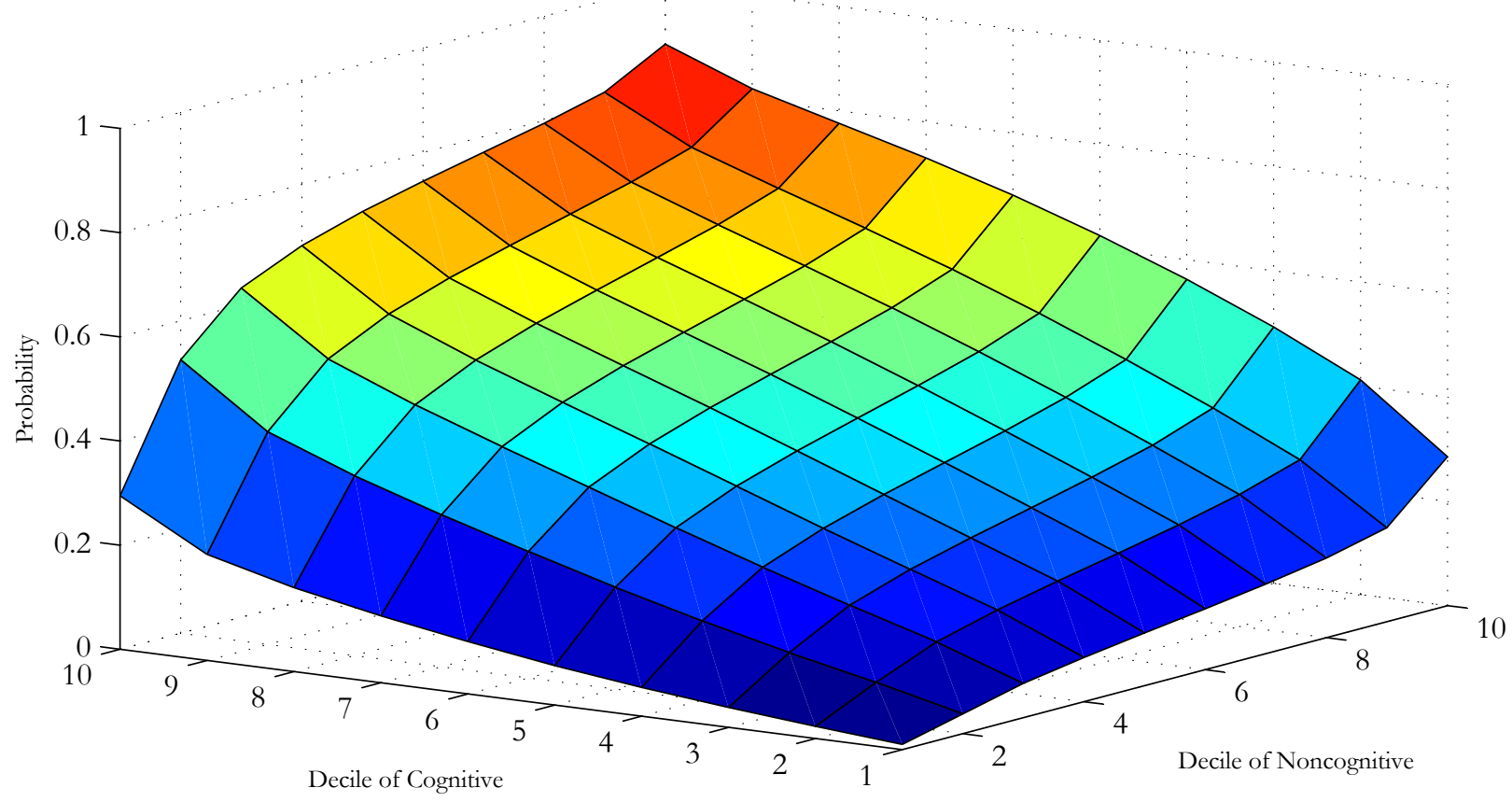

ii. By Decile of Cognitive Factor

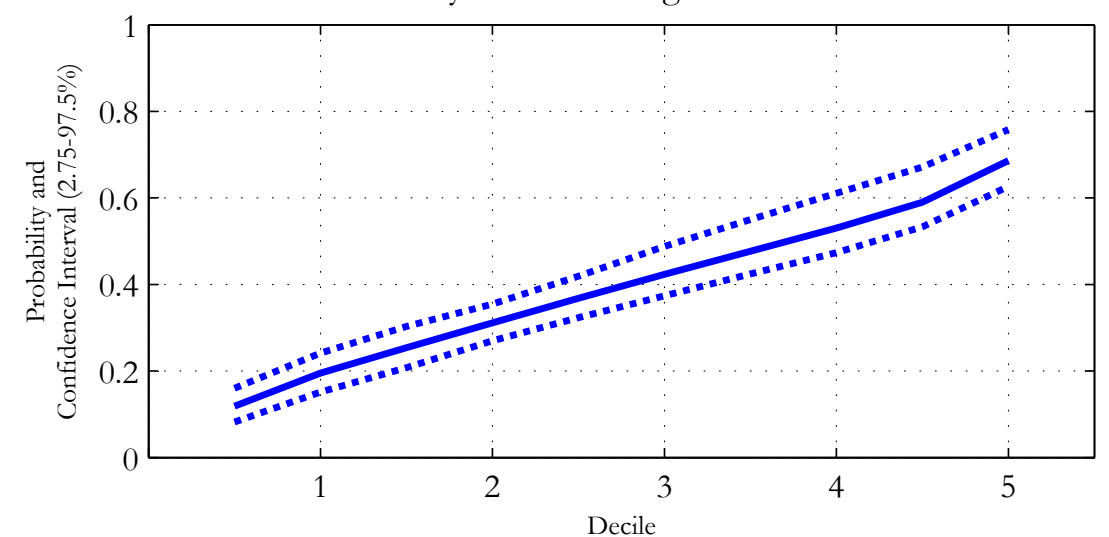

iii. By Decile of Noncognitive Factor

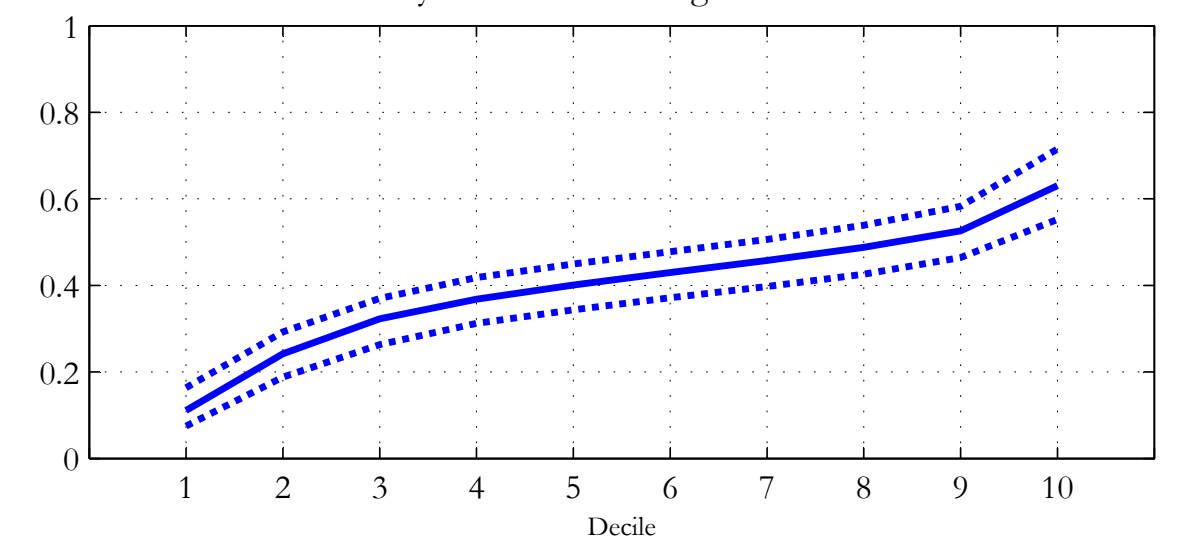

Notes: The data are simulated from the estimates of the model and our NLSY79 sample. We use the standard convention that higher deciles are associated with higher values of the variable. The confidence intervals are computed using bootstrapping (200 draws). 
Figure 14B. Probability Of Being a White Collar Worker by Age 30 - Females i. By Decile of Cognitive and Noncognitive Factor

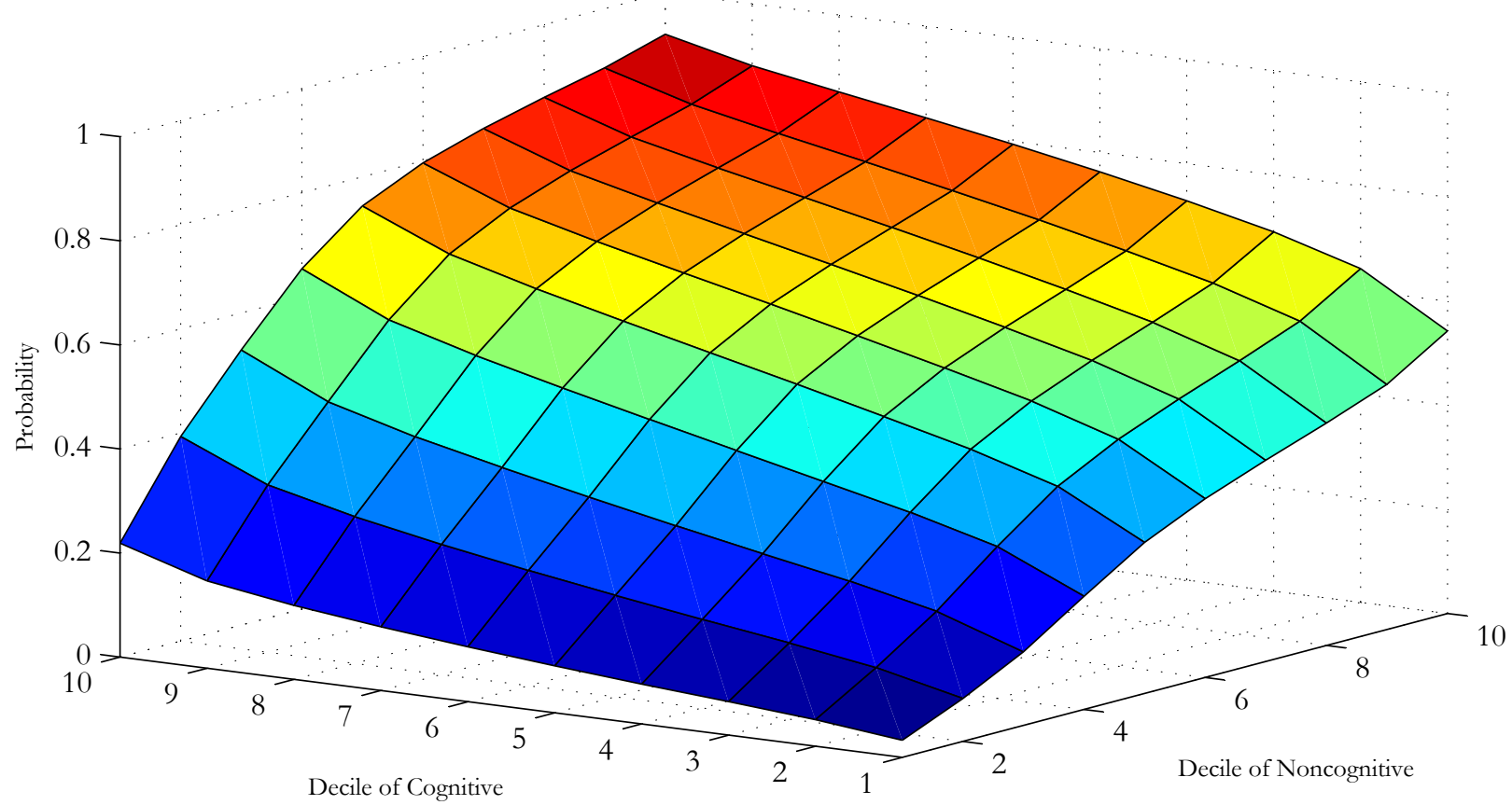

ii. By Decile of Cognitive Factor

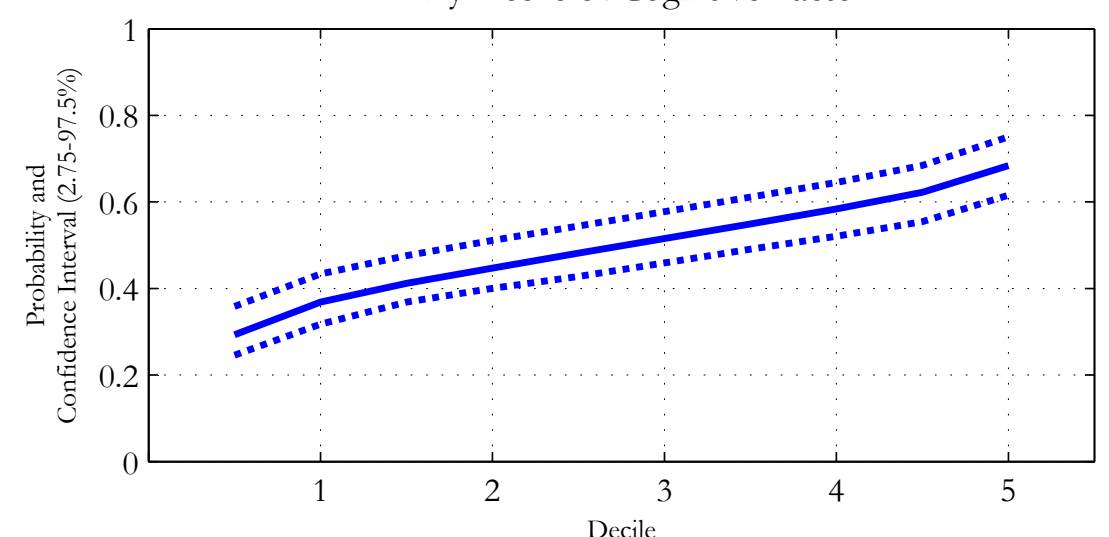

iii. By Decile of Noncognitive Factor

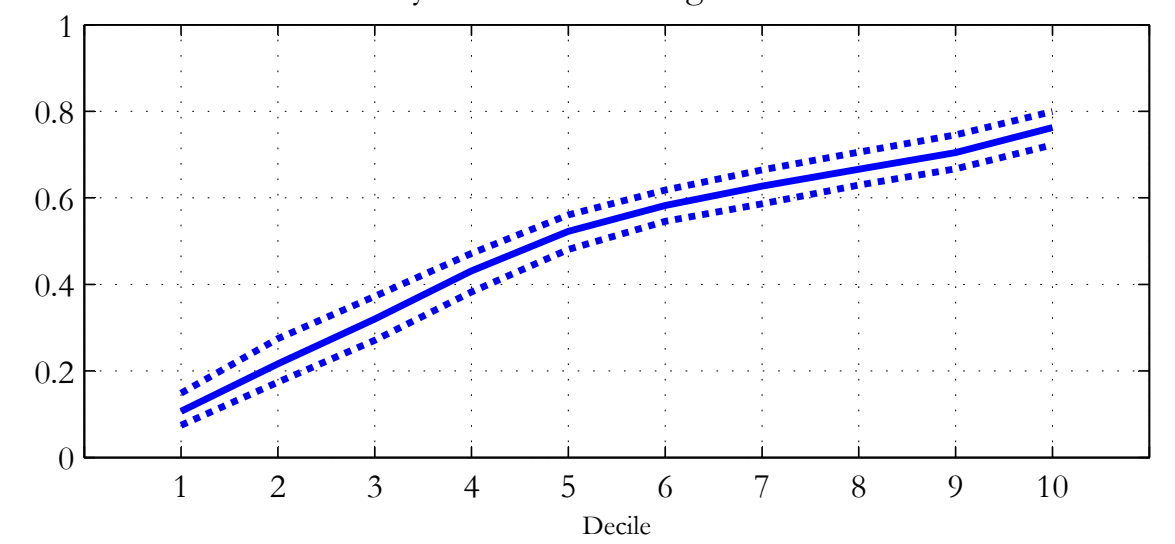

Notes: The data are simulated from the estimates of the model and our NLSY79 sample. We use the standard convention that higher deciles are associated with higher values of the variable. The confidence intervals are computed using bootstrapping (200 draws). 
Figure 15. Probability of Being a High School Dropout by Age 30 - Males

i. By Decile of Cognitive and Noncognitive Factors

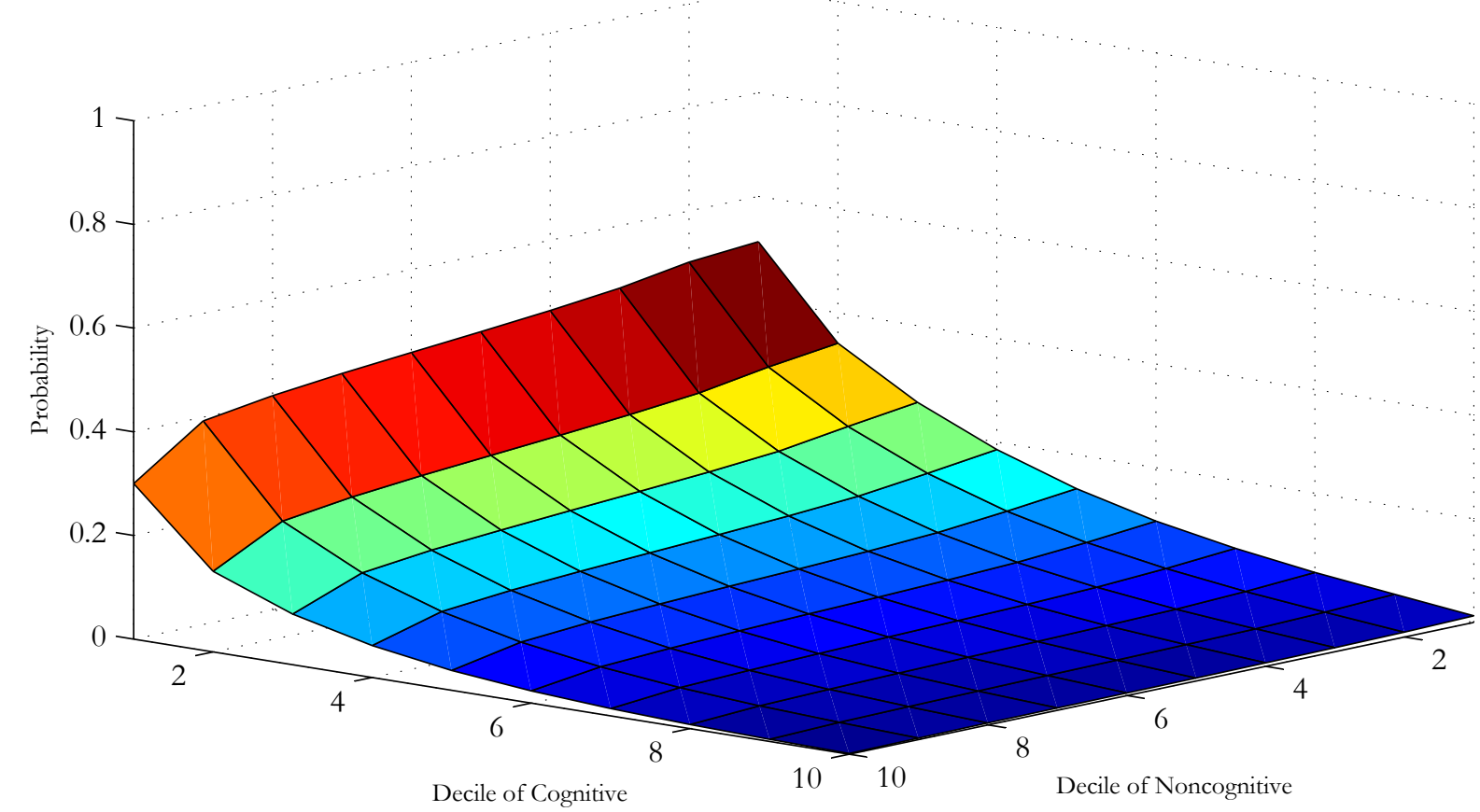

ii. By Decile of Cognitive Factor

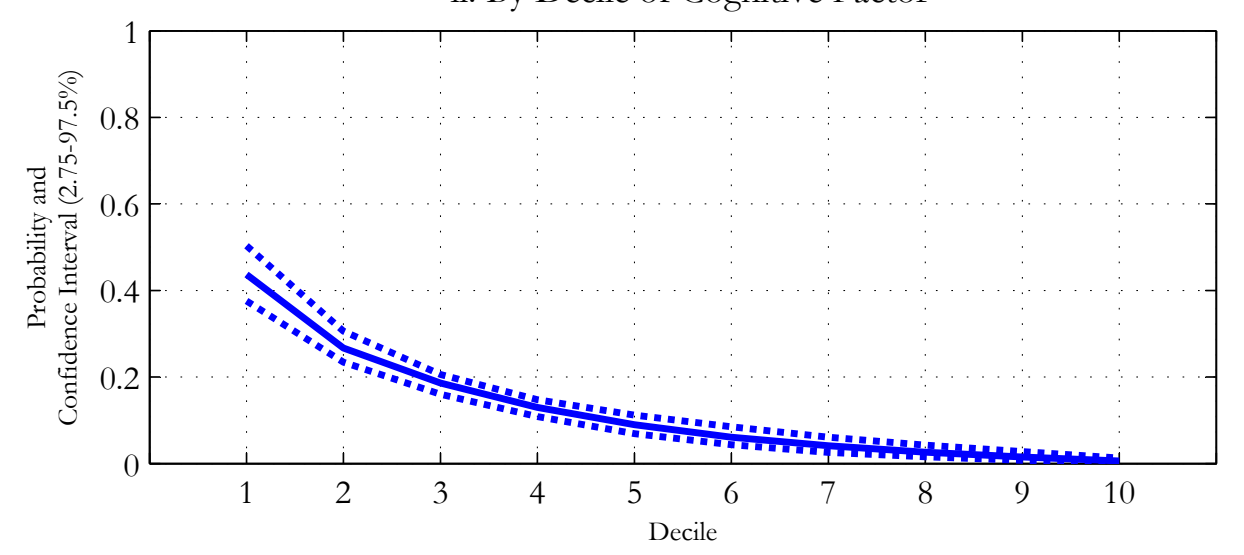

iii. By Decile of Noncognitive Factor

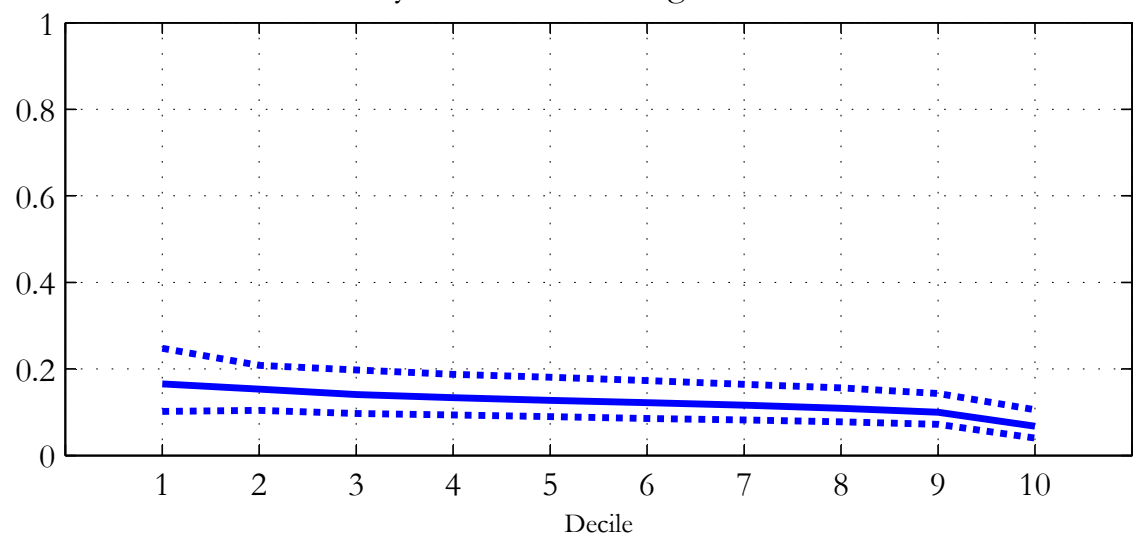

Notes: The data are simulated from the estimates of the model and our NLSY79 sample. We use the standard convention that higher deciles are associated with higher values of the variable. The confidence intervals are computed using bootstrapping (200 draws). 
Figure 16. Probability of Being a GED by Age 30 - Males

i. By Decile of Cognitive and Noncognitive Factors

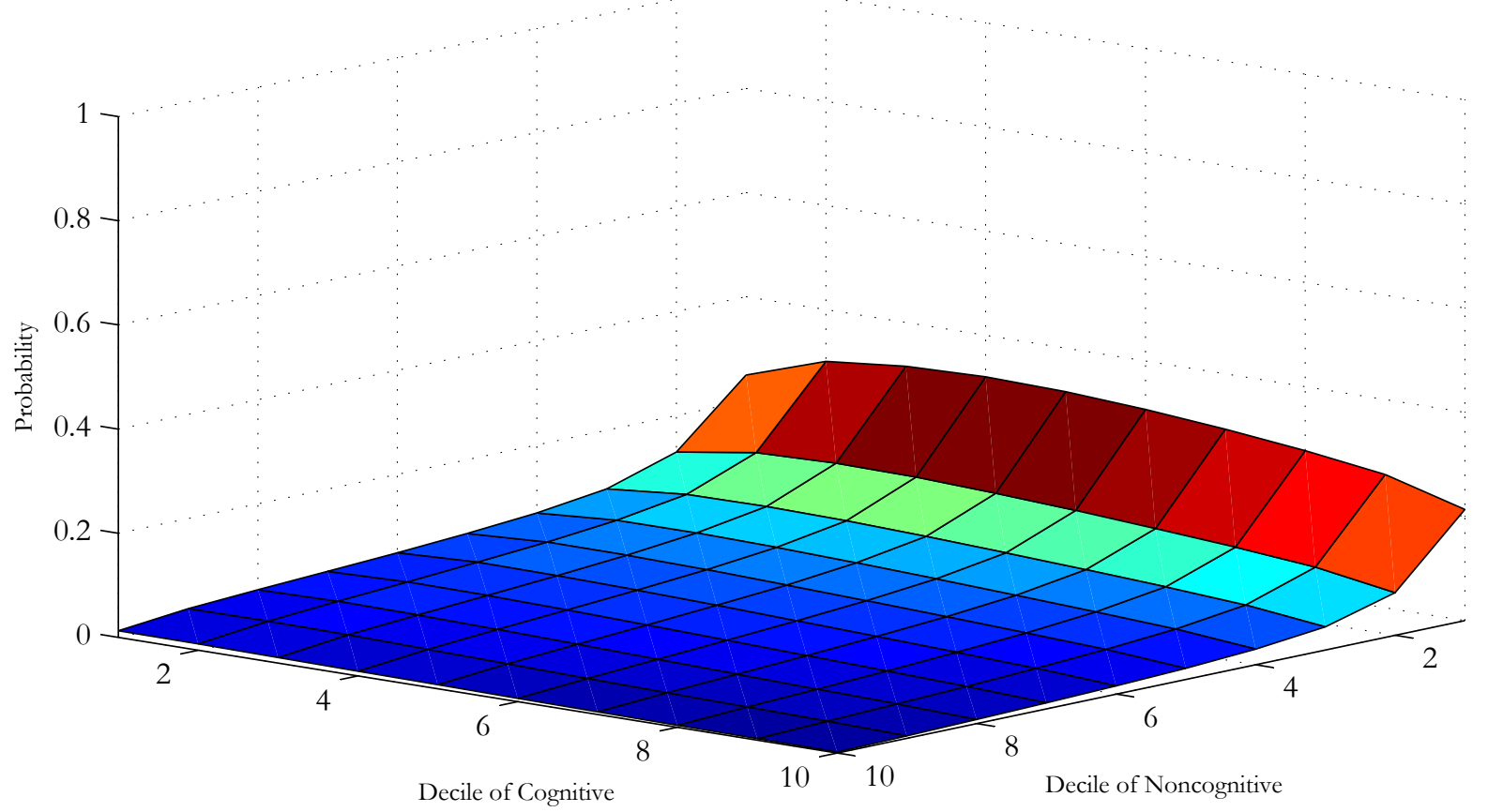

ii. By Decile of Cognitive Factor

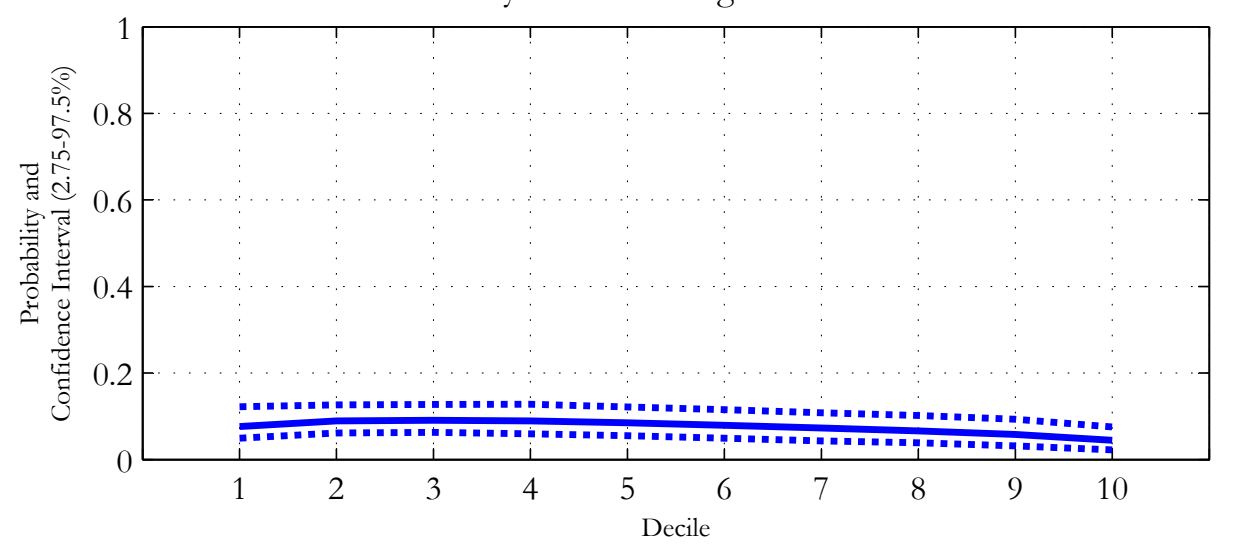

iii. By Decile of Noncognitive Factor

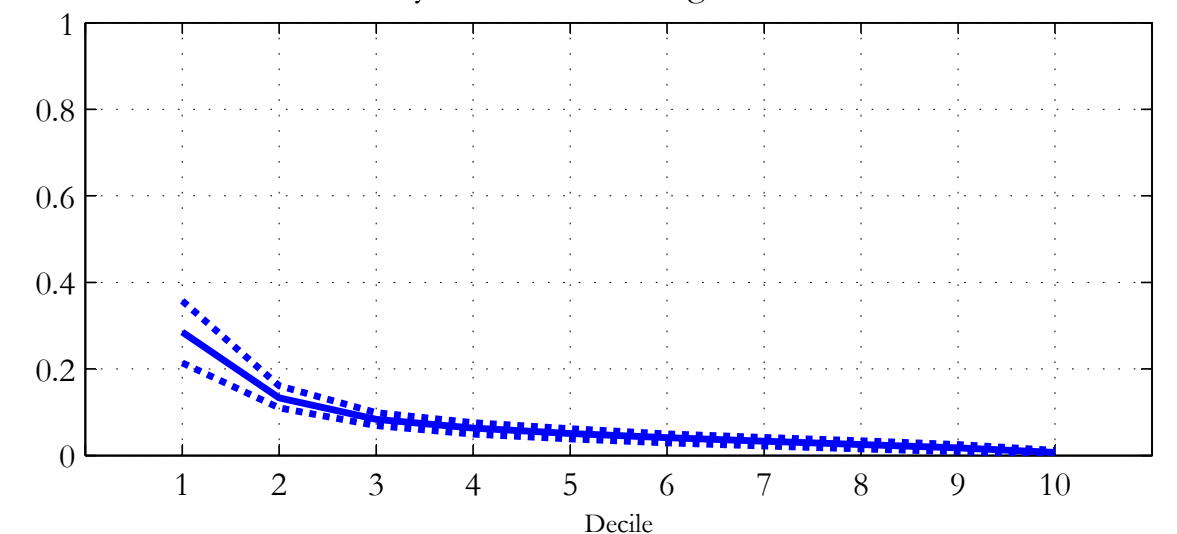

Notes: The data are simulated from the estimates of the model and our NLSY79 sample. We use the standard convention that higher deciles are associated with higher values of the variable. The confidence intervals are computed using bootstrapping (200 draws). 
Figure 17. Probability of Being a High School Graduate by Age 30 - Males

i. By Decile of Cognitive and Noncognitive Factors

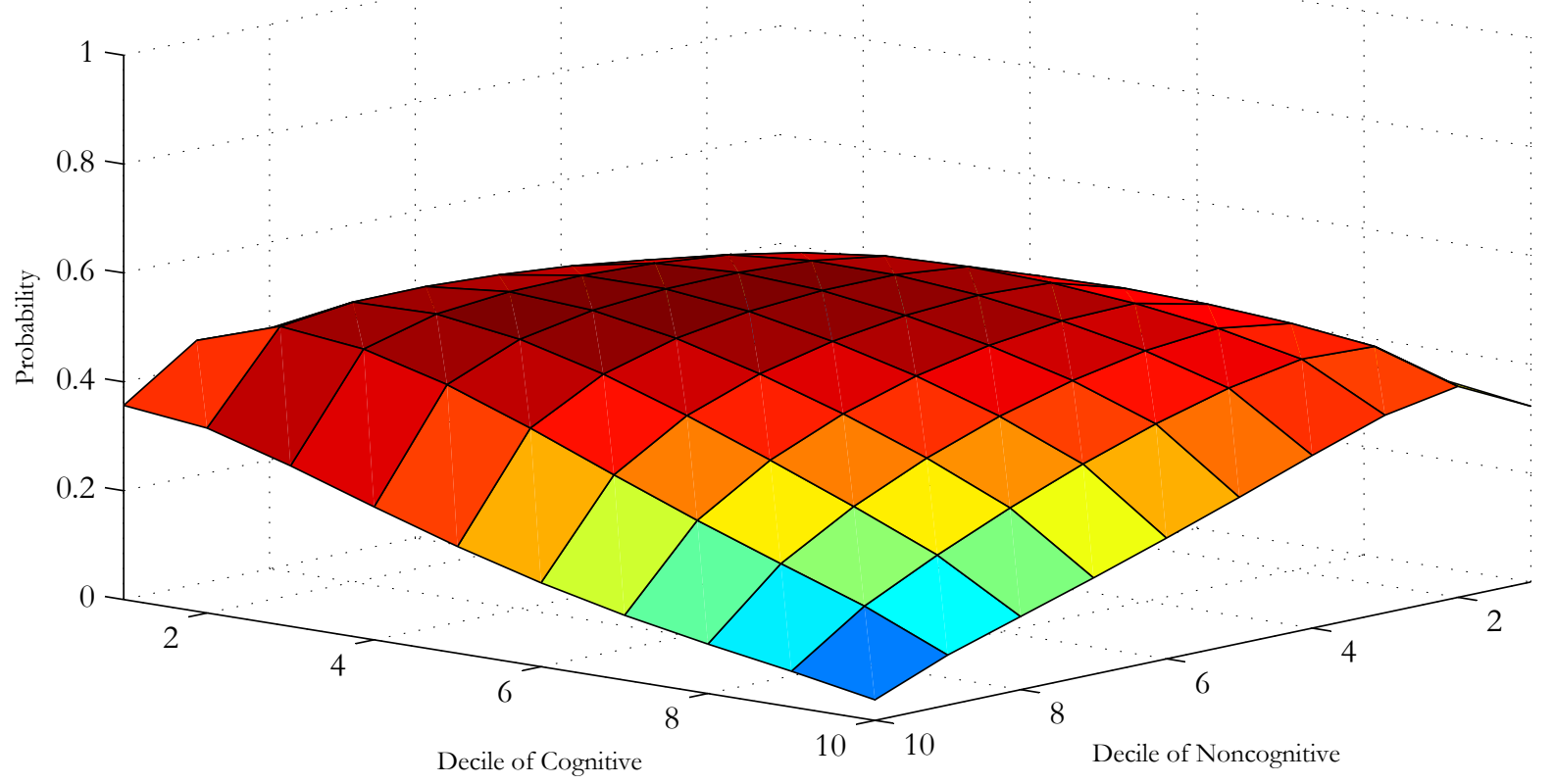

ii. By Decile of Cognitive Factor

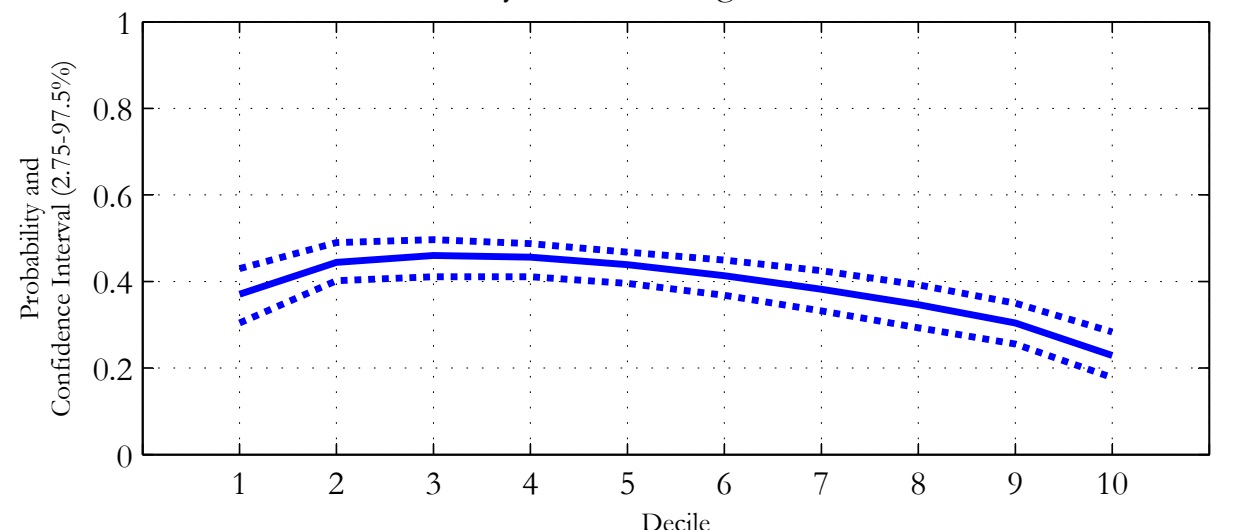

iii. By Decile of Noncognitive Factor

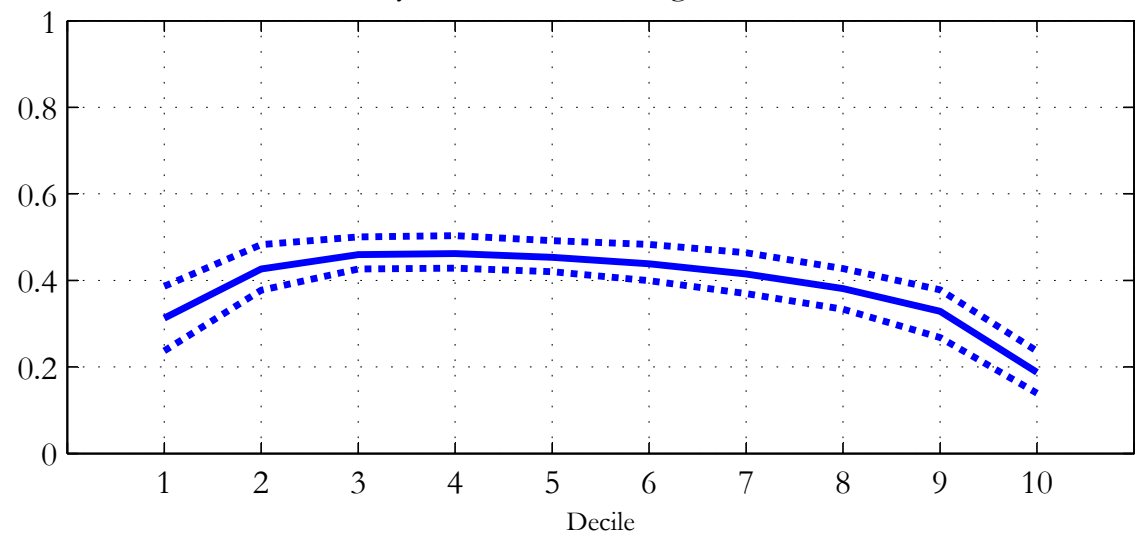

Notes: The data are simulated from the estimates of the model and our NLSY79 sample. We use the standard convention that higher deciles are associated with higher values of the variable. The confidence intervals are computed using bootstrapping (200 draws). 
Figure 18. Probability of Being a 2-yr College Graduate by Age 30 - Males

i. By Decile of Cognitive and Noncognitive Factors

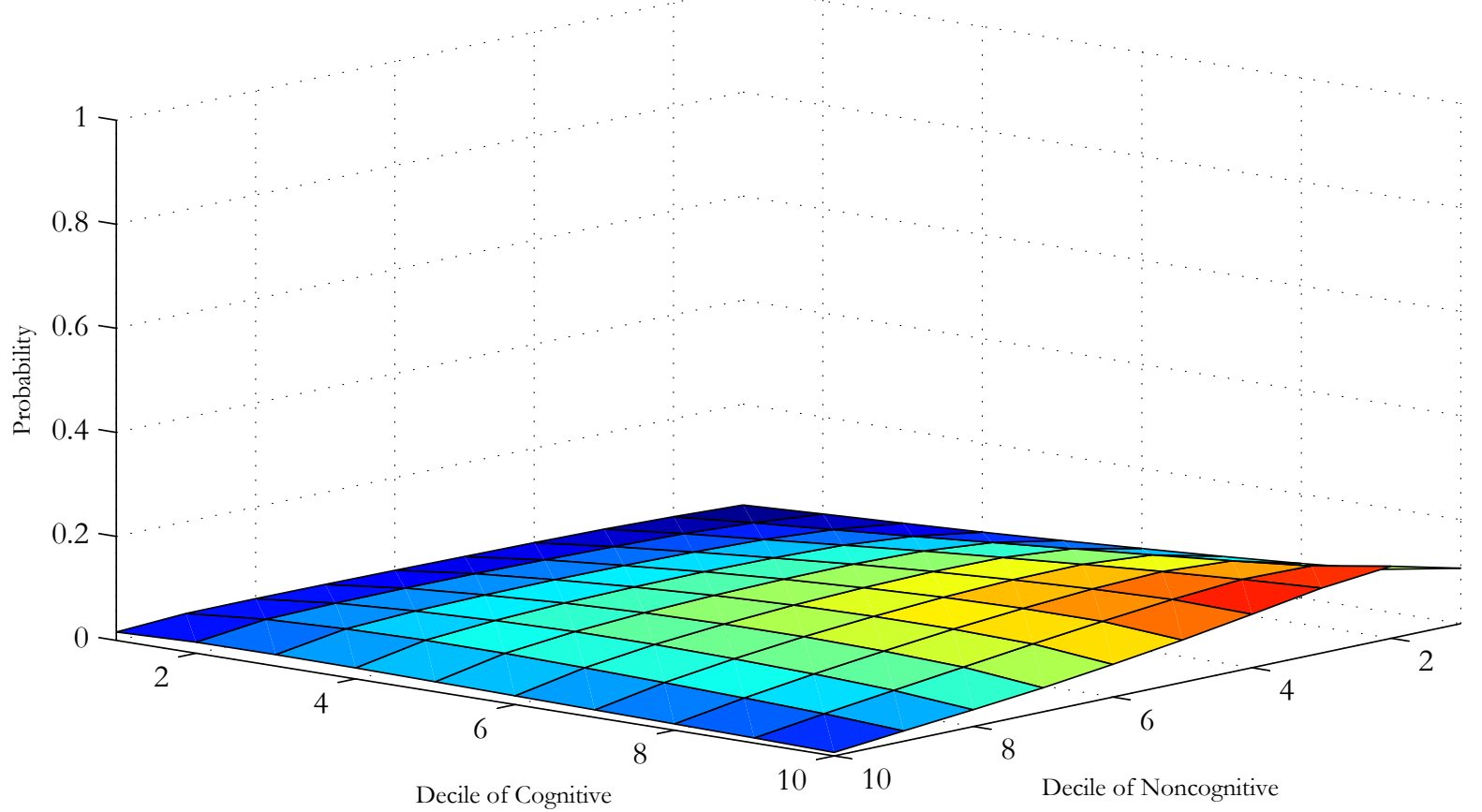

ii. By Decile of Cognitive Factor

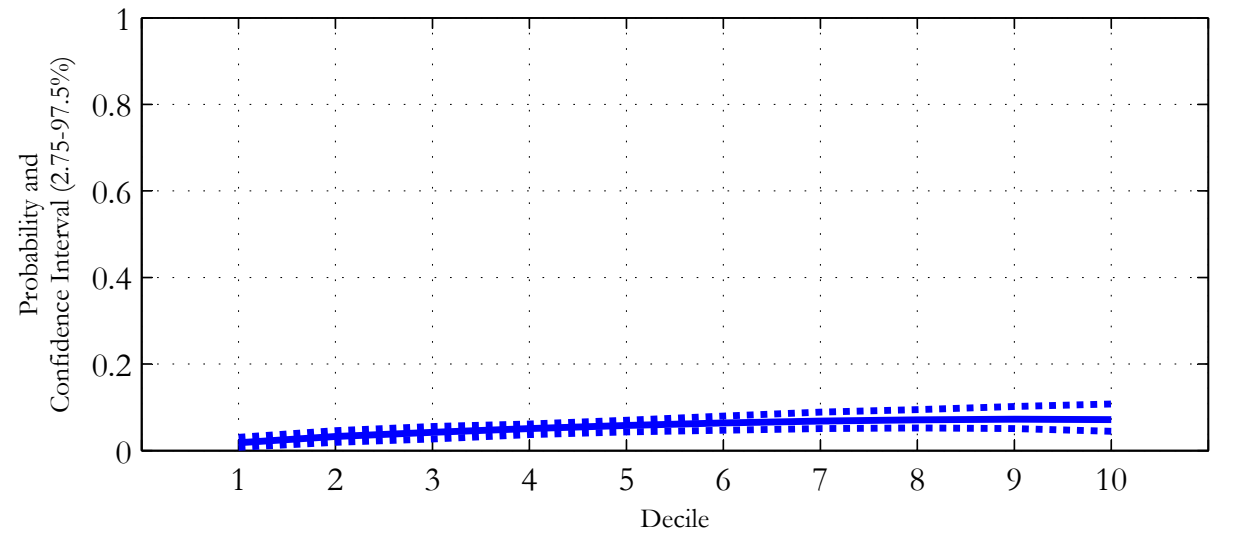

iii. By Decile of Noncognitive Factor

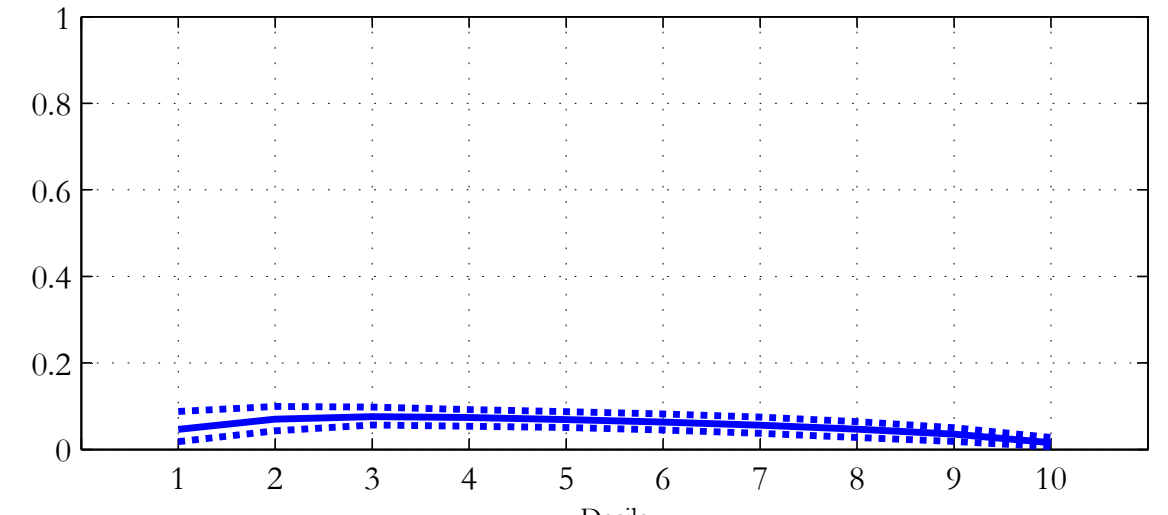

Notes: The data are simulated from the estimates of the model and our NLSY79 sample. We use the standard convention that higher deciles are associated with higher values of the variable. The confidence intervals are computed using bootstrapping (200 draws). 
Figure 19. Probability of Being a 4-yr College Graduate by Age 30 - Males

i. By Decile of Cognitive and Noncognitive Factors

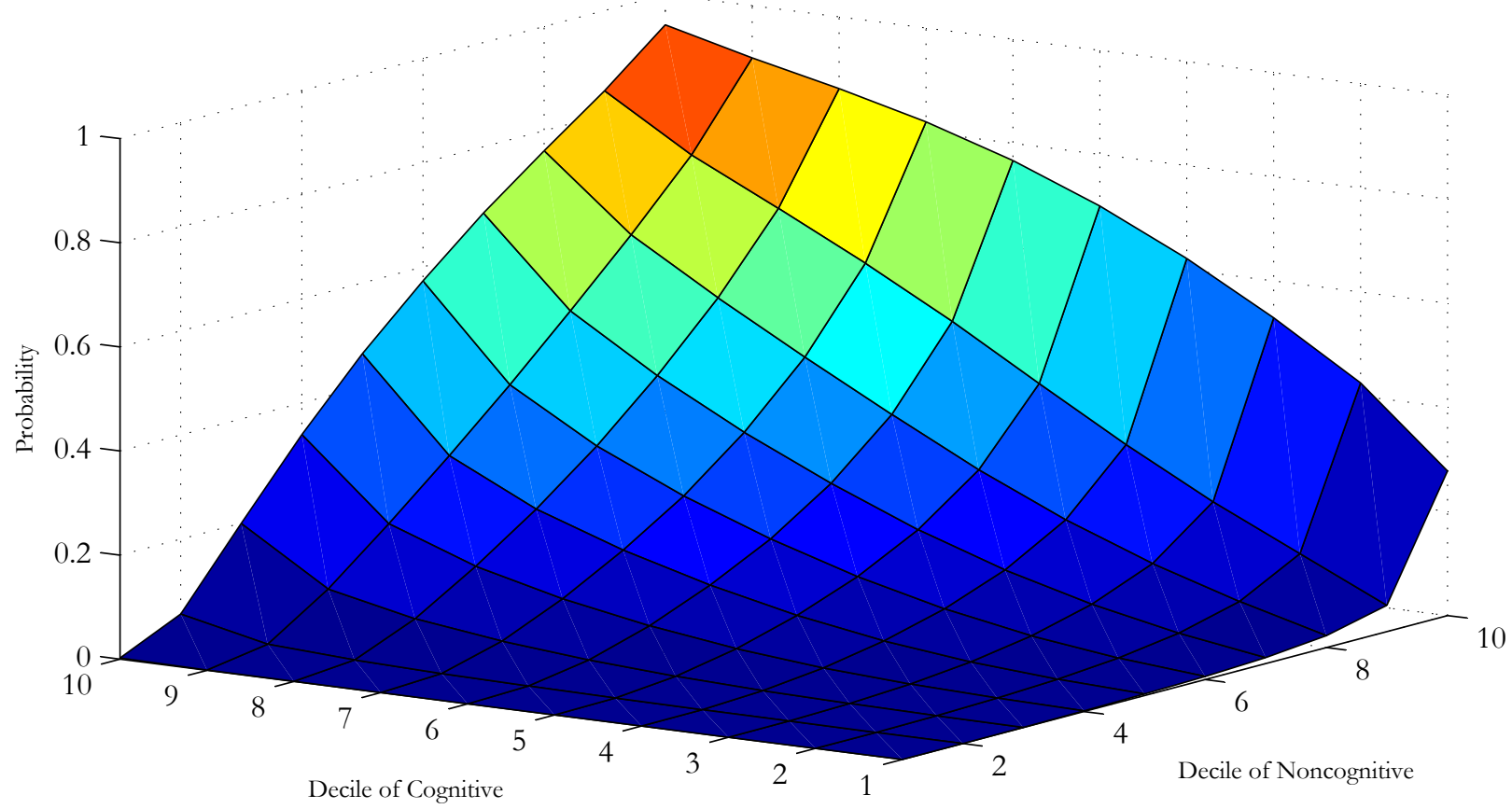

ii. By Decile of Cognitive Factor

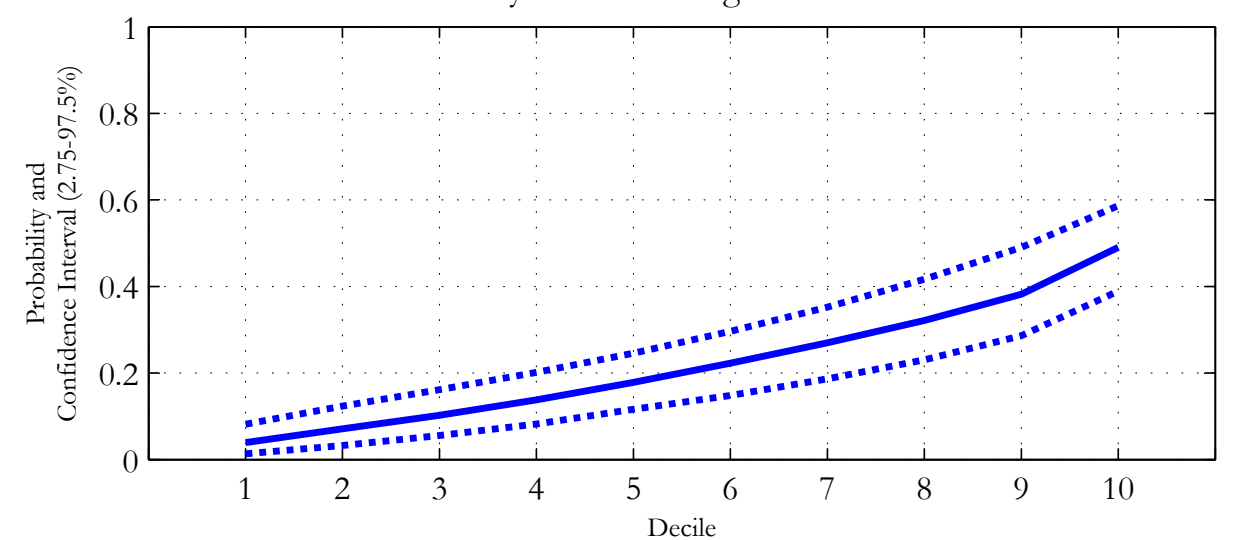

iii. By Decile of Noncognitive Factor

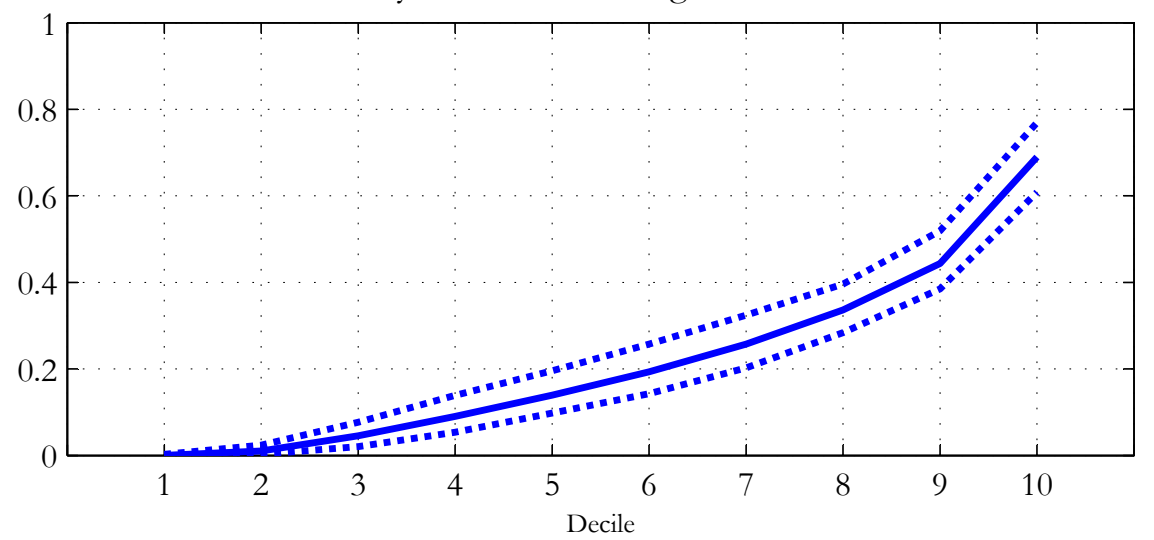

Notes: The data are simulated from the estimates of the model and our NLSY79 sample. We use the standard convention that higher deciles are associated with higher values of the variable. The confidence intervals are computed using bootstrapping (200 draws). 
Figure 20A. Probability Of Daily Smoking By Age 18 - Males

i. By Decile of Cognitive and Noncognitive Factor

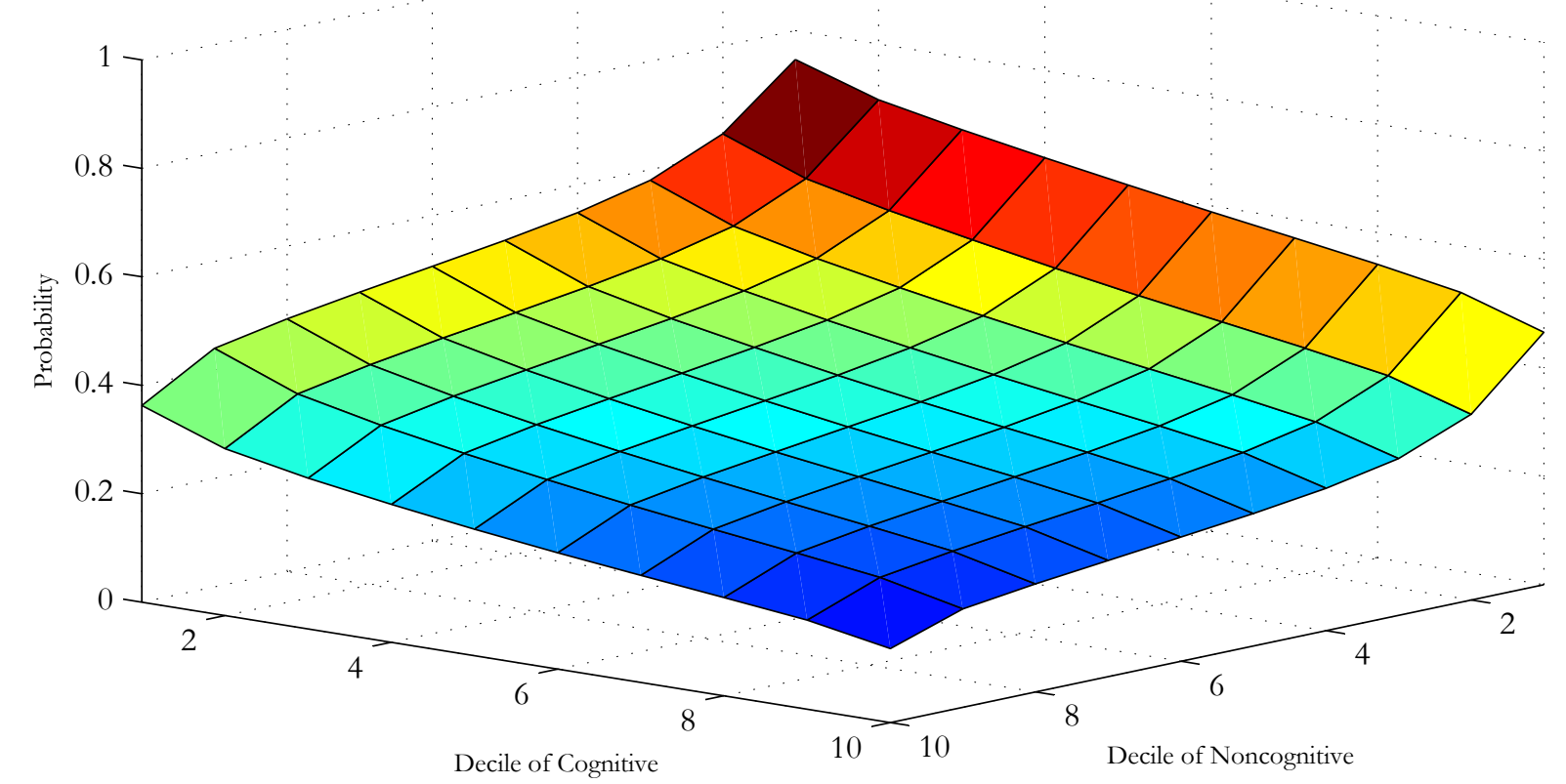

ii. By Decile of Cognitive Factor

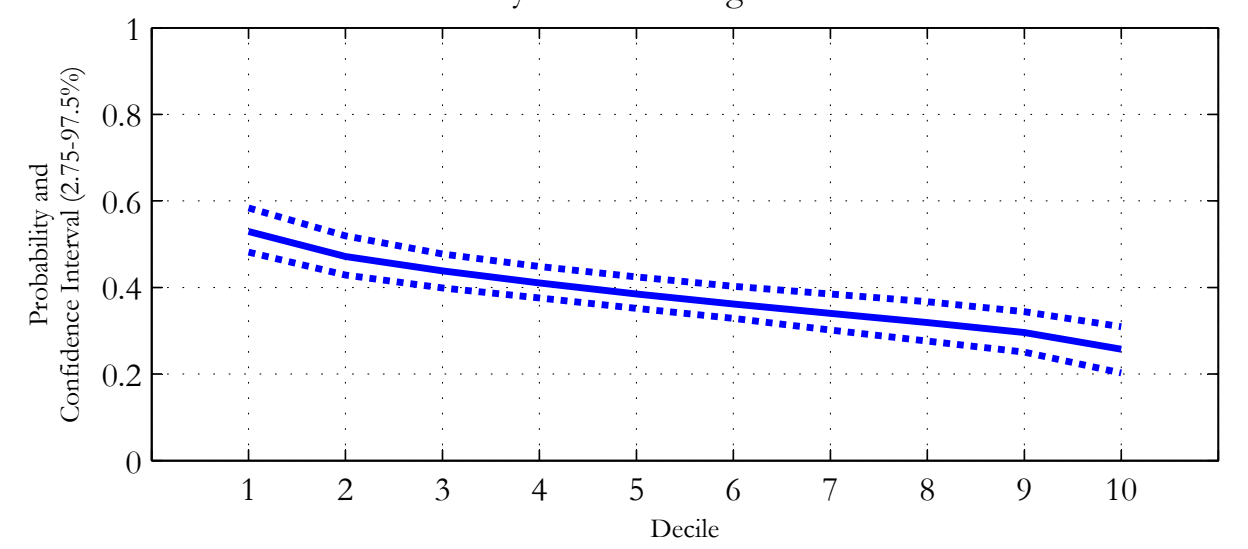

iii. By Decile of Noncognitive Factor

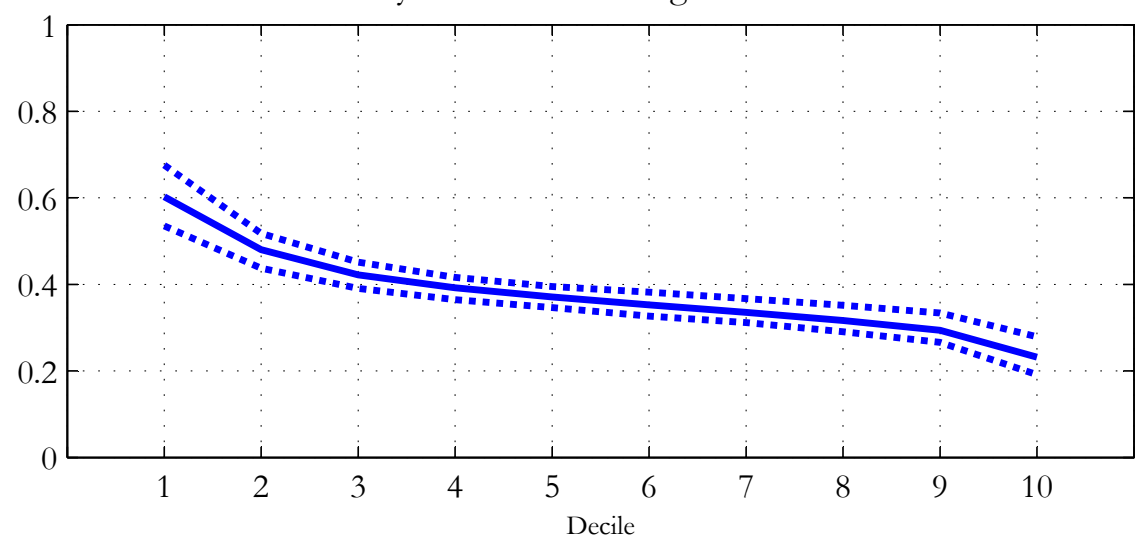

Notes: The data are simulated from the estimates of the model and our NLSY79 sample. We use the standard convention that higher deciles are associated with higher values of the variable. The confidence intervals are computed using bootstrapping (200 draws). 
Figure 20B. Probability Of Daily Smoking By Age 18 - Females

i. By Decile of Cognitive and Noncognitive Factor

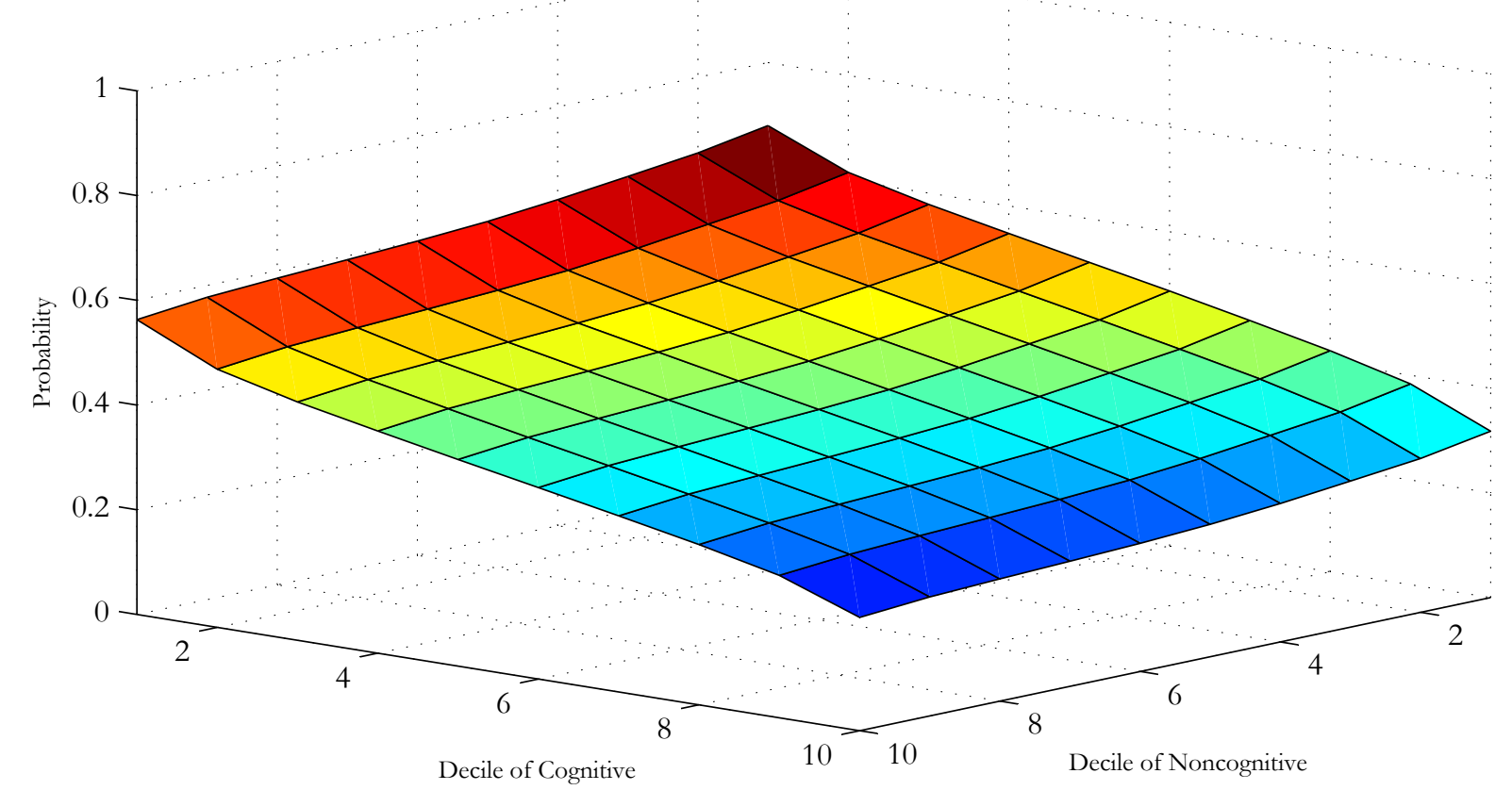

ii. By Decile of Cognitive Factor

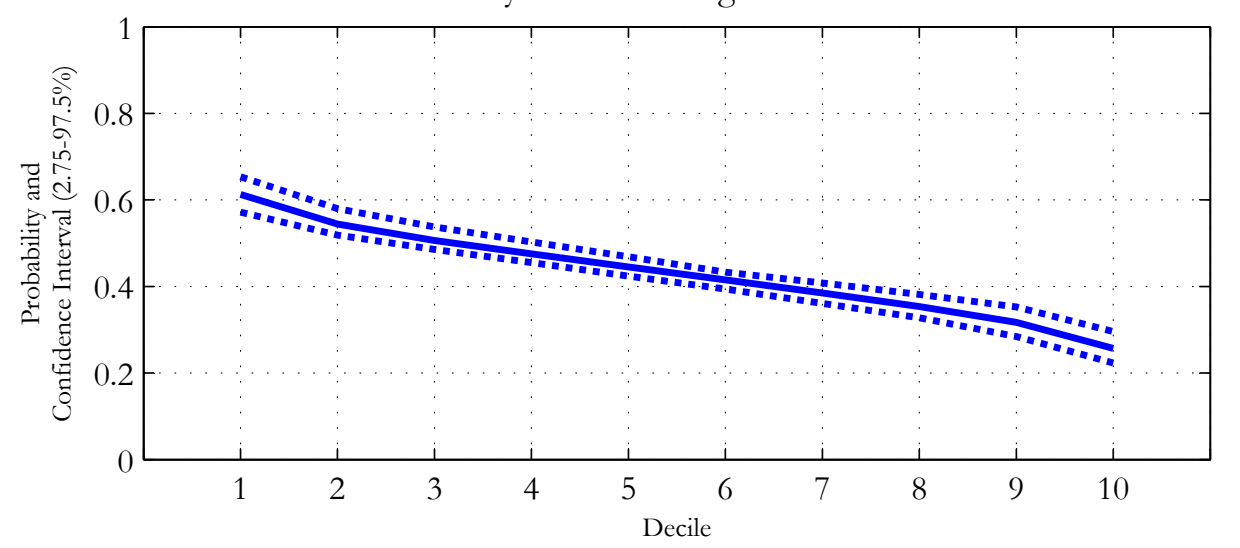

iii. By Decile of Noncognitive Factor

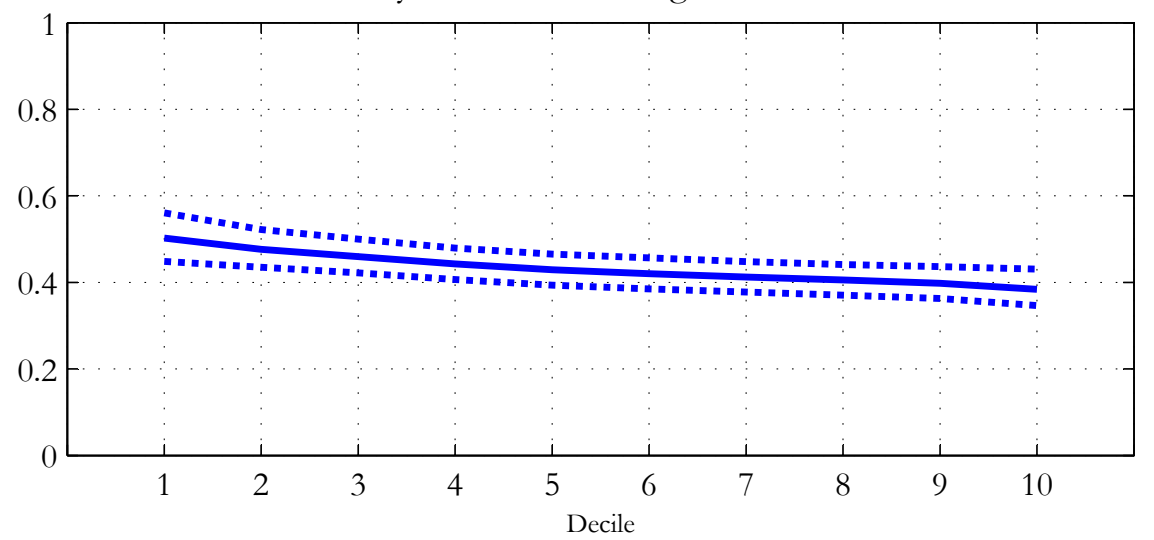

Notes: The data are simulated from the estimates of the model and our NLSY79 sample. We use the standard convention that higher deciles are associated with higher values of the variable. The confidence intervals are computed using bootstrapping (200 draws). 
Figure 21. Probability of Smoking Marijuana during the Year 1979 - Males

i. By Decile of Cognitive and Noncognitive Factor

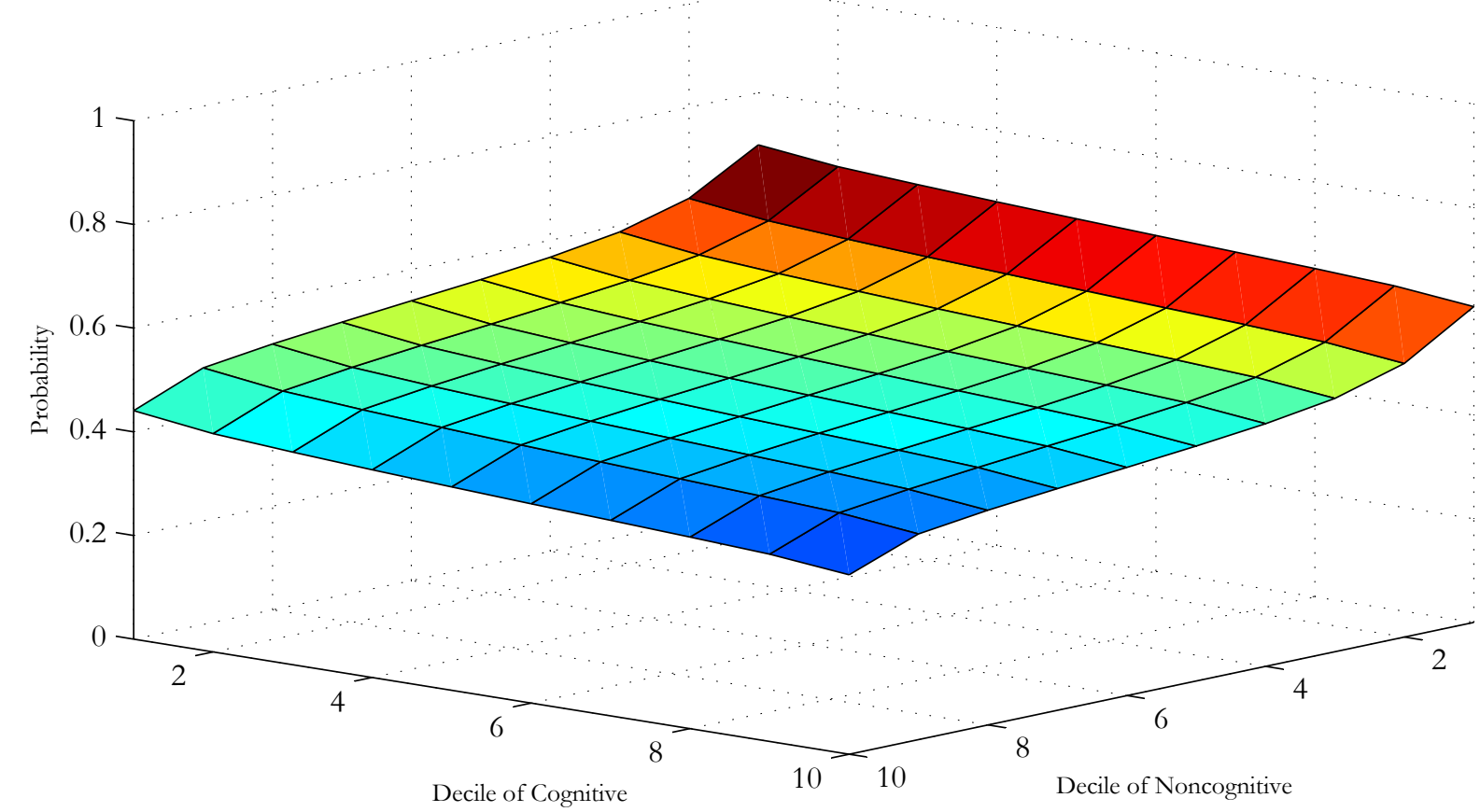

ii. By Decile of Cognitive Factor

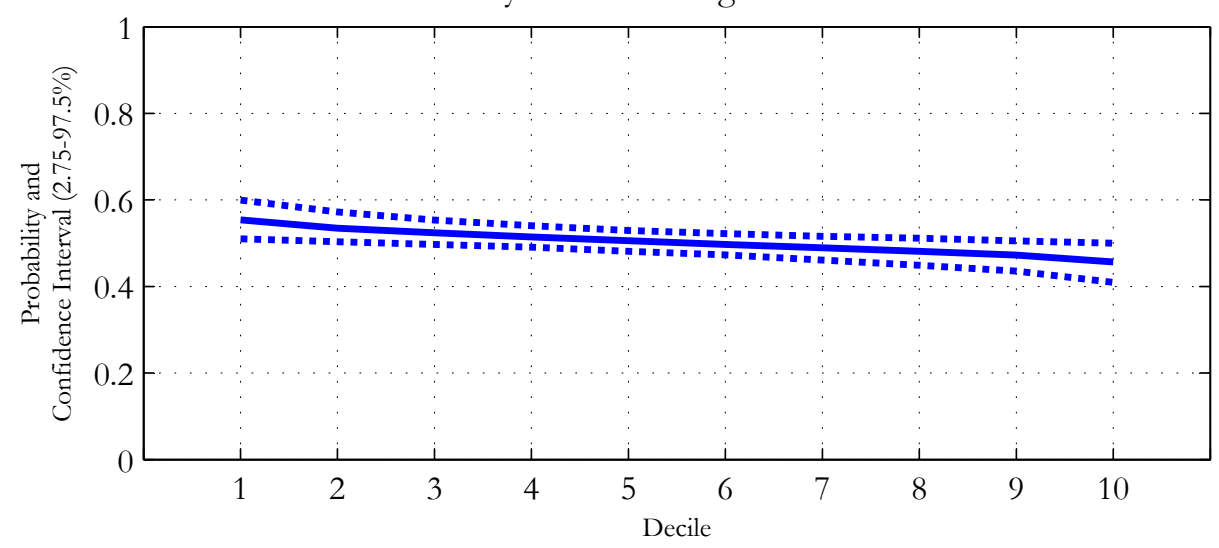

iii. By Decile of Noncognitive Factor

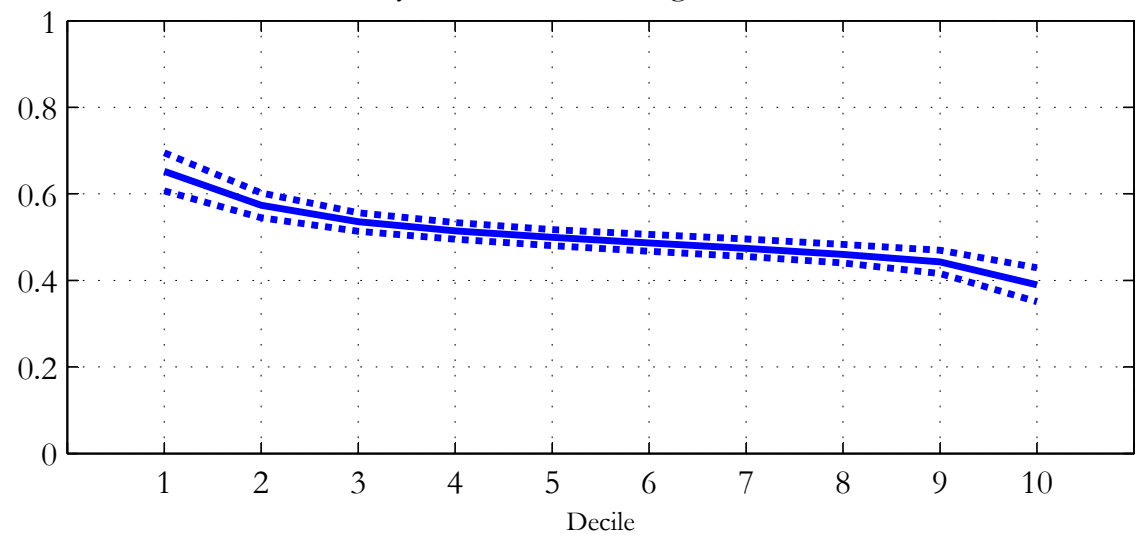

Notes: The data are simulated from the estimates of the model and our NLSY79 sample. We use the standard convention that higher deciles are associated with higher values of the variable. The confidence intervals are computed using bootstrapping (200 draws). 
Figure 22. Probability of Incarceration by Age 30 - Males

i. By Decile of Cognitive and Noncognitive Factor

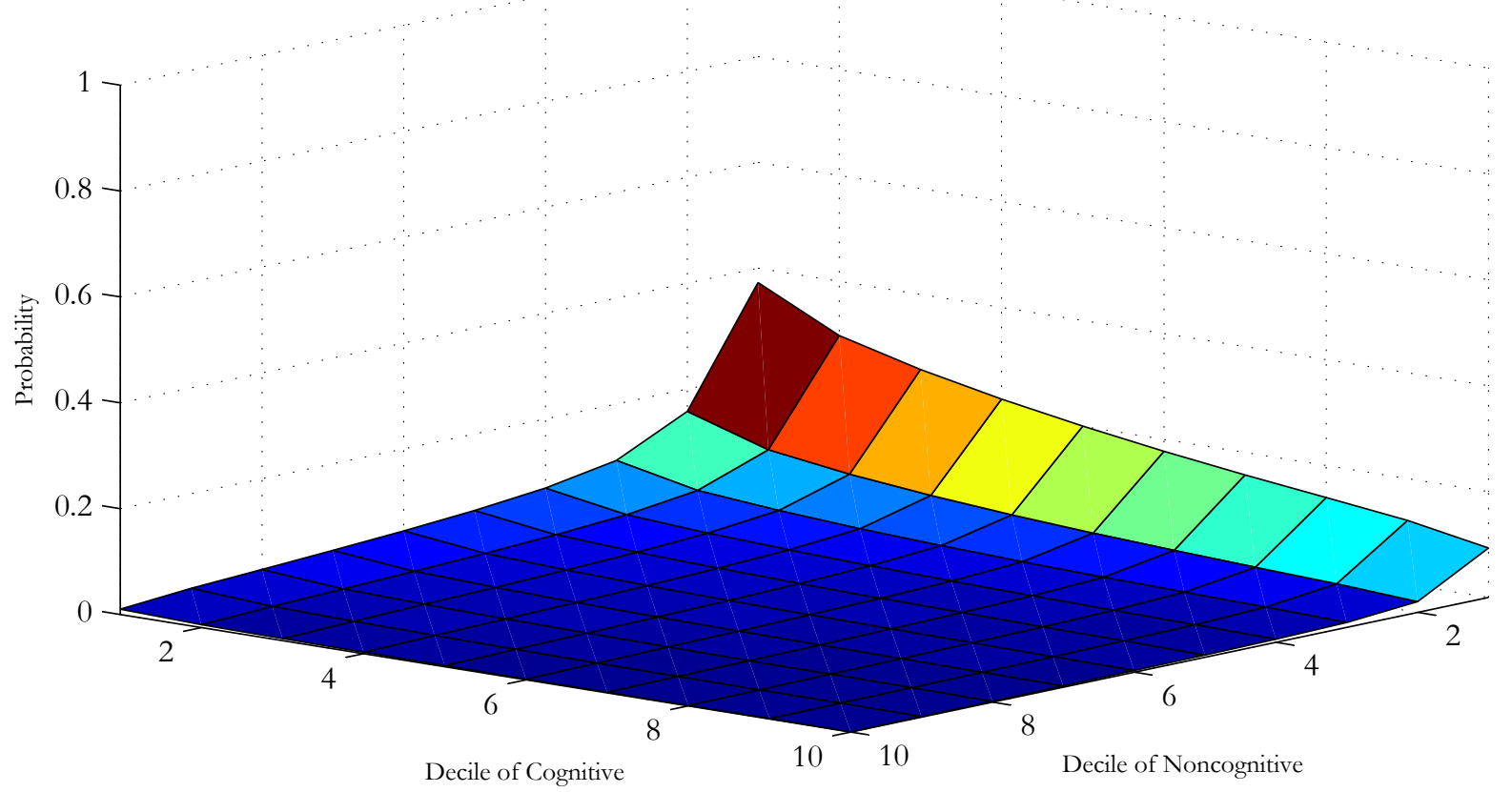

ii. By Decile of Cognitive Factor

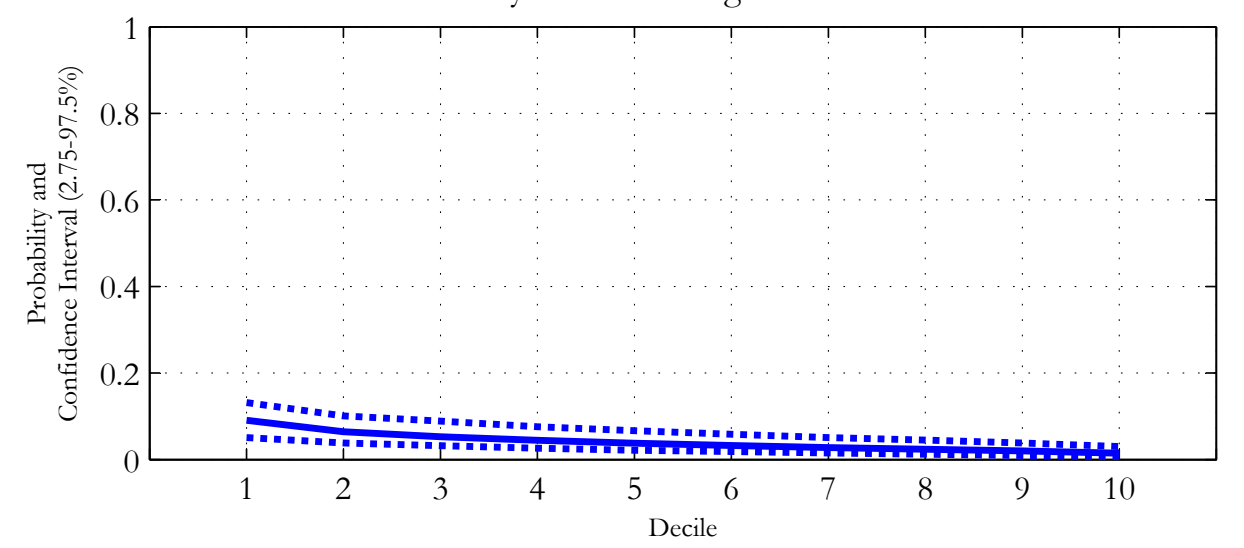

iii. By Decile of Noncognitive Factor

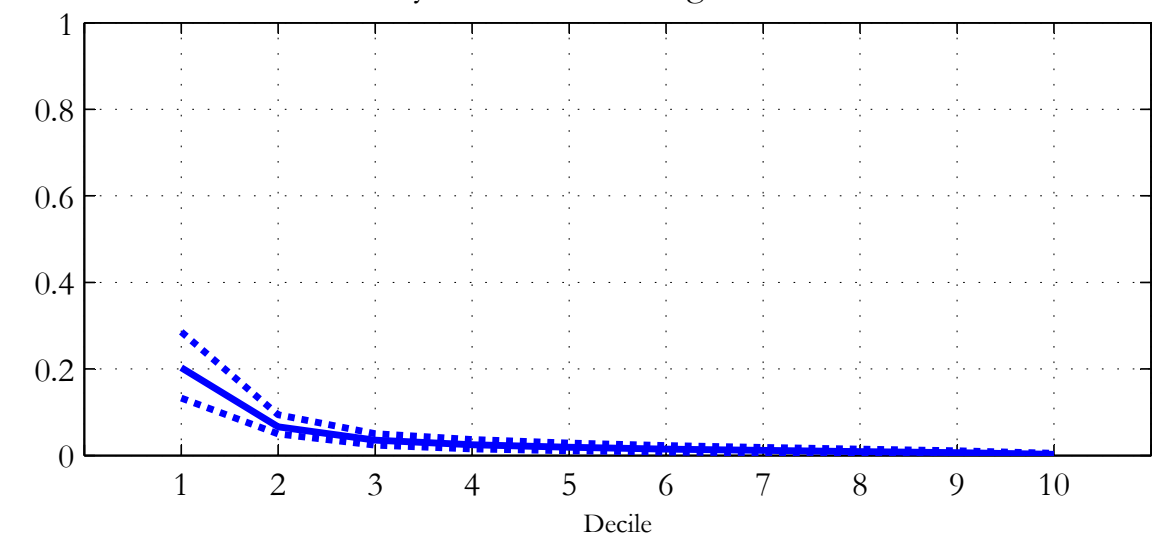

Notes: The data are simulated from the estimates of the model and our NLSY79 sample. We use the standard convention that higher deciles are associated with higher values of the variable. The confidence intervals are computed using bootstrapping (200 draws). 
Figure 23. Probability of Participating in Illegal Activities during the Year 1979- Males

i. By Decile of Cognitive and Noncognitive Factor

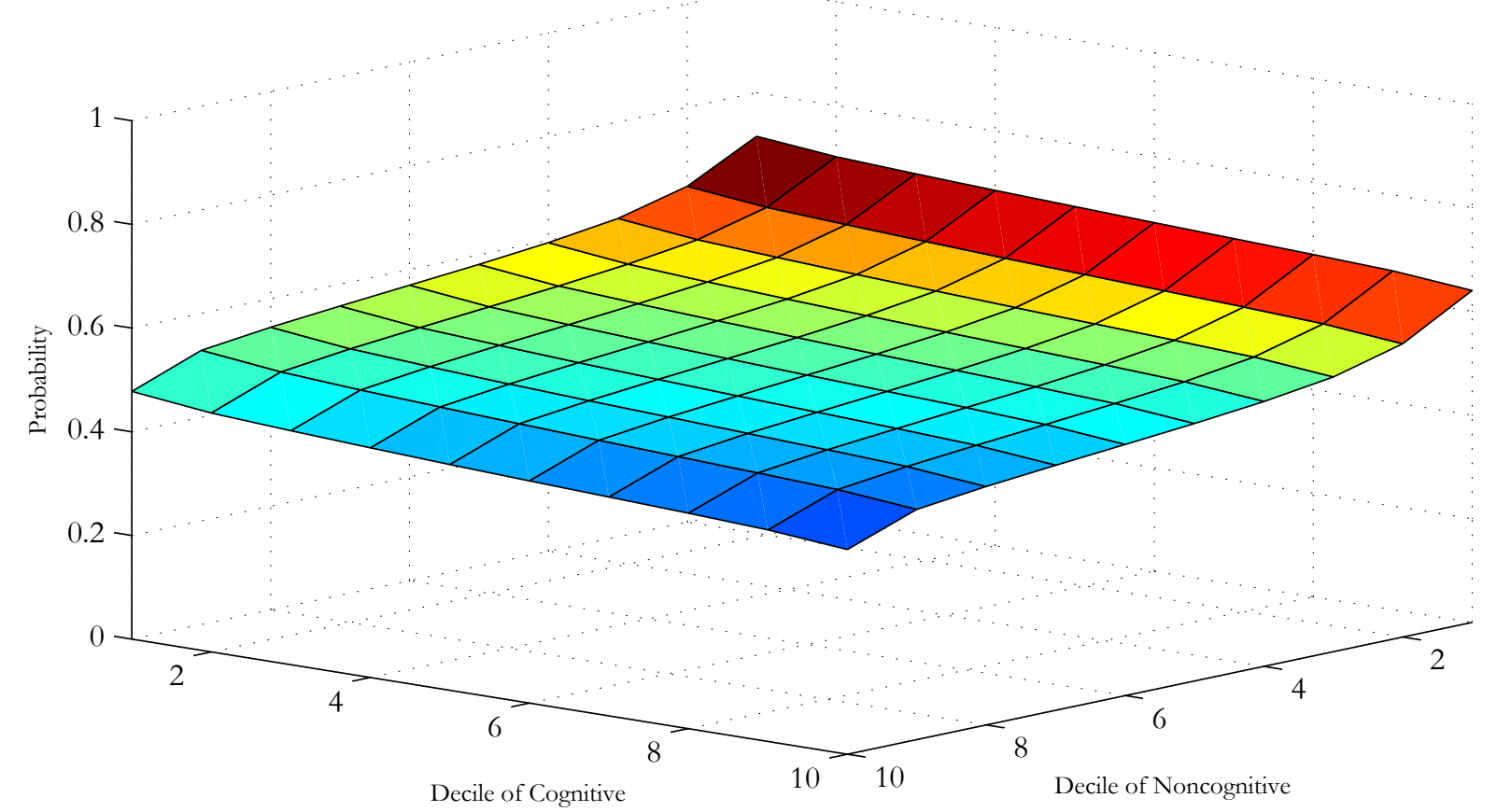

ii. By Decile of Cognitive Factor

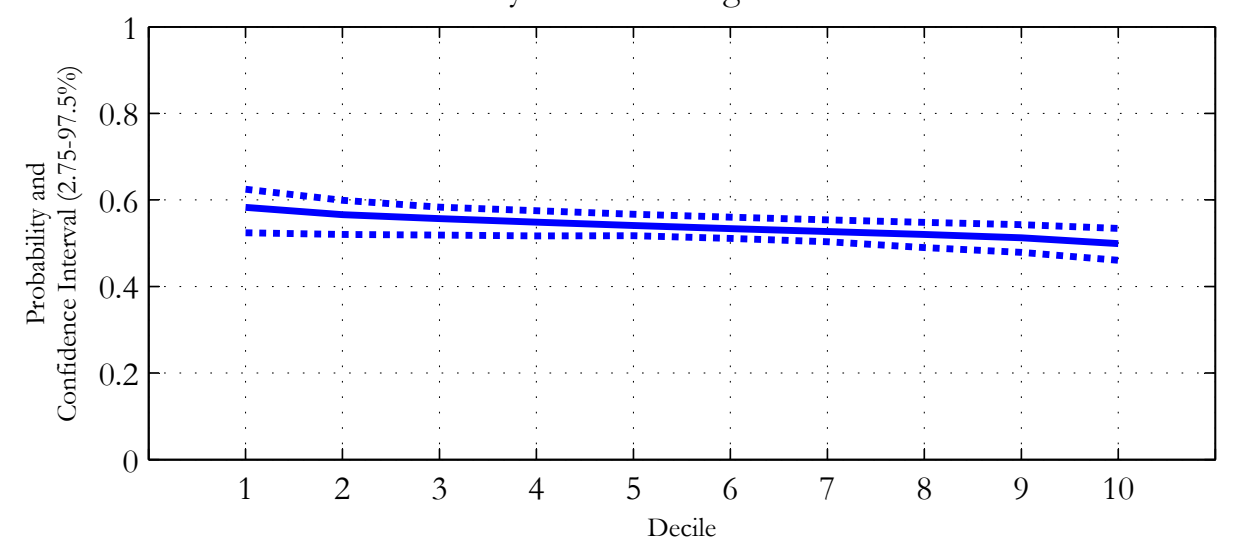

iii. By Decile of Noncognitive Factor

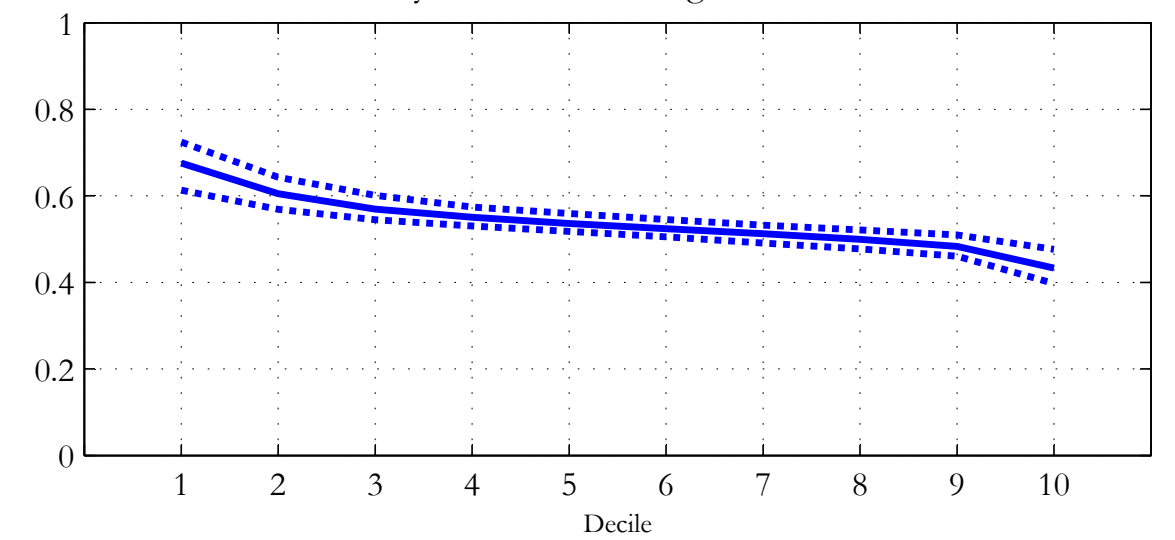

Notes: The data are simulated from the estimates of the model and our NLSY79 sample. We use the standard convention that higher deciles are associated with higher values of the variable. The confidence intervals are computed using bootstrapping (200 draws). 
Figure 24. Probability Of Being Single With No Child at Age 18 - Females

i. By Decile of Cognitive and Noncognitive Factors

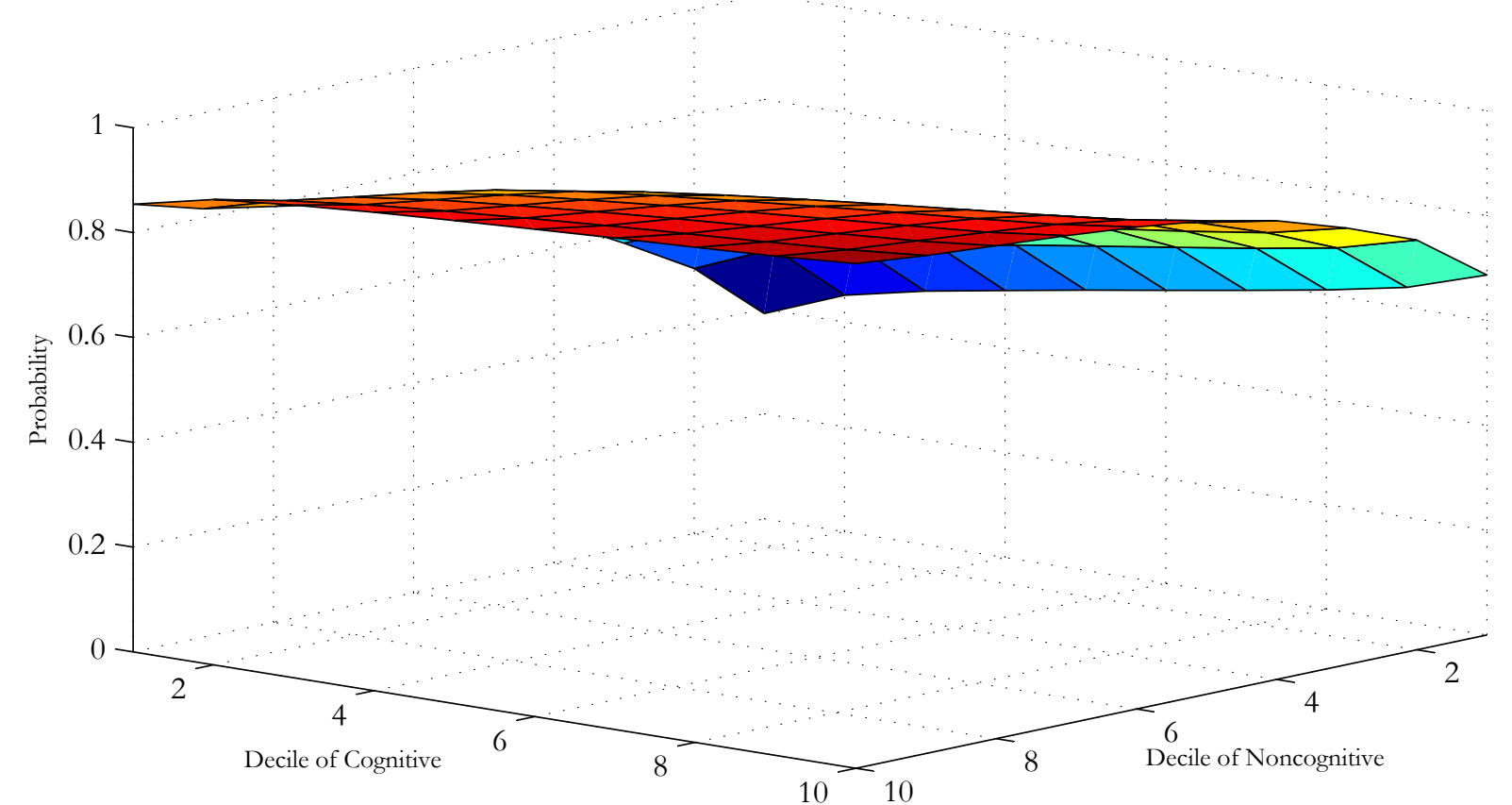

ii. By Decile of Cognitive Factor

iii. By Decile of Noncognitive Factor
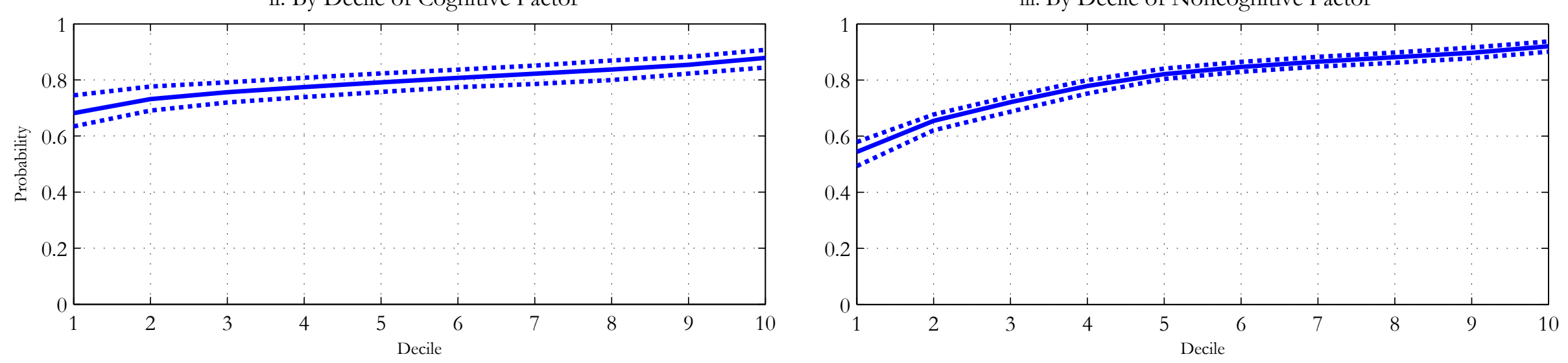

Notes: The data are simulated from the estimates of the model and our NLSY79 sample. We use the standard convention that higher deciles are associated with higher values of the variable. The confidence intervals are computed using bootstrapping (200 draws). 
Figure 25. Probability Of Being Single With Child at Age 18- Females

i. By Decile of Cognitive and Noncognitive Factors

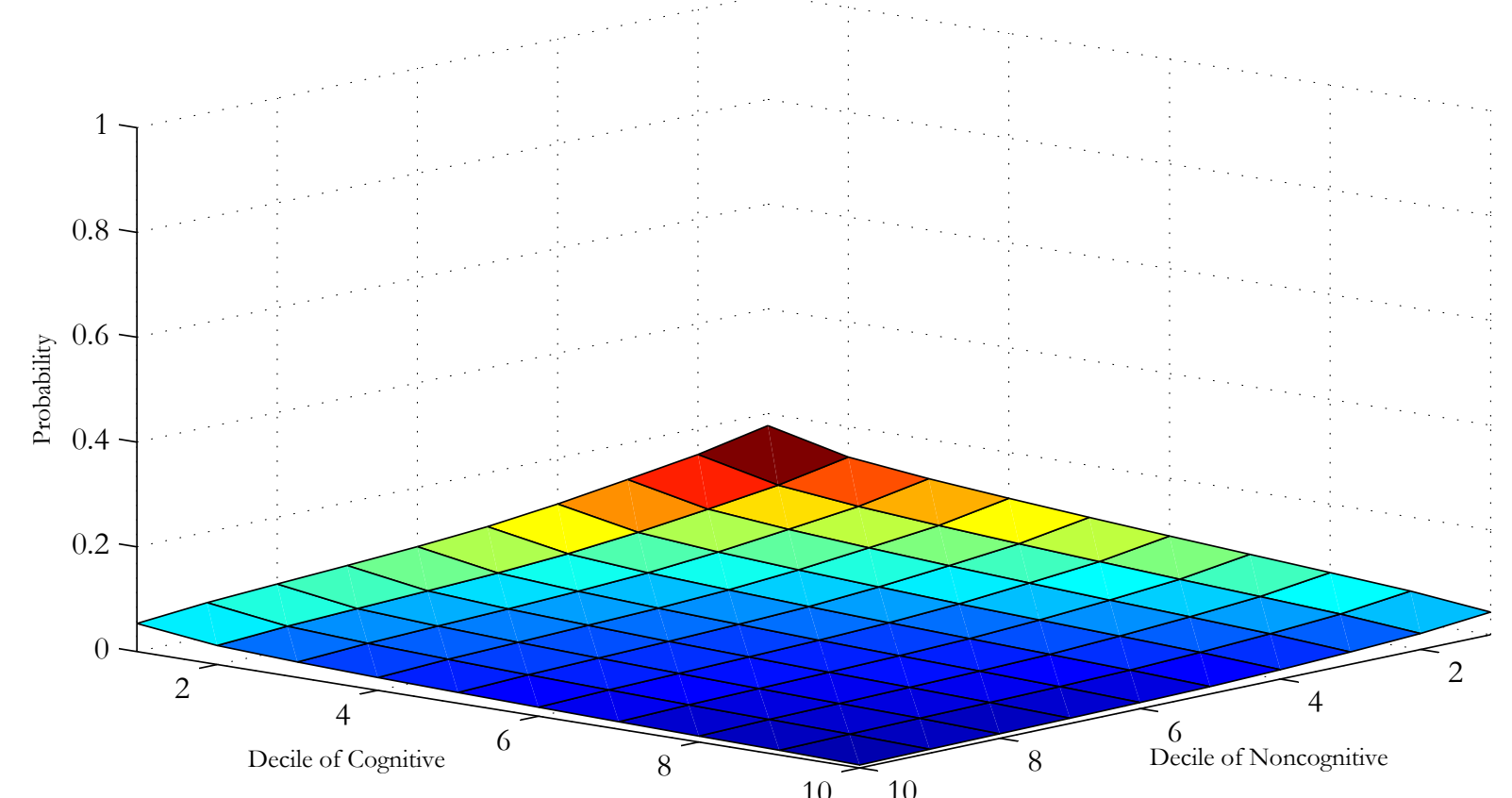

ii. By Decile of Cognitive Factor

iii. By Decile of Noncognitive Factor
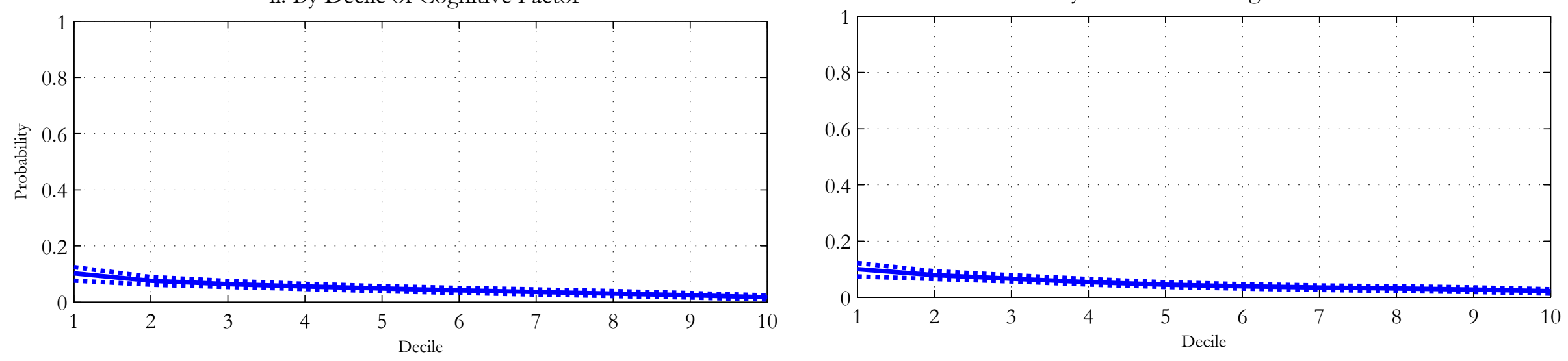

Notes: The data are simulated from the estimates of the model and our NLSY79 sample. We use the standard convention that higher deciles are associated with higher values of the variable. The confidence intervals are computed using bootstrapping (200 draws). 